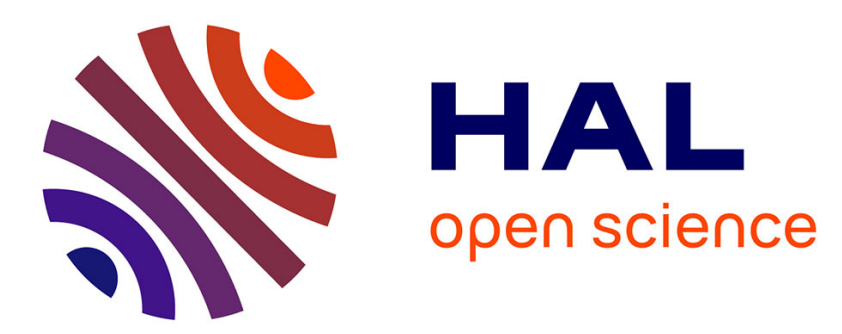

\title{
Characterization of biomass and its derived char using 13 C-solid state nuclear magnetic resonance
}

\author{
Niki Baccile, Camillo Falco, Maria-Magdalena Titirici
}

\section{To cite this version:}

Niki Baccile, Camillo Falco, Maria-Magdalena Titirici. Characterization of biomass and its derived char using 13 C-solid state nuclear magnetic resonance. Green Chemistry, 2014, 16 (12), pp.4839-4869 10.1039/C3GC42570C . hal-01455121

\section{HAL Id: hal-01455121 \\ https://hal.sorbonne-universite.fr/hal-01455121}

Submitted on 3 Feb 2017

HAL is a multi-disciplinary open access archive for the deposit and dissemination of scientific research documents, whether they are published or not. The documents may come from teaching and research institutions in France or abroad, or from public or private research centers.
L'archive ouverte pluridisciplinaire $\mathbf{H A L}$, est destinée au dépôt et à la diffusion de documents scientifiques de niveau recherche, publiés ou non, émanant des établissements d'enseignement et de recherche français ou étrangers, des laboratoires publics ou privés. 
IMPORTANT NOTE: Please be aware that slight modifications occurring after Proof correction may occur between this version of the manuscript and the version on the Publisher's website

\title{
Characterization of Biomass and its derived chars using ${ }^{13} \mathrm{C}$-Solid State Nuclear Magnetic Resonance
}

\author{
Niki Baccile*1,2,3, Camillo Falco ${ }^{4}$, Maria-Magdalena Titirici*5
}

1. UPMC Univ Paris 06, UMR 7574, Chimie de la Matière Condensée de Paris, F-75005, Paris, France. E-mail : niki.baccile@upmc.fr

2. CNRS, UMR 7574, Chimie de la Matière Condensée de Paris, F-75005, Paris, France

3. Collège de France, UMR 7574, Chimie de la Matière Condensée de Paris, F-75005, Paris, France

4. Institute for Advanced Sustainability Studies, Berliner Straße 130, D-14467 Potsdam, Germany

5. Queen Mary University of London, School of Engineering and Materials Science, Mile End Road, E1 4NS, London, United Kingdom

\begin{abstract}
The role of ${ }^{13} \mathrm{C}$ solid state Nuclear Magnetic Resonance (ssNMR) in the elucidation of the structure of biomass and carbonaceous solids derived from biomass has been crucial since the mid-70's, which makes more than 30-years old history. As soon as magic angle spinning was coupled to crosspolarization, ssNMR suddenly became of high use to approach structural resolution in cellulose, lignin, coals and various types of carbonaceous materials, up to the more recent hydrothermal carbons (HTC). This review focuses on the specific contribution that ssNMR has brought to this field and in particular, the technical advances in the field of ssNMR (advanced pulse sequences for spectral editing, more advanced Magic Angle Spinning probes, high-field spectrometers) will be outlined in term of their usefulness for the specific purpose of studying the structure of complex biomass (lignin, cellulose) and their chars obtained either via a pyrolitic or hydrothermal approach.
\end{abstract}

\footnotetext{
${ }^{1}$ E-mail : niki.baccile@upmc.fr; Tel. 0033 (0)1 442715 44; E-mail: m.m.titirici@qmul.ac.uk; Tel. 0044 (0) 2078828739
} 


\subsection{Introduction}

The past 50 years have been characterized by an intense research activity in the field of carbon, carbonaceous and coal-like materials, with particular focus on their structure. This task was approached by combining several characterization techniques like infra-red, X-Ray Photoelectron and Raman spectroscopies. However, the interpretation of the results has always shown a certain degree of uncertainty because these materials are particularly heterogeneous from the chemical point of view and especially those characterized by an amorphous structure. [1] Solid-state NMR (ssNMR) has been since decades a relevant technique to study carbon-based materials but its analytical potential was only put in evidence in the past two decades due to recent theoretical and technical developments. Magic Angle Spinning (MAS) and Cross Polarisation (CP), fully developed together since only the 70's to improve spectral resolution and sensitivity, are nowadays routinely employed. However, their employment alone might not be sufficient for the study of some specific materials. A lot of work has been done to perform experiments with a sensitivity, spectral resolution and signal selection and filtration, which were inconceivable not longer than 20 years ago. This concerns: advances in NMR probe engineering (e.g., fast MAS probes, reliable microelectronic circuits within the probes), spectrometers with strong static magnetic field (up $1 \mathrm{GHz}$ ), spin manipulation engineering to design more selective pulse sequences (e.g., homonuclear dipolar decoupling, dipolar recoupling schemes). These advances definitely make ssNMR one of the most powerful tools to study the structure of materials in general and of carbonaceous materials, in particular. $[2,3,4,5]$ In the former case, the chemical heterogeneity generates spectra, the analysis and interpretation of which can still represent a great challenge. To solve the structural complexity of carbonaceous materials, one must combine the largest number of tools possible and that are available to the NMR spectroscopist: $\mathrm{CP}$, double quantum single quantum filtering (DQ-SQ), dynamic nuclear polarization (DNP), dipolar dephasing (DD), Jcoupling based filtering like Insensitive Nuclei Enhanced by Polarization Transfer (INEPT), etc...

ssNMR has been applied in the study of carbons since long time and a number of reviews has already been published on this topic. $[6,7,8,9,10]$ However, none of them to the best of our knowledge has specifically focused on the added value that ssNMR, and in particular its technical and methodological improvement in time, has brought to the specific problem of structural resolution of biomass and their derived chars. Most of these works are more than 10 or 20-year old $[7,8,9,10]$ and they mainly concentrate on coal science; $[7,8,10]$ In some cases they discuss only a specific family of coal (e.g., Argonne Premium) [7] or they focus on soil science/geochemistry. [9,11] On the contrary, the most recent work by Freitas et al. [6] is mainly focused on developing the NMR methodological 
approach for non-experts who want to employ ssNMR in the study of carbons. They also provide a large number of examples that go from the study of diamonds to new forms of carbons but none of them is described in its historical context of structural resolution in parallel with NMR methodological and technical development. Similar approaches have been published by others in the literature. [12] Furthermore, most of these works, including our own contribution,[13] have been published partly or entirely in books or book chapters, $[6,7,8,9,10]$ thus making their accessibility less straightforward.

This review paper aims at showing how ssNMR can be employed to better understand the chemical structure of selected biomass and some of its carbon-based materials, with a particular focus on those obtained by the thermal treatment of biomass. As a first step, we provide a short summary of the principal NMR spectroscopic tools and their usefulness. Later on, we discuss, in a historical perspective, how ssNMR was used in the structural characterization of various families of biomass (wood, lignin, polysaccharides) and their derived chars obtained by their pyrolysis, chemical activation, torrefaction and hydrothermal treatment in water. Most importantly, we specifically outline how improvements (fast Magic Angle Spinning probes, new decoupling schemes, signal enhancement techniques, stronger magnetic fields, etc...) in the field of ssNMR has contributed to structural-solving problem.

\subsection{Generalities on Solid State NMR in the framework of cabonaceous materials}

The goal of this review is not to instruct the reader to the use of ssNMR but to discuss how recent advances in this technique allow a better characterization of biomass and its chars. For this reason, we only provide a very short introduction on some generalities concerning the use of NMR in solids and we prefer to direct the reader towards a restricted selection of relevant review papers that either deal with the basics of this technique or with its practical use for the study of carbonaceous materials. For an overview on NMR, one could refer to [14], while for more insights on solid state NMR, one could refer to $[15,16,17]$. A fair compromise between a broader explanation and shorter reading of basic NMR principles and their application in chemistry can be found in the manuscripts provided by Andrew and Szczesniak [18], by Blanc et al. [19] and, in particular, by Laws et al. [20]. For a practical description on how to apply the ssNMR methodology for the study of carbonaceous materials, one can read ch.1 and ch.2 in Ref. [7]. Finally, a couple of recent works [6, 12] give a detailed description of both positive aspects and drawbacks of using ssNMR to the study of carbons.

NMR is commonly associated to the fields of organic chemistry and structural biology, where analysis is generally performed in liquid solutions. On the contrary, NMR is less known as a routine 
technique to study solid state matter. In fact, the Brownian motion typical for solutions averages out specific interactions. In the solid state, these interactions are detected, leading to poor signal-to-noise ratio and peak broadening. Two of the most relevant interactions to deal with in solid state for a $1 / 2$ spin system are: chemical shift anisotropy (CSA), which is related to the chemical environment of the nuclei and described, in solid, by a tensor; dipolar coupling, which refers to a magnetic coupling between two close nuclei, non-necessarily engaged in a chemical bond, and inversely proportional to their distance. These interactions have a dramatic effect on the spectral resolution:

Chemical Shift Anisotropy is responsible for the large broadening of NMR peaks in the spectra acquired in solid samples. It can be efficiently averaged by spinning the sample holder (commonly a zirconia rotor) around its axis at a $54.74^{\circ}$ angle with respect to the external magnetic field. This is generally addressed to as Magic Angle Spinning (MAS) [21] and it only refers to a mechanical treatment of the sample. The faster the spinning rate, the higher the spectral resolution; however, fast MAS employs small-sized rotors, the diameter of which commonly range between $7 \mathrm{~mm}$ and $1.3 \mathrm{~mm}$ (typical MAS rates achievable consequently range from few $\mathrm{Hz}$ to more than $60 \mathrm{kHz}$ ) and which is a problem in terms of quantity of matter for the smallest rotors when studying rare nuclei like ${ }^{13} \mathrm{C}$.

Dipolar coupling depends on the distance between two magnetically-coupled spins (S-I). Its magnitude is proportional to $\left(\gamma_{S} \gamma_{I}\right) / r^{3}$, where $\gamma_{S}$ and $\gamma_{I}$ are the gyromagnetic ratio of, respectively, the spin-S and spin-I and $r$ is their distance in space. This interaction is a source of important line broadening effect for solids; in the particular case for homonuclear coupling in proton systems that are close in space, the magnitude of the dipolar coupling can reach $100 \mathrm{kHz}$. Two main ways exist to average the dipolar interaction and achieve an acceptable resolution: via MAS and/or via use of specific Radio Frequency (RF) decoupling pulse sequences. [22,23] In both cases, the characteristic frequency associated to MAS or RF pulses must be larger than the characteristic frequency of the interaction. Despite its drawbacks, dipolar interaction can be exploited for a number of informative experiments, which bring valuable pieces of structural information. For instance, Cross Polarization (CP) is a dipolar coupling-related technique, which consists in transferring the magnetization between abundant (I) and dilute (S) nuclear spins close in space. Together with MAS, CP is routinely used to enhance the sensitivity of rare, low $\gamma$, (S) nuclei (e.g., ${ }^{13} \mathrm{C},{ }^{29} \mathrm{Si}$ ) using, most commonly, the magnetization transfer from abundant nuclei, like ${ }^{1} \mathrm{H}$. This has several benefits: 1) spin-lattice relaxation times $\left(\mathrm{T}_{1}\right)$ become shorter because they depend on the most abundant nucleus; 2 ) sensitivity is increased by a factor depending on the ratio of the gyromagnetic ratios, $\gamma_{I} / \gamma_{S}$; 3) the characteristic time of the S-I interaction can be manually tuned via the adjustment of the cross polarization contact 
time $\left(\mathrm{t}_{\mathrm{cp}}\right)$, thus allowing to probe internuclear distances; 4) valuable information on the structure and chemistry of the sample (sensitivity to a protic environment, molecular mobility) can be extracted by manipulating the $t_{\mathrm{cp}}$ time. A large number of dipolar coupling-based experiments can be set up to specifically address the general problem of structural resolution in solids, and amorphous solids in particular.

It is interesting to note that several ssNMR specialized research groups used biomass (e.g., lignin, cellulose) as model compounds to test pulse sequences that are able to probe local chemical environment and local connectivities, as discussed later. Even if the goal, in this case, is generally not to solve a specific structural problem of the analyzed material, it contributes to build specific NMR tools that are optimized for the study of biomass and biomass-derived carbons. From an NMR spectroscopist point of view this is quite important as one can use ready-made pulse sequences that do not need further improvement and testing when applied to real case studies. This is well described in the recent review of Mao on the development and applications of NMR tools for the study of kerogens. [11] A typical work by the same group, published few years ago, [24] shows the interesting use of a spectral editing, specifically-designed, dipolar dephasing pulse sequence to recouple long-range C-H dipolar interaction to differentiate condensed aromatic rings, typical in char, from conjugated ones, typical in lignin. More specifically, carbon-carbon connectivities were demonstrated to be easily probed in amorphous cellulose, xylan and lignin by applying a dipolar coupling based experiment exploiting both CP and the excitation of double quantum coherences. Despite the very large interest of these techniques to highlight connectivities in amorphous solids which would be impossible to put in evidence with any other technique, isotopic labeling is necessary to perform the experiment in a reasonable amount of time, which can be quantified in the range of few hours up to about 50 hours per single experiment. Longer experimental times are possible but rarely employed on a routine basis. In this sense, the recent application of Dynamic Nuclear Polarization (DNP), a signal-enhancing technique which exploits the magnetization transfer between free radicals and nuclear spins, to a cellulose sample allowed to perform ${ }^{13} \mathrm{C}-{ }^{13} \mathrm{C}$ correlation spectroscopy based on double quantum coherences excitation without isotopical enrichment and for a total acquisition time as low as 2 hours! [25] A specific note on the development of new ssNMR techniques to study carbons can also be found in Ref. 6. This shows how advances in solid state NMR spectroscopy, especially in terms of signal enhancement, will clearly bring more and more perspectives to the structural resolution of solids in general and biomass-related materials in particular.

A non-exhaustive list of typical information that one can obtain from advanced solid state NMR experiments is provided in Table 1 . The table provides the acronym of common NMR techniques or 
pulse programs, relevant notes on the conditions to perform the experiment, an evaluation of the feasibility and typical acquisition times. The reader should be aware that the table is merely indicative and is simply meant to help the reader to better understand the present article. Hints on feasibility are based on the authors' personal experience. In any case, non-experts must consult appropriate references (given above) or contact an expert users and, above all, they must be aware of the fact that solid state NMR offers a much broader spectrum of possibilities, which ARE NOT restricted to those enounced in Table 1. The definition of the acronyms given in the table and throughout the text is given hereafter:

MAS: Magic Angle Spinning. See Ref. [21,26]; SPE: Single Pulse Excitation (also described in old literature works as Bloch Decay); CP: Cross Polarization. See Ref. [27]; DD: Dipolar Dephasing (also known as NQS, Non-Quaternary Suppression); INEPT: Insensitive Nuclei Enhanced by Polarization Transfer. See Ref. [28]; IRCP: Inversion Recovery Cross Polarization. See Ref. [29]; HSQC: Heteronuclear Single Quantum Coherence or Heteronuclear Single Quantum Correlation. See Ref. [30] and [31]; HMQC: Heteronuclear Multiple-Bond Correlation [32]; INADEQUATE: Incredible Natural-Abundance DoublE-QUAntum Transfer Experiment. See Ref. [33]; HETCOR: HETronuclear CORrelation. see Ref. [34]; EXSY: EXcitation SpectroscopY (formally, same experiment as NOESY, Nuclear Overhauser Effect SpectroscopY, but in solids the nature of polarization transfer can be different than in solutions). See Ref. [35]; C7, SC14: see Ref. [36,37]; DNP: Dynamic Nuclear Polarization; $\mathbf{T}_{\mathbf{1}}=$ Spin lattice relaxation time; $\mathbf{T}_{\mathbf{2}}=$ spin-spin relaxation time; $\mathbf{T}_{\mathbf{C H}}={ }^{13} \mathrm{C}-{ }^{1} \mathrm{H}$ polarization transfer time (in CP experiments, also known as contact time); $\mathbf{T}_{\mathbf{1}}=$ spin-lattice relaxation time in the rotating frame; $\mathbf{T}_{\mathbf{m}}=$ mixing time (in EXSY experiments); $\mathbf{T}_{\mathbf{i}}=$ inversion ${ }^{13} \mathrm{C}-{ }^{1} \mathrm{H}$ polarization transfer time (in IRCP experiments)

Table 1 - Schematic presentation of the most common NMR techniques to obtain practical pieces of information on carbon materials. For explanation of acronyms, see text.

\begin{tabular}{|c|c|c|c|c|}
\hline Information & Technique & Notes & $\begin{array}{l}\text { Difficulty } \\
(\mathrm{E}, \mathrm{A}, \mathrm{D})^{\circ}\end{array}$ & $\begin{array}{c}\text { Typical acquisition } \\
\text { time* }\end{array}$ \\
\hline Spectral resolution $^{\S}$ & MAS $^{a}$ & $\begin{array}{l}\text { Rotor diameter: } 1.3,2.5,3.2,4,7 \mathrm{~mm} \\
\text { Max MAS rates : 67, 35, 25, 15, } 7( \pm 1) \mathrm{kHz} \\
\text { Max amount: } 1.7,14,30,70,246 \mu \mathrm{L}\end{array}$ & E & - \\
\hline Quantitative analysis & SPE & $\begin{array}{c}\text { Always at } 5 * \mathrm{~T}_{1} \\
\text { Not possible unless the } \mathrm{CP} \text { spin dynamics is } \\
\text { known. The condition is: } \mathrm{T}_{\mathrm{CH}}<<\mathrm{T}_{\mathrm{CP}}<<\mathrm{T}_{1 \rho} \text {. A } \\
\text { complete magnetization curve at variable } \\
\left.\text { contact times [I(T) } \mathrm{T}_{\mathrm{CP}}\right) \text { ]must recorded and fitted } \\
\text { to recover } \mathrm{M}_{0} \text {, the thermal equilibrium value } \\
\text { of the }{ }^{13} \mathrm{C} \text { magnetization. For more info, please } \\
\text { refer to Ref. } 38\end{array}$ & $\mathrm{E}$ & several hours \\
\hline $\begin{array}{l}\text { Increased } \mathrm{S} / \mathrm{N} \text { ratio } \\
\text { Short acquisition time }\end{array}$ & $\mathrm{CP}$ & $\begin{array}{c}\text { Need for protons. } \\
\text { Underestimates mobile (e.g., } \mathrm{CH}_{3} \text { ) and }\end{array}$ & $\mathrm{E}$ & $<2 \mathrm{~h}$ \\
\hline
\end{tabular}




\begin{tabular}{|c|c|c|c|c|}
\hline & & $\begin{array}{c}\text { quaternary carbons } \\
\text { Possible if typical } \mathrm{T}_{\mathrm{CP}}<<\mathrm{T}_{1 \rho} \text { (which can be } \\
\text { very short in highly aromatic carbons) } \\
\text { Typical } \mathrm{T}_{\mathrm{CP}} \text { : } \\
<500 \mu \mathrm{s} \rightarrow \text { close and/or rigid } \mathrm{CH}_{\mathrm{x}} \text { pairs } \\
<3 \mathrm{~ms} \rightarrow \text { all species } \\
>3 \mathrm{~ms} \rightarrow \text { distant and/or mobile } \mathrm{CH}_{\mathrm{x}} \text { pairs }\end{array}$ & & \\
\hline $\begin{array}{l}\text { Selection of quaternary } \\
\text { carbons }\end{array}$ & DD (NQS) & $\begin{array}{l}\text { Use of dephasing times in the order of tens of } \\
\mu \mathrm{s} \\
\text { Experiment can be CP or SPE-enhanced }\end{array}$ & E & $\begin{array}{l}<2 \mathrm{~h} \text { (if CP is used, } \\
\text { otherwise same as } \\
\text { SPE) }\end{array}$ \\
\hline \multirow{3}{*}{$\begin{array}{l}\text { Selection of non- } \\
\text { quaternary carbons }\end{array}$} & DD & $\begin{array}{l}\text { Substraction between full spectrum and DD } \\
\text { spectrum }\end{array}$ & \multirow{3}{*}{$\mathrm{E}$} & \multirow{3}{*}{$<2 \mathrm{~h}$} \\
\hline & $\mathrm{CP}$ & Short contact times, typically< $500 \mu \mathrm{s}$ & & \\
\hline & INEPT & $\begin{array}{c}\text { Based on }{ }^{1} \mathrm{H}^{-13} \mathrm{C} \text { J-coupling. OK for mobile } \\
\text { and/or crystalline species (in general, if } \mathrm{T}_{2}> \\
\text { 1/c, for c being the J-coupling constant) }\end{array}$ & & \\
\hline \multirow[t]{2}{*}{$\begin{array}{l}\text { Discrimination between } \mathrm{C} \text {, } \\
\mathrm{CH}, \mathrm{CH}_{2}, \mathrm{CH}_{3}\end{array}$} & IRCP & $\begin{array}{l}\text { CP-based experiment. } \\
\text { Variation in the inversion time, } \mathrm{T}_{\mathrm{i}} \\
\text { Rule of thumbs for normalized intensity: } \\
\mathrm{I}=-1 / 3-\mathrm{CH} 2 \\
\mathrm{I}=0-\mathrm{CH} \\
\mathrm{I}>0-\mathrm{CH} 3, \mathrm{C}\end{array}$ & \multirow[t]{2}{*}{ A } & \multirow[t]{2}{*}{ Same as CP } \\
\hline & INEPT & $\begin{array}{l}\text { If conditions for INEPT are met, then } \\
\text { possibility to edit directly } \mathrm{CH}_{\mathrm{x}} \text { (positive, zero } \\
\text { or negative intensity as a function of } \\
\text { refocusing time) }\end{array}$ & & \\
\hline \multirow{2}{*}{$\begin{array}{l}\text { 2D homo/hetero } \\
\text { correlation maps } \\
\text { (through-bond } \\
\text { interactions) }\end{array}$} & INEPT & $\begin{array}{l}\text { 2D version of } 1 \mathrm{D} \text { pulse. It selects chemically } \\
\text { bonded }{ }^{13} \mathrm{C}-{ }^{1} \mathrm{H} \text { pairs }\end{array}$ & A & $<3$ days \\
\hline & $\begin{array}{l}\text { INADEQUA } \\
\text { TE }\end{array}$ & $\begin{array}{c}{ }^{13} \mathrm{C}-{ }^{13} \mathrm{C} \text {, double quantum single quantum } \\
\text { experiment: on-diagonal peaks discriminate } \\
\text { self-interactions. Routine if isotopic } \\
\text { enrichment is done. Long } \mathrm{T}_{2} \text { values are } \\
\text { required. }\end{array}$ & $\mathrm{D}$ & $>3$ days \\
\hline \multirow{3}{*}{$\begin{array}{l}\text { 2D homo/hetero } \\
\text { correlation maps } \\
\text { (through-space } \\
\text { interactions) }\end{array}$} & HETCOR & $\begin{array}{l}{ }^{13} \mathrm{C}-{ }^{13} \mathrm{H} \text {, CP-based techniques. The most } \\
\text { commonly used for carbon materials }\end{array}$ & A & \multirow[b]{2}{*}{$<3$ days } \\
\hline & $\begin{array}{c}\text { EXSY } \\
(\text { NOESY) }\end{array}$ & $\begin{array}{c}{ }^{13} \mathrm{C}-{ }^{13} \mathrm{C} \text { proximities. Spin-diffusion based } \\
\text { technique. Use the } \mathrm{T}_{\mathrm{m}} \text { (from few ms to max } \\
500 \mathrm{~ms} \text { ) to explore nuclear proximities }(<5 \\
\AA) \text {. On-diagonal peaks ARE NOT discriminant } \\
\text { of self-interactions. Routine if isotopic } \\
\text { enrichment is done. }\end{array}$ & A & \\
\hline & C7, SC14... & $\begin{array}{l}{ }^{13} \mathrm{C}-{ }^{13} \mathrm{C} \text {, double quantum single quantum } \\
\text { experiment, on-diagonal peaks discriminate } \\
\text { self-interactions. The number of DQ loops is } \\
\text { related to spatial proximities ( } 1 \text { loop=closest } \\
\text { neighbour). Routine if isotopic enrichment is } \\
\text { done. Possibility to look at close proximities }\end{array}$ & $\mathrm{D}$ & $>3$ days \\
\hline Dynamics/Local mobility & $\begin{array}{l}\text { Relaxation } \\
\text { times }\end{array}$ & $\mathrm{T}_{1}, \mathrm{~T}_{2}, \mathrm{~T}_{1 \rho}$ & $\mathrm{E}$ & $\begin{array}{l}\text { Variable, from hrs to } \\
\text { days }\end{array}$ \\
\hline $\begin{array}{l}\text { Signal-to-noise } \\
\text { enhancement }\end{array}$ & DNP & $\begin{array}{l}\text { need of free radicals in the material and a } \\
\text { gyrotron coupled ton NMR spectrometer }\end{array}$ & $\mathrm{D}$ & minutes \\
\hline
\end{tabular}

* Acquisition time may depend on many parameters. Estimations here are given per single experiment for a material with carbon content

$>50 \mathrm{w} \%$ and proton content $>5 \mathrm{w} \%$, no ${ }^{13} \mathrm{C}$ isotopic enrichment, use of $4 \mathrm{~mm}$ rotor (internal volume $=70 \mu \mathrm{L}$ ) and $7.05 \mathrm{~T}$ spectrometer.

$\S$ Heteronuclear, and possibily homonuclear, decoupling schemes are routinely used with MAS in all experiments in order to achieve a good spectral resolution. 
${ }^{\circ} \mathrm{E}=$ Easy; A= Average; D= Difficult. Appreciation is based on the authors' personal experience and view of the literature, if pulse sequences are implemented on a routine Bruker AVANCE III spectrometer, if they need an experienced user to be either implemented exnovo or adapted, if they need specific knowledge of post-experimental processing, etc...

a Maximum MAS rates are given within a $1 \mathrm{KHz}$ error, which originates from the different nominal values provided by the fabricants of the zirconia rotors

\subsection{Solid state NMR study of selected carbon-based biomass}

Any lignocellulosic biomass has three major components: cellulose, hemicellulose and lignin. The relative proportion of cellulose varies according to the biomass origin from $20 \%$ to $45 \%$ for agricultural wastes.[39] Chemically, cellulose is a linear and syndiotatic polymer of $\beta$-D-glucose.[40] The anhydroglucose units (AGU) are bonded to each other through a glycosidic linkage at positions 1 and 4 and the number of repeating AGU defines the degree of polymerization (DP) of cellulose on which its solubility depends. A relatively dense network of intermolecular $\mathrm{H}$ bonds is established in polymers with more than 30 AGU. Consequently, these macromolecules have high resistance against chemical and biological transformations, and insolubility in most of the common solvents. Hemicellulose, the second biomass component contains many different sugar monomers, has a random structure, it is amorphous and easy hydrolysable. Different from carbohydrate based cellulose and hemicelluloses, lignin is a class of complex, cross-linked, 3D biopolymer with phenyl propane units and hydrophobic properties. Lignin is concentrated between the outer layers of the biomass fibers leading to structural rigidity and holding the polysaccharide's fibres together. The decomposition and degradation of lignin and hemicelluloses is way easier than for cellulose. [41,42] Based on this different reactivity it is feasible to separate cellulose and hemicelluloses from lignin, especially using alkaline treatments. $[43,44]$ Lignin can be further processed to obtain important phenol-derived chemicals used in various chemical industries. [45,46]

This section shows several well-known biomass-based carbons for which ${ }^{13} \mathrm{C}$ MAS ssNMR has provided an extremely valuable contribution to their structural analysis. Examples focus on lignin and cellulose, both being C-rich natural biopolymers, and their related amorphous chars, obtained from their pyrolytic and chemical/physical treatment.

The structural resolution of complex, carbon-rich, biopolymers and biopolymer-derived chars is a longdate task, which has always represented a major challenge for both ssNMR analysis and other spectroscopic techniques. First of all, these materials are most of the time non-crystalline or partially crystalline solids, which means that X-ray diffraction is either useless or only partially informative. Chemical heterogeneity, very common, makes these materials difficult to analyze with classical techniques like FT-IR, XPS and NMR because the resulting spectra are generally composed of very 
broad, superimposed, peaks difficult to attribute correctly and quantitatively. Spectral deconvolution is a common procedure to better put in evidence and understand the contribution of each individual component but the way this is done in practice is often arbitrary in terms of number, shape and peak width for each component characterizing one single resonance. To bypass this problem, many researchers have transferred the problem from solid to liquid state analysis, where the main idea is to fraction the material in its smaller constituents, soluble in solution. Analysis under these conditions is then much easier and more precise than in solids and it allowed, for instance, to isolate the individual phenyl alcohols building blocks constituting wood. [47,48] Unfortunately, the process of cracking naturally alters the initial material structure, thus leaving many questions open on the distribution and proximity of the individual bricks in the starting compound and if any part of the material has been irremediably altered. Specific problems concerning the use of NMR are the lack of protons (in chars), which limits the efficiency of cross polarization and the presence of paramagnetic centers which contribute to reduce both the spin-spin relaxation times (consequently broaden the NMR signal) and the spin-lattice relaxation time in the rotating frame $(\mathrm{t} 1 \rho)$ in a CP experiment. These problems are wellknown and have been discussed in detail by various authors since decades. $[7,49,50]$ In the following section, we focus on the use of ssNMR in the study of lignin, a widespread phenylpropanoid-based biopolymer, cellulose, a crystalline D-glucose based polysaccharide, and their derived chars.

\subsection{Wood and lignin}

Lignification [51] is the polymerization process in plant cell walls transforming phenolic monomers into radicals, and coupling them with other monomer radicals (only during initiation reactions), or more typically cross-coupling them with the growing lignin polymer/oligomer, to build up a phenylpropanoid polymer. [52,53,54,55] Even though extensive research efforts have been made to elucidate the finer structural details of the highly complex polyaromatic lignin, a definitive model does not yet exist (one of the available models can be found in [56, 48]). This task is further complicated by the wide natural variation in lignin structure, with the main difficulties arising during characterization due to the high level of chemical and structural heterogeneity of its bonding patterns. Nonetheless, the polyphenolic nature of lignin has been ascertained, and the most abundant constituent monomers characterized as p-coumaryl, coniferyl and synapyl alcohols. [57] The study of lignin is generally interconnected to the study of wood itself, which also includes both cellulose and hemicellulose fractions. Most NMR studies, both in solution and solid state, are focalized on structural elucidation of wood and the specific study of its various components. 
Solution NMR spectroscopy has been long used in the analysis of wood, but lignin must be extracted and the use of model compounds is necessary for precise spectral attribution. [48, 58, 59, 60] Even if ball milling is the most common lignin extraction technique from wood, the entire lignin fraction can also be analyzed in the so-called “cellulolytic enzyme lignin,” in which large fractions of the polysaccharides are removed by enzymatic (cellulases) digestion of crude wood. [61,62] Despite the intrinsic problem of relating the individual lignin building blocks with bulk lignin itself, and which strongly depends on the lignin treatment, [63,64] several works have shown the interest of using solution NMR for a precise attribution. In particular, two-dimensional (2D) NMR spectroscopy with single and multiple quantum filtering of the signal (e.g., ${ }^{13} \mathrm{C}-{ }^{1} \mathrm{H}$ correlatations using HSQC, HMQC or ${ }^{1} \mathrm{H}-{ }^{1} \mathrm{H}$ connections using INADEQUATE) continues to be the method of choice to identify unambiguously the different lignin units and the sub-unit bonding patterns $[65,66]$ or to study the stereochemistry of lignin. [59] Unfortunately, isolation or fractionation may cause significant modification of the original lignin structure yielding unrepresentative final results. [63,64] For this reason, ssNMR spectroscopy was proposed 30 years ago as an interesting alternative to study wood directly, $[67,68]$ even if line broadening constitutes a real problem for precise chemical shift attribution and structural resolution. The very first studies were mainly focused on the idea that ssNMR could bring valid pieces of information on wood structure, like peak attribution and quantification of lignin with respect to polysaccharides, effect of extraction methods, spectroscopic effects upon chemical modification (e.g., methylation, acetylation), number of free phenolic groups, distinction between hard (lignin fraction constitutes of a mixture of guaiacyl and syringyl units) and soft (lignin rich in guaiacyl units) woods, etc. $[67,68]$ More recent works have shown that implementation in the NMR technology (e.g., fast-spinning MAS probes, high fields) [69,70] and methodology applied to material science (e.g., development of robust spectral editing pulse sequences) [63] can improve the level of understanding of these complicated materials. Finally, mastering isotopic enrichment techniques of natural woods brings an additional benefit in the final objective of using ssNMR as main characterization tool. [71]

Fast Magic Angle Spinning (MAS) rotors bring obvious advantages in terms of spectral resolution, as spinning side bands are completely removed from the spectral window, thus making the spectrum much easier to interpret, both qualitatively and quantitatively. The main inconvenient in this case concerns the use of reduced amount of matter $(\sim 14 \mu \mathrm{L}$ for a $2.5 \mathrm{~mm}$ rotor with respect to $\sim 250 \mu \mathrm{L}$ for a $7 \mathrm{~mm}$ rotor), which can be a problem for the study of low abundant nuclei like ${ }^{13} \mathrm{C}$. A specific example of the influence of such a parameter in the study of archaeological woods is given in Ref. 69. The same effect of efficient removal of spinning side bands at low MAS rate can be combined with the use of 
large rotors if specific pulse sequences are used, as shown in Ref. 63. In the same work, authors nicely combine different pulse sequences (DEPT, dipolar dephasing, CP) to select specific parts of the complex wood spectrum and edit either carbonyls, protonated carbons or non-protonated carbon groups. In this way they could show that carbonyl content in wood strongly depend on the type of wood (mature vs. juvenile vs. genetically-modified plants) and extraction procedure (ball milling under various conditions). A similar approach was adopted by Wikberg and Maunu, [72] who have shown that thermal treatment strongly affects the lignin structure as the $\beta-\mathrm{O}-4$ linkage is cleaved. Interesting ${ }^{13} \mathrm{C}$-enrichment techniques have been developed to allow a direct study of protolignin directly in the cell walls. [73, 74] Selective ${ }^{13} \mathrm{C}$-enrichment can be obtained by using ${ }^{13} \mathrm{C}$-enriched compounds (e.g., monolignol glucosides, ferulic acid, phenylalanine) in seedlings cultures and tissue cultured cells, for instance. The achievement of selective ${ }^{13} \mathrm{C}$-enrichment at a specific carbon has been confirmed by ssNMR [73, 75] and structural studies were proposed, for instance, by Terashima et al., [76]. They evaluated specific alkyl-alkyl and alkyl-aryl ether linkages on enriched wheat straw via ${ }^{13} \mathrm{C} C P-M A S$ experiments. Evaluation of alkyl-aryl ethers has also been a matter of debate both in lignin and ligninderived polymers. In lignins, for instance, their amount has evaluated from $63 \%$ to $80 \%$ and eventually to $74 \%$. [76,77] On the contrary, type III kerogens, which are lignin geo-derived coals, were shown not to contain significant amounts of alkyl-aryl ethers by means of chemical shift analysis of the corresponding ${ }^{13} \mathrm{C}$ ssNMR spectra and using DFT calculations as modeling supporting tool. [78,79] These pieces of information are extremely helpful in the study of structural evolutions during the lignin coalification process and further works using CP-MAS have contributed to study the structure of natural coals and in particular the problem of signal attribution to aromatic and aliphatic species. [80]

\subsection{Cellulose}

Cellulose is a polysaccharide consisting of a linear chain of $\beta(1 \rightarrow 4)$ linked D-glucose units (which differs from the $\alpha(1 \rightarrow 4)$-glycosidic bonds in starch) and is the structural component of the primary cell wall of green plants, many forms of algae and the oomycetes as well as a secretion product of some species of bacteria (e.g., Gluconacetobacter xylinus). Cellulose is a straight chain polymer where no coiling or branching occurs, with extended and stiff rod-like conformation. The multiple hydroxyl groups on the glucose monomers form hydrogen bonds with oxygen atoms on the same or on a neighboring chain, holding them firmly together side-by-side and forming microfibrils with high tensile strength. From a structural point of view, native cellulose is a crystalline solid for which two forms are generally accepted, cellulose I and cellulose II, where the latter is obtained from cellulose I by a regeneration or mercerization process. Cellulose I is composed of two crystalline allomorphs, $\mathrm{I}_{\alpha}$ and $\mathrm{I}_{\beta}$, 
where the former is the metastable, low density, form while the latter is the thermodynamically most stable, high density, form. In terms of relative abundance, $I_{\alpha}$ and $I_{\beta}$ are generally found in differing mixtures and the proportion depends on the nature of the cellulose biopolymer. For instance, Valonia and bacterial cellulose are rich in $\mathrm{I}_{\alpha}$ while animal cellulose contains more of $\mathrm{I}_{\beta}$ structure. [81,82] If the history of structural determination of cellulose is very long because of the many different types of cellulose found in nature, ${ }^{13} \mathrm{C}$ solid state NMR has been a crucial technique to contribute to elucidate the structures of cellulose I and II and, in particular, in the discovery and identification of $\mathrm{I}_{\alpha}$ and $\mathrm{I}_{\beta}$ forms. [83, 84] Even if the role of solid state NMR in the study of cellulose was reviewed in1999, [85] we will make a short summary and in particular we will focus on some important studies that occurred later than 1999, year in which Lesage et al. implemented the INADEQUATE pulse sequence for solids and in particular for the study of through-bond carbon-carbon connectivities. [86]

The initial use of ssNMR to study cellulose is reported at the same time by Atalla et al. [87] and Earl et al. [88] and immediately followed by several others. [84, 89, 90] The main reason for such a burst in the use of ssNMR to study cellulose is directly related to the development, in the seventies, of cross polarization [91] and CP coupled to MAS for the study of carbon-13 containing materials. [92] The mere application of CP-MAS to various types of cellulosic materials allowed, using a comparative approach, to describe polymorphs cellulose I and II [87] and measure the characteristic carbon T1 and T2 relaxation times for cellulose I. [88] Effect of ball milling on the residual crystalline fractions in cellulose and consequent NMR response was described by Maciel et al. [89] while a comparison between the spectrum of cellulose II and various cellulose oligomers allowed to conclude that the spectral features of the former starts to be observed in an oligomer containing at least 4 glucose units. Undoubtedly, the main achievement of the comparative NMR approach was obtained by Atalla and Vanderhart, [84] who realized, by studying cellulose obtained from different sources, that native cellulose I is actually a mixture of two crystalline modifications, cellulose $I_{\alpha}$ and $I_{\beta}$. In particular, they observed that the C4 signal between $80 \mathrm{ppm}$ and $95 \mathrm{ppm}$ is composed of a collection of multiplets at about 89-90 ppm and a broad band centered at about 83-85 ppm (Figure 1). The former were assigned to segments in the interior of the chains while the latter to elements on the crystallite surface and in disordered regions. Additional differences occurred to C1 and C6 resonances. Since the relative intensities of the multiplets vary with the nature of the cellulosic sample, authors proposed that this signal actually represents a combination of two crystalline forms whose proportion varies from one sample to the other. They also provide the typical ${ }^{13} \mathrm{C}$ NMR spectral signatures for cellulose II, $\mathrm{I}_{\alpha}$ and $I_{\beta}$ and relative assignment (Figure 1). 


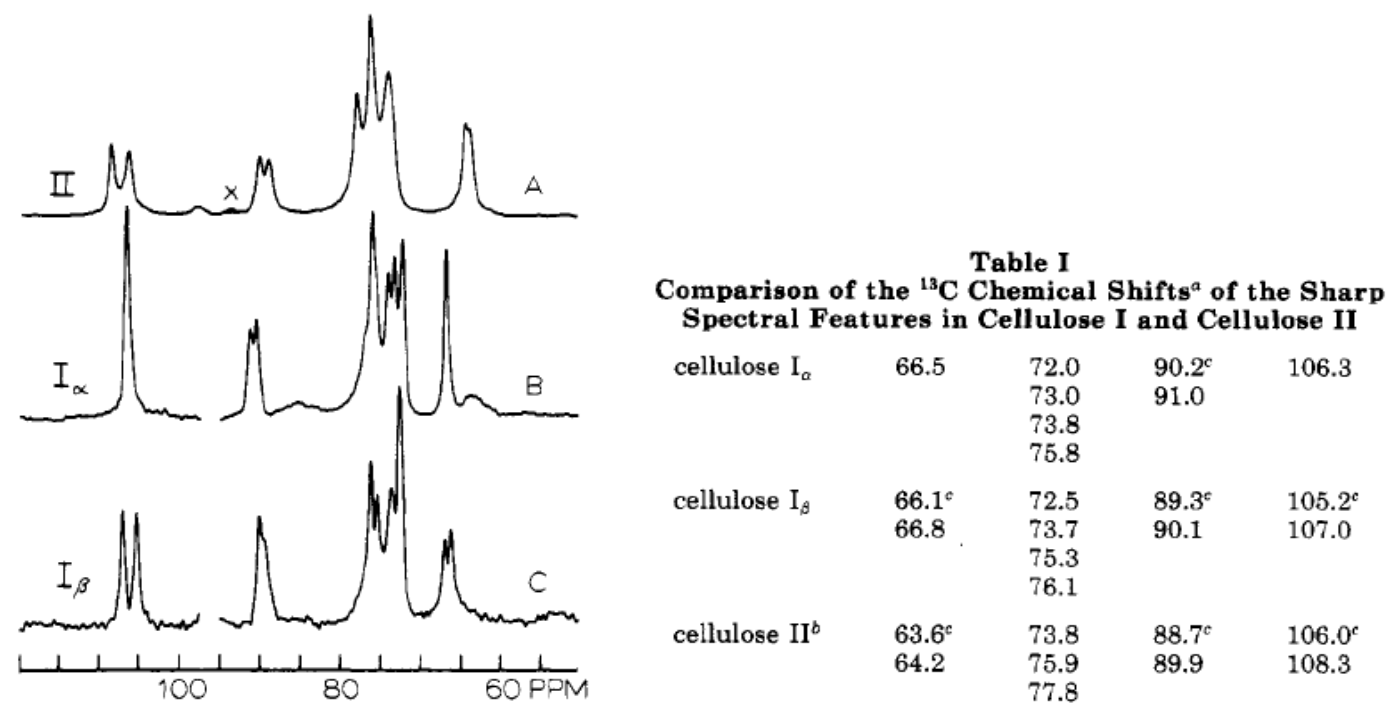

Figure 1 - A) Cellulose II with low degree of polymerization. (B) and (C) show the proposed crystalline forms of cellulose $I, I_{\alpha}$ and $I_{\beta}$. The table highlights the typical chemical shifts between the three forms of cellulose. Letters in the table refer to: a) Shifts are given in ppm and are measured with linear polyethylene as an internal chemical shift standard. Its crystalline resonance position is taken to be $33.63 \mathrm{ppm}$ with respect to tetramethylsilane at $0.0 \mathrm{ppm}$. b) These shifts were measured on a low-DP cellulose I1 sample that gave sharp lines. c) Doublets with approximately equal intensities. Adapted from Ref. [84]

These early studies had mainly the merit to show that understanding of the cellulose structure was still incomplete and motivated further work using complementary techniques like neutron diffraction to precisely attribute the positions of hydrogen in the unit cell. Moreover, along with the improvement of solid state NMR technique, probe technology and pulse sequence development, more works started to appear in the past 20 years where researchers went further in terms of the exploitation of 1D spectra but also in the use of advanced pulse sequences, like spin diffusion and multiple quantum coherences excitation, to probe the molecular proximities between the amorphous and crystalline fractions. This allowed going further in the more precise signal attribution in cellulose I and II materials.

Deconvolution of the ${ }^{13} \mathrm{C}$ CP-MAS spectra combined with linewidth and spin lattice relaxation times analyses allowed a more precise attribution of the C-4 region in the 80-92 ppm interval, [93,94,95,96] and which contains the signals of the crystalline cellulose together with para-crystalline domains, where the broad region closer to $80 \mathrm{ppm}$ is clearly attributed to disordered fractions. Very precise chemical shift attribution based on deconvolution shows a number of components: I $\alpha$ at 89.42 ppm, I $\beta$ at $87.87 \mathrm{ppm},(\mathrm{I} \alpha+\mathrm{I} \beta)$ at $88.74 \mathrm{ppm}$, para-crystalline at $88.45 \mathrm{ppm}$, accessible fibril surfaces at 84.22 ppm and 83.18 ppm, inaccessible fibril surfaces and xylan residues at 83.38 and 81.72 ppm. Moreover, it was defined a crystallinity index which is based on the ratio between all crystalline C4 components in 
the 85-90 ppm interval over the amorphous components in the 80-85 ppm interval. Despite the practical aspects of this approach, several critics on the pertinence of the methodology have been raised in the review proposed by Atalla and Vanderhart. [85]

After the review work by Atalla, several works based on 2D NMR have brought additional insight to solve several issues that were still open in the attribution of the C4 signal but also the less studied C2, C3 and C5 resonances between 70 and 80 ppm. Most experiments have been run on bacterial cellulose, which is easy to enrich in ${ }^{13} \mathrm{C}$, thus allowing complex time-consuming $2 \mathrm{D}$ experiments at reasonable time scales. Masuda et al. [97] have used both intramolecular (within cellulose) and intermolecular (from purposely added poly(vinylalcohol) towards cellulose) ${ }^{13} \mathrm{C}$ and ${ }^{13} \mathrm{C}$-detected ${ }^{1} \mathrm{H}$ spin diffusion to show that the signal from the C4 in the 80-85 ppm region, tentatively attributed to accessible and nonaccessible surface fibrils, does not represent a phase-separated fibrillar network (surface vs. core), because the typical spin diffusion time constant (and consequent spatial proximity) is of the same order of magnitude (20 s) for both the C4 signals below and above $85 \mathrm{ppm}$. Authors propose that the C4 signal in the 80-85 ppm region can then probably be attributed to structural defects in the fibrils associated to disordered hydrogen bonding.

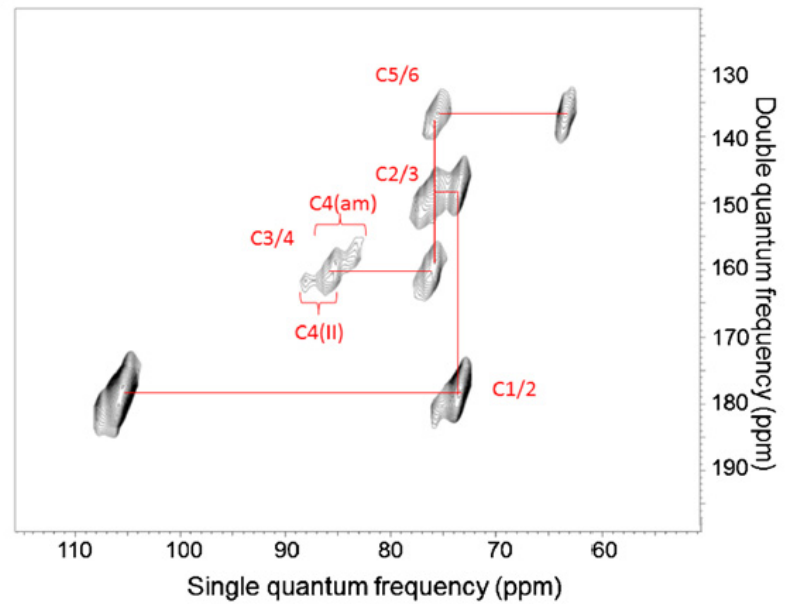

Figure 2 - Solid state ${ }^{13} \mathrm{C}-{ }^{13} \mathrm{C}$ INADEQUATE spectrum of cellulose. Solid lines represent connections between chemically-connected carbons and are focused on the cellulose amorphous signal. "am" stands for "amorphous" while "II" stands for cellulose II. From Ref. [100].

Finally, several groups continued their work on ${ }^{13} \mathrm{C}$-enriched cellulose derived from bacteria and in particular they have used the solid state version of the INADEQUATE pulse sequence to probe direct ${ }^{13} \mathrm{C}-{ }^{13} \mathrm{C}$ chemical bonds using double quantum single quantum coherences excitation. This powerful 2D experiment applied to cellulose was able to precisely attribute all signals and draw the skeleton of local connectivities on cellulose I, [98] II [99] and even amorphous samples, as shown in a typical spectrum 
in Figure 2. [100] For cellulose I, it was found that cellulose $I_{\alpha}$ and $I_{\beta}$ contain two non magnetically equivalent anhydroglucose units and whose conformation is different in both allomorphs. For cellulose II, all ${ }^{13} \mathrm{C}$ chemical shifts could be assigned and it was found that this material contains as well two non-equivalent anhydroglucose units, whose individual skeletons are now perfectly known. The use of the 2D J-HMQC experiment, adapted from solution NMR, was able to assign proton chemical shifts to each residue. In the same way, the chemical shifts of the C1-C6 atoms of amorphous cellulose were precisely attributed. The use of the INADEQUATE pulse sequence was crucial to resolve each individual chemical shift in the broad peaks that characterize this material. As a conclusion, it is clear that further insight in the structural understanding of cellulose polymorphs will be achieved by combining 1D and 2D NMR spectroscopy, and the recent work using the signal-enhancement property of DNP on a natural abundant ${ }^{13} \mathrm{C}$ cellulose sample [25] indicates that this can now occur on any type of cellulosic material and not only on selected isotopically enriched ones.

\section{0 ${ }^{13} \mathrm{C}$ solid state NMR studies of chars}

The word carbonaceous can be referred to many type of distinct carbon-rich materials, such as coals, humic acids, pyrolized biomass, etc... where each category could be divided into additional others; for coal, for instance, one can find bituminous cols, lignite, etc... For this section, we show how solid state NMR contributed to the structural understanding for a short selection of carbonaceous materials. This is because the NMR tools that are commonly employed to study carbonaceous matter are very similar, disregarding the nature of the material itself. Even if some advanced studies can be performed for isotopically-enriched materials, that is rarely done for most carbons, for which, in contrast to cellulose, isotopic enrichment is not easily possible. The following systems will be presented in more detail: coal followed by pyrolized biomass (cellulose and wood) and hydrothermal carbons. We stress the fact that coal is presented here as a term of comparison for the other two systems because of the long-date use of ssNMR as an important characterization tool for this material.

\subsection{Coal}

The early works on the use of solid state NMR to study the structure of solid fossil fuels were proposed in the 70's - 80's decades. [7,8,10,101,102,103,104,105] The main goal of many of these works was the evaluation of the aromaticity content in coals by various quantification procedures of the aromatic signal in the $100-160$ ppm region. The most obvious approach was the use of ${ }^{13} \mathrm{C} C P-M A S$ followed by peak integration while dipolar dephasing was used to evaluate the amount of non- 
protonated quaternary carbons. Unfortunately, due to several problems, the task was not easy. First of all, the complex spin dynamics in solids does not permit quantification easily when performing cross polarization (CP) experiment because the efficiency of $\mathrm{CP}$ depends on the proximity to protons. Secondly, the generally low MAS rate $(<5 \mathrm{kHz})$ employed in many studies bring residual spinning side bands, which overlap with the main signal. Then, paramagnetic centers constitute an important source of peak broadening (reduction of $\mathrm{T}_{2}$ relaxation times) or CP inefficiency (short $\mathrm{t} 1 \rho$ ). [49] To overcome some of these problems, more advanced approaches were needed to study the extent of aromaticity in coals. In [105], the authors set up a complex experimental and data processing analysis based on CP and dipolar dephasing (DD): they performed experiments at variable contact time, for CP, and dephasing time, for DD. By plotting the signal intensity vs. these specific adjustable parameters, it is possible to fit the curves and extract the dynamic parameters characteristic for each single resonance. From the typical equations (given in [105]), one determines two sets of very important parameters: the interaction and relaxation time constants, which characterize the nature and the dynamics of the ${ }^{1} \mathrm{H}-{ }^{13} \mathrm{C}$ polarization transfer, and the values for the initial magnetization, $\mathrm{M}_{0}$, used as a scaling constant in the analytical expressions. From the values of $\mathbf{M}_{0}$, which are unique for each resonance in the spectrum, it is then possible to quantify the relative amount of all aromatic resonances ( $\delta>100 \mathrm{ppm})$ with respect to the aliphatic one $(\delta<100 \mathrm{ppm})$. The approach applied to the dipolar dephasing dynamic experiments allows extracting the relative amount of protonated vs. non-protonated carbons in the aromatic region. From the combination of both techniques, it is not only possible to evaluate the extent of aromaticity for the coal samples but also the size of the aromatic clusters by looking at the percentage of bridgehead carbons (shared between 2 or 3 aromatic rings) with respect to peripheral C-H carbons. In the end, authors determine that all their coal samples contain between 10 and 20 carbon atoms per aromatic cluster.

Despite the strength of the coupled CP-DD approach to quantify the cluster size, little was till known about the exact attribution of each resonance, due to the large, poorly resolved, signals. The contribution from Supaluknari et al. [106] brought some answer to this problem, even if there was no novelty in the type of pulse sequence employed. In particular, they used CP and DD but added a spinning side band suppression sequence (TOSS) to achieve a “clean” isotropic signal. By analyzing different types of coals, from low to high rank (increasing extent of aromaticity), they determined, for instance, that quaternary aliphatic groups exist in the 30-40 ppm region, actually common in terpenoids, and that mobile components in the aliphatic region are also found. They also proposed a much deeper analysis on the amount of protonated and oxygenated carbon groups. Despite the fact that 
CP and DD are generally accepted as the optimal solutions, still largely used nowadays in the study of this class of materials, the problem of quantification, especially for H-poor coals, has been largely debated. This is the leit-motiv that motivated several work published in the 90's [1, 107], where the use of simple Bloch decay, also referred to as Single Pulse Excitation (SPE), was employed and compared to CP. The SPE is the simplest experiment in NMR and it is fully quantitative provided that magnetization of all spins has fully relaxed. Unfortunately, the spin-lattice relaxation times (T1) are generally very long (tens of seconds) for carbon materials and the general rule consists of waiting $5 * \mathrm{~T} 1$ (recycle time) before acquiring a new transient that contribute to NMR signal. In practice, recycle times as high as $100 \mathrm{~s}$ have been proposed to fully recover the magnetization.[1] Considering the low isotopic abundance of ${ }^{13} \mathrm{C}$, a single SPE experiment for a given sample can last several hours for an exploitable signal-to-noise ratio. This problem of long acquisition time can be overcome by using large amount of matter combined with stronger magnetic fields $\left(\mathrm{B}_{0}\right)$, even if in this case the CSA interaction (proportional $\mathrm{B}_{0}$ ) becomes stronger, thus imposing the use of faster MAS rates (smaller rotors = smaller quantities). CP can considerably help to reduce the recycle time because relaxation in this experiment depends on ${ }^{1} \mathrm{H}$, generally the most abundant nucleus having shorter relaxation times ( seconds) than ${ }^{13} \mathrm{C}$. It then became important to know if CP can replace SPE in the quantification of ${ }^{13} \mathrm{C}$ spectra. In [1], authors determined the fraction of aromatic carbons in several coal samples using a typical ${ }^{13} \mathrm{C}$ CP-MAS experiment to be comparable with the one found via a quantitative SPE but authors in [107] found that CP provides results that are about 10\% smaller than SPE. However, at higher carbons content $(\mathrm{H} / \mathrm{C}<0.4)$, the discrepancies between them is reduced. Furthermore, the same authors also argued that the presence of paramagnetic centers relatively affected the overall signal, which is $>75 \%$ using SPE.

In the late 90's, early 2000, the structural characterization of coals does not carry much innovation from an NMR point of view. Many works rely on combining CP and DD with physicochemical treatment of the chars $[108,109,110]$, which can give some insight on the structural functional groups inside the material. Hu et al. [111] have nicely employed these techniques with a Chemical Shift Anisotropy (CSA) filtering pulse sequence, which gives insight on the local carbon symmetry. In this way, DD and CP (at short contact time) can be used to select, respectively, non-protonated and protonated carbons, whose local symmetry can be successively analyzed, in a two-dimensional map, using the CSA-filtering method (Figure 3). 

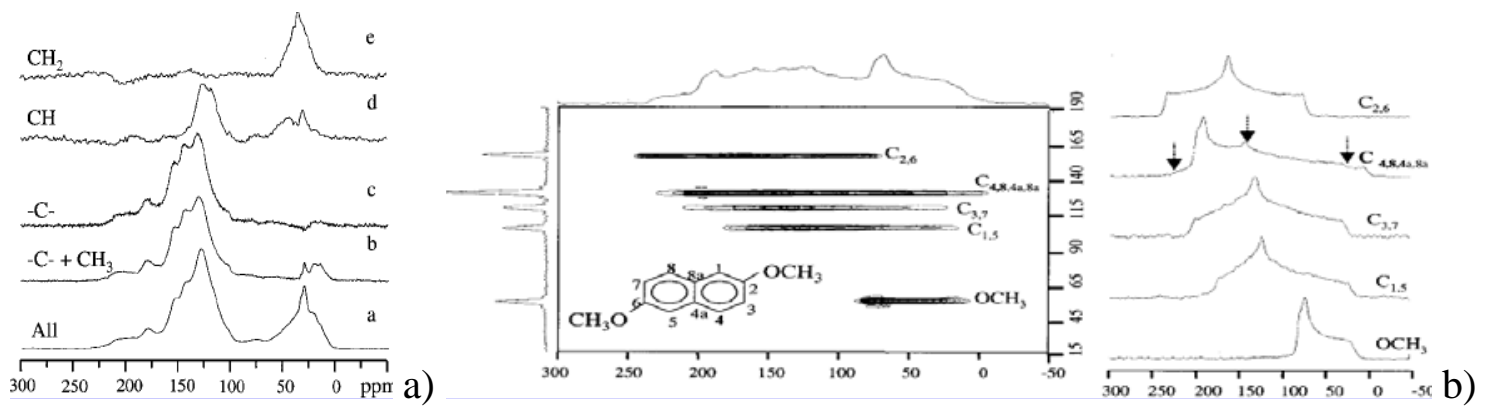

Figure 3 - (a) Series of ${ }^{13} \mathrm{C}$ spectra recorded on the same carbonaceous solid using different spectral filtering techniques (see Ref. 111 for more details). The type of selected carbon is indicated on the left-hand side of each spectrum. (b) Typical 2D ${ }^{13} \mathrm{C}$ CSA-filtered experiment that correlates the isotropic chemical shift for each resonance (indirect, Y-dimension) with the corresponding Chemical Shift Anisotropy (CSA) experience by each chemical group (direct, $\mathrm{X}$-dimension). On the right side, the cross-sections of the 2D map are externalized along with the attribution of each chemical group. From Ref. [111].

A specific comparison with model compounds allowed to show that an overestimation of the cluster size calculated with the method given in [105] and discussed above can be expected for carbonaceous materials with important oxygen-substitutions (e.g., $\mathrm{COOH}$ groups), because these can move the isotropic chemical shift for these groups in the region of the bridgehead carbons, used to establish the cluster size. An example of a recent work in which physico-chemical treatment of coals was used for structural understanding purposes has been proposed by the group of Mao, [110] who has made a considerable amount of research in the application of solid state NMR methodology to the study of carbonaceous materials, mainly kerogens and humic substances. [11] The goal was to observe if different structural features of coals (lignite and anthracite, where $97 \%$ of the latter is mainly constituted by aromatics with respect to $76 \%$ of lignite) actually affect the final black carbon structure obtained by their pyrolysis. The NMR editing work has been done using various pulse sequences: ${ }^{13} \mathrm{C}$ SPE (which in the cited work it is referred to as Direct Polarization, DP) for quantitative analysis, CP combined with TOSS for suppression of side bands, CSA filter to selectively suppress the signal of $\mathrm{sp}^{2}$ aromatic carbons in the 90-120 ppm range and only recover the signal from $\mathrm{sp}^{3}$ carbons, $2 \mathrm{D}{ }^{1} \mathrm{H}-{ }^{13} \mathrm{C}$ heteronuclear correlation experiments to attribute proton signals (otherwise very broad and difficult to assign) through carbons and, finally, ${ }^{1} \mathrm{H}-{ }^{13} \mathrm{C}$ long-range recoupled dipolar dephasing, DD, experiments combined with SPE and TOSS to efficiently detect all carbons and eventually recover only the signal from non-protonated and mobiles $\mathrm{CH}_{2} / \mathrm{CH}_{3}$ carbons. In particular, by applying the DD technique to the study of the aromatic cluster size (the size of the cluster limited by the presence of external protons contouring the cluster itself), [24] they have shown that high-rank coals (large aromaticity) are not the ones having the largest aromatic cluster sizes. For instance, anthracite has a $>95 \%$ aromaticity with respect to its black carbon derivative (87\%) but the cluster size is larger in the black carbon than in 
anthracite. The other interesting point is that despite the type of coal structure, the nature of their derived black carbons is very similar.

We end this section by referring to a recent work by the group of Pruski [112] strengthening the fact that application of ssNMR to the study of coals has mainly been developed in the 80's and since then few innovations have been brought in this field despite the fact that the "NMR tool box" has considerably developed in the past 20 years in terms of accessibility to strong magnetic fields $(>9.4 \mathrm{~T})$, fast MAS (> $30 \mathrm{kHz}$ ), newly implemented pulse programs, improved electronics and so forth. For this reason, many classical approaches (e.g., use of TOSS to suppress spinning side bands, use of low magnetic fields) should be revised. For instance, the use of dipolar decoupling to discriminate between protonated and non-protonated carbons can be replaced, to some extent, by the J-filtered INEPT pulse sequence, which is commonly used in solution NMR spectroscopy. This was done, for instance, by us in the study of hydrothermal carbons and detailed later. Reference [112] shows then how structural resolution of various types of coals can be achieved at high fields and fast MAS by proper implementation of CP using, for instance, a tangential ramp to be more efficient in meeting the Hartmann-Hahn condition; it also shows how 2D ${ }^{1} \mathrm{H}-{ }^{13} \mathrm{C}$ correlation maps can be obtained in a reasonable amount of time and acquired under advanced homonuclear decoupling schemes like Phase Modulated Lee-Goldburg (PMLG).

\subsection{Thermal treatment of biomass (cellulose and wood)}

In the following section, we report the study of biomass treated under dry conditions in an inert atmosphere. Pyrolysis (section 4.2.1) refers to thermal treatment at temperature typically higher than $300^{\circ} \mathrm{C}$ and torrefaction (section 4.2.2) represents a thermal treatment at temperature between $200^{\circ} \mathrm{C}$ and $300^{\circ} \mathrm{C}$. Nonetheless, despite this general classification, a clear distinction is not always possible because each author does not always respect it when referring to his own work. Our choice is to report as pyrolysis or torrefaction those works that clearly address themselves as such but the reader should be aware that overlapping in terms of operating conditions can be easily found.

\subsubsection{Pyrolysis}

Upon pyrolysis, carbonaceous biomass including cellulose and wood undergoes thermal decomposition leading to the elimination of small volatile species (e.g., $\mathrm{CO}_{2}, \mathrm{CO}, \mathrm{CH}_{4}, \mathrm{H}_{2} \mathrm{O}$ ) and condensation reactions which produce a complex polyaromatic network, commonly referred to as char. Early FT-IR studies of pyrolized cellulose can be traced back to the 60s, [113] while solid state ${ }^{13} \mathrm{C}$ NMR started to be employed much later. [4,5] Interestingly, if compared to study of cellulose itself or 
to the study of coals, solid state NMR is far from being employed at its best for the study of the effect of pyrolysis on the structure of biomass. In fact, it is generally employed as a complementary technique to the use of FT-IR or chromatography, as it was shown by Pastorova et al. [4], who combined ${ }^{13} \mathrm{C}$ ssNMR with GC-MS and FT-IR to elucidate the structure of char obtained from pyrolyzing cellulose between $250-400^{\circ} \mathrm{C}$ for 150 minutes. Authors showed that cellulose keeps its initial structure up to $250^{\circ} \mathrm{C}$, while major chemical modifications occur at $270^{\circ} \mathrm{C}$; both phenolic and furanyl groups were detected as volatile compounds and authors proposed a reaction mechanism that leads from cellulose decomposition to furans to substituted aromatics rings, contained in the final char. The main purpose for using ${ }^{13} \mathrm{C}$ ssNMR was merely to bring some spare information in terms of chemical shift attribution, which was based on referencing to all works investigating the structure of both cellulose itself and coals. The lack of important works using NMR to understand the fate of cellulose after pyrolysis is very clear from the recent review paper by Lédé, [114] who carefully and critically reviews the entire activity that has been done on the understanding of the intermediate species (also called "active cellulose”) that form from the treatment of cellulose at intermediate temperature and before the formation of char. For this reason, this section will not enter such a historical debate, which can be read in [114], but will merely bring some detail on how ssNMR has contributed to that, even if in this case the overall contribution was far from being relevant as for coals and crystalline cellulose.

One interesting point concerns the attribution of the ${ }^{13} \mathrm{C}$ NMR spectra, which are generally acquired under CP. Experiments are often run on samples treated at increasing temperatures and the most critical resonances to assign are in the 60-110 ppm and 110-150 ppm regions. The first set is related to cellulose signal upon structural modification into the so-called “active cellulose", whose sense is deeply discussed in [114]; the second is related to the carbonaceous components that form during pyrolysis and in particular to aromatic carbons. By analogy with coals, the bands in the 125-130 ppm region correspond to fused aromatic rings and the ones in the $150 \mathrm{ppm}$ region to oxygenated aromatic groups. Above 150 ppm, functional groups (carboxylic acids, esters, ketones, aldehydes) are depicted. Such a typical attribution is done, for instance, in references [115, 116, 117] where either CP or dipolar dephasing where employed to perform a rapid attribution to the ${ }^{13} \mathrm{C}$ spectrum. Even the NMR methodology was exactly the same, Zhang et al. [118] attributed the peak at 150 ppm, for its comparable intensity with the one at $110 \mathrm{ppm}$, to furfuryl motifs in char materials obtained from pyrolyzed starch. Nevertheless, in most studies, both the structure of cellulose-derived and, more generally, wood-derived chars have been described as being composed of a network of polyaromatic hydrocarbons, [5, 80, 115, 119, 120, 121] as found either in lignins or coal, more or less rich in oxygen 
functionalities. The study in which a close analysis of the lineshape and width of the ${ }^{13} \mathrm{C}$ NMR peaks has brought some significant insight on the structure was published by Wooten et al. [5], who have shown that, after 30 minutes at $300^{\circ} \mathrm{C}$, cellulose undergoes depolymerization to form an "intermediate cellulose" product, which then transforms into a "final carbohydrate” (FC) before aromatization and which was associated with large amounts of oligo- and polysaccharides. According to the authors and to the analysis by Lédé [114], IC corresponds to the so-called active cellulose, which seemed to be a disordered carbohydrate derived from fragmented cellulose rather than a form of crystalline cellulose with a lower degree of polymerization. [5] In the late 2000, several works started to use more advanced NMR techniques, like double quantum single quantum ${ }^{1} \mathrm{H}-{ }^{1} \mathrm{H}$ 2D NMR spectroscopy performed on biomass pyrolized at different temperature. [120] The main message that could be obtained by this technique was that the aliphatic and aromatic regions are intimately mixed together (on the NMR experiment timescale), rather than phase separated.

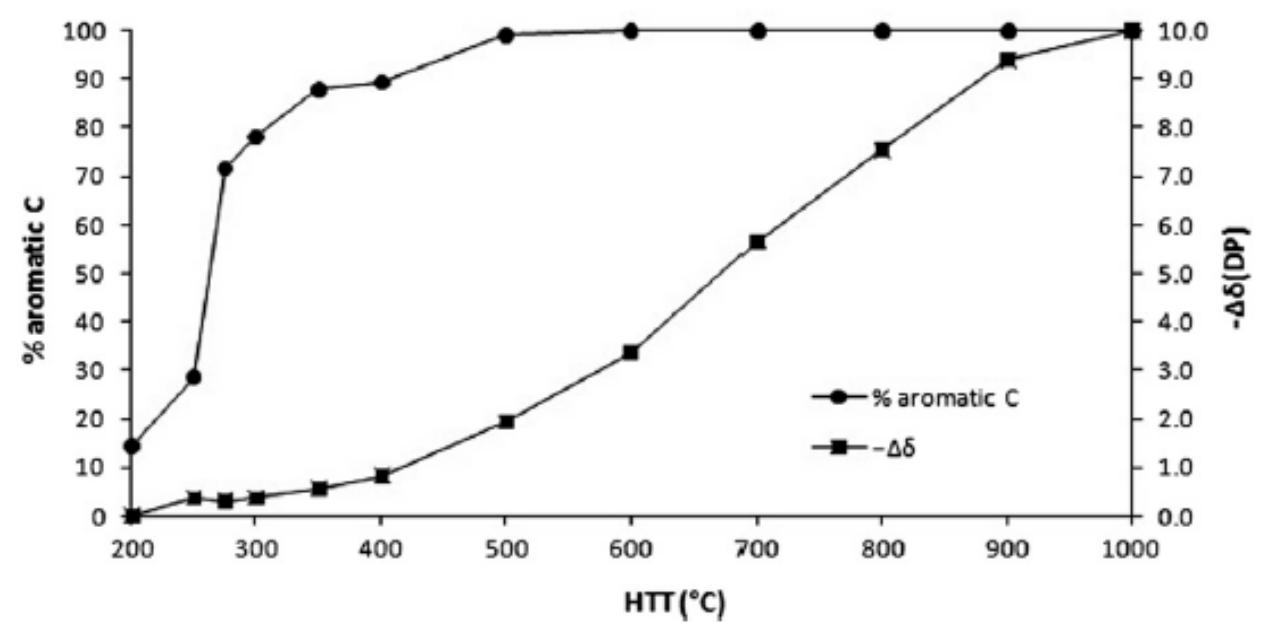

Figure 4 - Evolution of the percentage of aromatic carbons calculated from the SPE spectra recorded at various temperatures and $-\Delta \delta$ obtained from the adsorbed ${ }^{13} \mathrm{C}$-benzene on the same materials. From Ref. [124]

More recently, some interesting experiments with the aim of probing the extent of cluster size in char and thermally processed biomass have been proposed. [122, 123, 124] The idea is very simple and it is based on following the Nucleus Independent Chemical Shift (NICS) variation [125] of physisorbed ${ }^{13} \mathrm{C}$-labelled benzene on carbonaceous materials $\left(\Delta \delta=\delta_{\text {AdsorbedBenzene }}-\delta_{\text {FreeBenzene }}\right)$. In fact, diamagnetic ring currents are induced in the conjugates aromatic structures when placed in a magnetic field. Under these conditions, a magnetic field is induced and it adds (or subtracts) to the applied magnetic field: if an upfield shift of the ${ }^{13} \mathrm{C}$ resonance of the adsorbed benzene is recorded $(\Delta \delta<0)$, one speaks of an aromatic effect; if a downfield shift is observed $(\Delta \delta<0)$, one speaks of an anti-aromatic effect: the 
larger the shift, the higher the degree of aromatic condensation. In fact, chemical shifts of the ${ }^{13} \mathrm{C}$ peak characteristic of aromatic carbons in chars and associated to diamagnetic ring currents are largely known. [126] Both CP and SPE experiments can then be run and both the percentage of aromatic C signal from integration of the SPE spectra (aromatic region, 110-160 ppm) and the $\Delta \delta$ are plotted against the calcination temperature, as shown in Figure 4. [124] One comment should be made. Plotting the SPE intensity gives complementary information with respect to the $-\Delta \delta$ approach, the $\%$ of aromatic carbon groups is higher at low calcination temperatures. The discrepancy may come from the nonhomogeneous adsorption of the ${ }^{13} \mathrm{C}$-benzene throughout the carbonaceous material, which could underestimate the effective extent of the condensed aromatic rings.

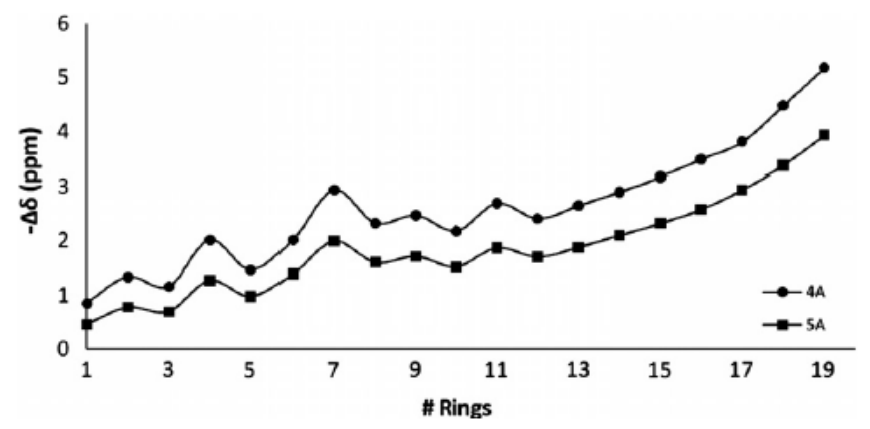

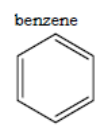
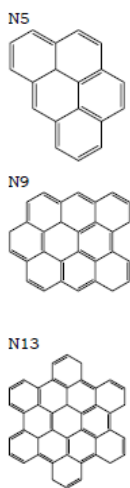

a)
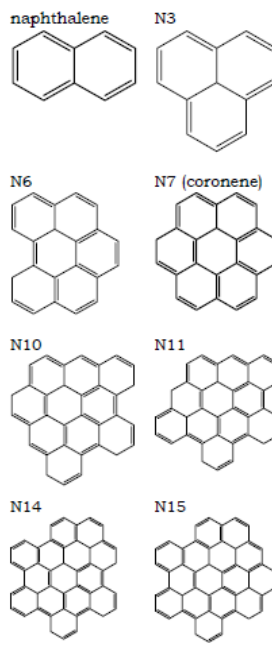

N18
N11

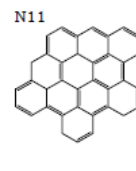

N19

19
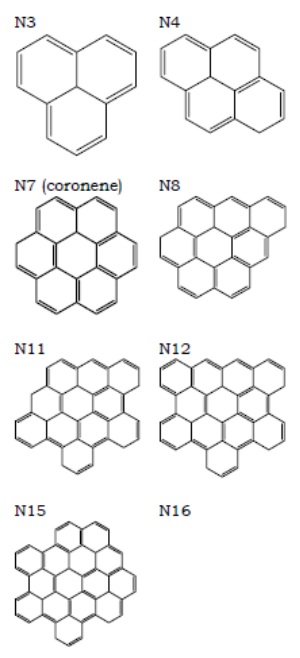

N16

b)

Figure 5 - a) Calculated $-\Delta \delta$ for adsorbed benzene as a function of the number of clustered benzene rings shown in (b). Effect of the distance ( 4 or $5 \AA$ ) between benzene and the ring surface is also shown. Adapted from Ref. [124]

Using $a b$ initio molecular modeling to calculate the expected chemical shift variation, one can eventually plot $\Delta \delta$ against the number of condensed rings. Figure 5 shows the evolution of the calculated $-\Delta \delta$ for benzene adsorbed on a series of clustered benzene rings. They also show that the closer benzene to the surface, the stronger the NICS effect. In this way, authors find that at temperature below $500^{\circ} \mathrm{C}$, aromatic domains are not larger than coronene $(\Delta \delta<3 \mathrm{ppm})$ while at higher temperature $\left(500^{\circ} \mathrm{C}-900^{\circ} \mathrm{C}\right)$, as many as 19 rings can be found $(\Delta \delta>4 \mathrm{ppm})$. In an even more recent study, Cao et al. [127] have investigated the effect of temperature on wood samples and used a combination of advanced ssNMR techniques: direct polarization for quantification (SPE); dipolar dephasing (DD) for non-protonated and mobile species; CSA-filtered CP experiments to only recover sp3 carbons; CP at short contact time combined with $\mathrm{DD}$ in order to recover only the $\mathrm{CH}$ signal from slow $\mathrm{CH}_{\mathrm{x}}$ groups; 
recoupled long range DD to evaluate the aromatic cluster size. The main results, whose details are not reported here, concern the precise attribution of each single ${ }^{13} \mathrm{C}$ peak in terms of protonation degree and nature of the condensation extent (mobile vs. non-mobile carbons) and it also allowed establishing the typical cluster size evolution with temperature, to be compared with the work in [124]. In particular, if they also found that the aromatic cluster size increases with calcination temperature, their estimation was slightly in defect with respect to that of McBeath et al., especially in the $500^{\circ} \mathrm{C}-800^{\circ} \mathrm{C}$ temperature range, where it was estimated that larger clusters contain less than 15 rings. The discrepancy is attributed to the different processing conditions (heating rate, heat treatment time, gas flow rate, etc...).

Recently, Bridgwater et al. provided a review of fast pyrolysis of biomass. Typical weight yields for liquid, solid and gas products obtained by different thermal conversion process such as fast pyrolysis intermediate carbonization, gasification, torrefaction have been summarized. [128] In the particular case of lignin, fast pyrolysis leads to the formation of liquid products which have been intensively studied by NMR. For example, Raguskas et al studied the pyrolysis of softwood kraft lignin and pine wood in different pyrolysis systems at 400, 500 and $600{ }^{\circ} \mathrm{C}$ NMR using quantitative ${ }^{13} \mathrm{C}$ and Heteronuclear Single-Quantum Correlation (HSQC)-NMR. They found out that the content of methoxy groups decreased by $76 \%$ for pine wood and $70 \%$ for lignin when using fast the pyrolysis system. The carbonyl groups also decreased by $76 \%$ and nearly completely eliminated in $600{ }^{\circ} \mathrm{C}$ pine wood fast pyrolysis oil. Compared to the slow pyrolysis process, fast pyrolysis process was found to improve the cleavage of methoxyl groups, aliphatic C-C bonds and carbonyl groups and produce more polyaromatic hydrocarbons (PAH) from lignin and aliphatic C-O bonds from carbohydrates. Another remarkable difference between fast and slow pyrolysis oils was the molecular weight of fast pyrolysis oils increased by $85-112 \%$ for pine wood and 104-112\% for lignin. [129]

Van Eck et al. studied the effects of thermochemical treatments (aquathermolysis, pyrolysis, and combinations thereof) on the lignocellulosic structure and composition of wheat straw were studied with ${ }^{13} \mathrm{C}$ and ${ }^{1} \mathrm{H}$ solid state NMR spectroscopy and proton $\mathrm{T}_{1 \rho}$ relaxation measurements. Results show that aquathermolysis removes hemicellulose, acetyl groups, and ash minerals. As a result, the susceptibility of lignocellulose to pyrolysis is reduced most likely due to the removal of catalytically active salts, although recondensation of lignin during aquathermolysis treatment can also play a role. In contrast to pyrolysis of wheat straw, pyrolysis of aquathermolysed wheat straw leaves traces of cellulose in the char as well as more intense lignin methoxy peaks. Finally, it was found that both pyrolysis chars contain aliphatic chains, which were attributed to the presence of cutin or cutin-like 
materials, a macromolecule that covers the aerial surface of plants, not soluble in water and seemingly stable under the pyrolysis conditions applied. [130]

Link et al. have also studied the effects of properties of the different biomass samples, the leaching pre-treatment process to remove inorganics, and the pyrolysis heating rate on the composition of chars obtained during pyrolysis at $800^{\circ} \mathrm{C}$. They have also attempted to investigate the changes in carbon structure and sodium environment because of pyrolysis with ${ }^{23} \mathrm{Na}$ nuclear magnetic resonance (NMR) ${ }^{13} \mathrm{C}$ solid-state cross-polarization magic-angle spinning (CP-MAS) NMR was used, resulting in spectra indicating the various groups of carbons present in the pure biomass samples. No evidence was found that the leaching process could affect the carbon composition of the biomass samples. In the char samples at $800^{\circ} \mathrm{C}$, only aromatic groups of carbon were left, shown by ${ }^{13} \mathrm{C}$ solid-state single-pulse MAS NMR. According to the results, the origin of biomass, the leaching procedure, and the different heating rates do not affect the char carbon composition. Therefore, it could be assumed that the carbon structure does not affect the reactivity of the char. ${ }^{23} \mathrm{Na}$ single-pulse solid-state MAS NMR was applied to investigate the sodium environment in the biomass and char samples. Despite experimental difficulties, the authors were able to observe definite differences in line width and shifts of the studied compounds. This proves that leaching affects the fuel properties, i.e., sodium chemistry in a biomass sample, and therefore, it could be assumed that the char reactivity is affected. [131]

There is an increasingly amount of literature on the conversion of lignin into carbon materials. It all started using activation methods [132] (see next paragraphs). Lignin has been also used as a precurors for the production of microporous carbons via hard templating. [133] Considerable research efforts are also directed towards the use of lignin to prepare carbon fibres via electrospinning or melt spinning of anhydride-modified lignin. [134,135,136,137] However, none of these studies provide an extensive characterization of the carbon materials using ${ }^{13} \mathrm{C}$-solid state NMR.

A further category of biomass-derived carbon materials is constituted by activated carbons (ACs). Their synthesis (activation) relies on the thermal treatment of the biomass precursor in the presence of an activating agent. The activation methods are usually divided into 2 different categories: physical and chemical. In the former case, a two-step process is usually employed. The AC precursor is first carbonized and then selectively oxidized using a gas phase, most frequently $\mathrm{CO}_{2}$ or $\mathrm{H}_{2} \mathrm{O}$. During chemical activation instead, the AC precursor is firstly impregnated with an activating agent (eg. $\mathrm{ZnCl}_{2}, \mathrm{H}_{3} \mathrm{PO}_{4}, \mathrm{KOH}, \mathrm{NaOH}$ ), then heat-treated and finally washed to remove all the inorganic side products. Temperatures, used during the activation process, are usually within the range $500-800{ }^{\circ} \mathrm{C}$. [138] As a consequence the ACs chemical structure is predominantly composed of aromatic pre- 
graphitic domains. This translates into an extreme paucity of protons within the ACs sample, which renders the utilization of CP sequences extremely challenging, when it comes to analysing ACs by ${ }^{13} \mathrm{C}$ solid state NMR means. This difficulty is the main explanation, why ${ }^{13} \mathrm{C}$ solid state NMR works, focussing on the characterization of ACs, are extremely rare, if not unique, within the literature.

In the first traceable works ${ }^{13} \mathrm{C}$ solid state NMR is not used to characterize ACs, but it is instead employed to determine the evolution of the biomass precursor chemical structure into the final carbon product. [139] To this regard one of the most complete analysis is the one provided by Solum et al. [140] In this study, the ${ }^{13} \mathrm{C}$ NMR spectra of samples obtained from simple pyrolysis of white oak at different temperatures are compared to samples, which were instead activated with phosphoric acid at the same temperatures. The authors describe the evolution of the spectra as a function of temperature highlighting that phosphoric acid significantly reduces the reactivity temperature threshold of cellulose and accelerates the development of aromaticity on heat treatment. Furthermore the authors speculate that phosphoric acid promotes the formation of cross-links within the biomass precursors at low temperatures $\left(200-250^{\circ} \mathrm{C}\right)$ allowing the retention of volatile species and resulting consequently into a higher carbon yields. Puziy et al. carried out a similar work and confirmed the common difficulties in regard to the characterization of ACs. [141] They were only able to obtain spectra predominantly characterized by broad resonances. The lack of resolutions is attributed to the presence of free radicals, the amorphous nature and the complex structure of the highly dipolar coupled materials.

Exploiting the chemical shift variation $(\Delta \delta)$ of physisorbed ${ }^{13} \mathrm{C}$-labelled benzene on carbonaceous materials depending on their degree of conjugation, as previously explained, McBeath et al. also included ACs (two samples: the first commercially available, the second obtained via steam activation of manure char) in the aromaticity quantization analysis of several carbonaceous materials. This study also concludes that ACs yield very poor quality CP spectra characterized by broad resonances. Furthermore spectra of the ACs, obtained with SPE experiments, highlight the major aromatic nature of the samples and the absence of functional groups. []

Cheng et al have conducted one of the most complete studies on the characterization of ACs by ${ }^{13} \mathrm{C}$ solid state NMR. In order to overcome the limits of CP sequences, the authors complemented their analysis with SPE experiments, explaining that combining these two categories of NMR experiments allows a reliable quantitative and qualitative characterization of the ACs. [142] The CP spectra provide information on the chemical composition of the biomass precursor and on how the activation process leads to its modification. The SPE experiments allow observing and quantifying the graphitic carbons, which are underestimated in CP experiments due to the lack of protons in their proximity. Cheng et al 
employed also more complex pulse sequences in order to obtain more specific information regarding the chemical structure of ACs. Dipolar dephasing coupled to CP was used to calculate the mole fraction of bridgehead aromatic carbon. Variable-contact-time experiments provided information regarding the mobility and homogeneity of carbons in the sample. The mobility of the carbon matrix was also analyzed with experiments aimed at testing the relaxation response of the carbon nuclei (Inversion Recovery for measuring the spin-lattice relaxation times, $\mathrm{T}_{1}$ ). [142]

The above-described studies clearly show that the use of ${ }^{13} \mathrm{C}$ solid state NMR for the characterization of ACs is indeed a challenging task. Lack of protons, high density of paramagnetic centers, high heterogeneity of magnetization dynamics due to various carbon environments are only some of the several challenges hindering the use of ${ }^{13} \mathrm{C}$ solid state NMR. On the other hand the continuous improvement of spectrometers and increased NMR understanding are certainly allowing a more widespread use and easier accessibility of this characterization technique. Therefore it is foreseeable that in the future ${ }^{13} \mathrm{C}$ solid state NMR will certainly gain more and more importance in the field of ACs characterization providing more detailed insights on the chemical structure of these functional carbon materials.

As a conclusive remark, even if the list of works using ssNMR to study processed biomass is probably not exhaustive, it is quite clear that only recently a small amount of researcher worldwide starts to apply the most recent developments in this spectroscopic technique to better understand both structural features in the processed material and the effect of the process itself on the initial cellulosic and/or lignitic structures. This is even clearer in the next section, where carbons obtained from the hydrothermal treatment of carbohydrate and biomass are analyzed using advanced NMR tools which allowed drawing the structure of this particular class of carbonaceous structure and effectuate a parallel with the charcoals.

\subsubsection{Torrefaction}

Torrefaction is another thermal conversion method of biomass in the low temperature range of 200-300 ${ }^{\circ} \mathrm{C}$. Biomass is pre-treated to produce a high quality solid biofuel that can be used for combustion and/or gasification. Torrefaction is based on the removal of oxygen from biomass which aims to produce a fuel with increased energy density by decomposing the reactive hemicellulose fraction. Different reaction conditions (temperature, inert gas, reaction time) and biomass resources lead to various solid, liquid and gaseous products. There are several excellent reviews in the literature on biomass torrefaction, and we address the reader to them for a more comprehensive overview of this 
thermal treatment. [143] Here, we will limit ourselves to describe how ${ }^{13} \mathrm{C}$-solid state NMR has brought valuable information on the composition and structural changes of torrefied biomass.

The use of solid state NMR in the study of torrefied biomass is only very recent and it does not benefit, so far, of an extensive use of the most advanced tools. Single Pulse, CP-MAS and dipolar dephasing experiments are the ones which have been employed so far, and at different degrees. Probably the most accurate and complete study has been published by Melkior et al. [144] on the torrefaction of beech wood at temperatures between $200^{\circ} \mathrm{C}$ and $300^{\circ} \mathrm{C}$. The interesting point in this work is the rigorous approach in terms of quantification for NMR spectra. CP-MAS spectra have been carefully decomposed and their intensity was corrected to take account of the magnetization build-up as a function of the contact time. By this way, they were able to show that: 1) hemicelluloses loose their acetyl groups just above $200^{\circ} \mathrm{C}$; 2) cellulose (and hemicellulose) starts its degradation process above $245^{\circ} \mathrm{C}$; 3) between $200^{\circ} \mathrm{C}$ and $245^{\circ} \mathrm{C}$ amorphous cellulose (C-4 signal at $84 \mathrm{ppm}$ ) partially recrystallizes into ordered domains (increase of the C-4 signal at $89 \mathrm{ppm}$; 4) demethoxylation process in lignins also starts above $200^{\circ} \mathrm{C}$. Finally, they have used a series of ${ }^{13} \mathrm{C}-{ }^{1} \mathrm{H}$ 2D HETCOR NMR experiments to show that the increased aromatic fraction (110 ppm - $130 \mathrm{ppm}$ ) occurring after treatment at $300^{\circ} \mathrm{C}$ is not linked to oxygenated units (e.g., derivatives of cellulose) but is must be linked to an aromatic network, whose exact nature was not discussed.

A similar experimental approach was proposed for the study of torrefaction mechanisms of pine wood [145]. Interestingly, somewhat opposite results have been found. For instance, these authors found that crystallinity of cellulose actually decreases, instead of increasing, as proposed by Melkior. They have also reported that carbonylation increases with temperature instead of decreasing, as shown by Melkior. Such significant differences in terms of result interpretation may be explained in various ways. From a sample preparation point of view, the thermal treatment (temperature, residence time, heating rate) may not be the same, as well as pre-heating step to remove water. Secondly, as we mentioned several times, the crude use of CP-MAS spectra for quantitative purposes is not correct. In particular, Melkior at al. [144] use corrected intensities and normalize their spectra to the mass introduced in the NMR rotors CP-MAS, while Ben et al. [145] do not seem to care about such an important issue, thus suggesting their quantification process to be probably less reliable. To avoid these problems, Park et al. [146] have employed SPE for quantification purposes and coupled them to DD experiments to identify quaternary carbon species. This study seems to show that the amount of carbonyl groups slightly increases (and then decreases) with temperature, as shown by Melkior. However, the poorer quality of SPE experiments (with respect to CP-MAS) may induce important 
errors (which were not estimated) in low intense peaks. In addition, authors have shown that the amount of aromatics increases with temperature and the size of the aromatic clusters becomes larger. This latest assumption was made by evaluating the proportion of non-protonated carbons (by DD) with respect to protonated ones. A couple of additional studies can be added to this short list, but since the approach is strictly the same as the ones described so far, they will not detailed further. $[147,148]$.

\subsection{Hydrothermally treated biomass}

Hydrothermal Carbonization of biomass has recently emerged as an alternative for the production of sustainable carbon materials from biomass and biomass derivatives. A recent review paper related to this technology can be found in ref [149]. Here we will only limit to the description of the final chemical structure of these materials analyzed using ${ }^{13} \mathrm{C}$ ssNMR as well as to potential chemical reactions involved in the HTC formation mechanism.

Hydrothermal carbonization is a process that generates materials with a degree of structural complexity that recalls the one found in other carbonaceous materials (e.g., chars from lignins and cellulose) and with a relative amount of elemental carbon content above $60 \mathrm{w} \%$, obtained from elemental analysis. [150] FT-IR and XPS spectroscopies do not provide enough resolution to precisely depict the structure of HTC, as spectra are poorly-resolved and composed of overlapping peaks. The presence of a broad hump and absence of diffraction peaks in XRD indicate that the material is macroscopically amorphous. According to the broad literature discussed above on the use of ssNMR to solve the structure of coal and chars, one can probably successfully employ techniques like CP-MAS to obtain a preliminary analysis of the HTC carbon chemical structure. However, this approach will most likely not provide a definitive structure model, as it was in the case of lignins, kerogens or any other biopolymer-derived char. To better proceed in the characterization of these materials, a different analytical strategy has been employed in the literature and in this section we show how the combination of advanced ${ }^{13} \mathrm{C}$ ssNMR techniques, use of model compounds and isotopic enrichment contribute to a deeper understanding of HTC-derived materials.

Early structural studies employed FT-IR, Raman, XPS and even standard ${ }^{13} \mathrm{C}$ ssNMR spectroscopies and two structural models have been proposed to interpret the results generated by these techniques. [151,152,153] Figure 6 summarizes the two possible structures representing the carbonaceous scaffold. Authors describe it as composed of: 1) "small clusters of condensed benzene rings forming stable groups with oxygen in the core” [151] or of condensed polyaromatic structures. 
[152] In any case, these structural models are very similar and, even if they satisfactorily help to interpret FTIR, XPS and XRD experimental data, they are not consistent with ${ }^{13} \mathrm{C}$ ssNMR experiments.

In the following sections we will describe in detail the potential chemical paths involved in the formation of HTC materials but also the structure of their carbonaceous scaffold obtained by ssNMR. We discuss in particular HTC obtained from model carbohydrates, including cellulose, but also from non-model lignocellulosic biomass.

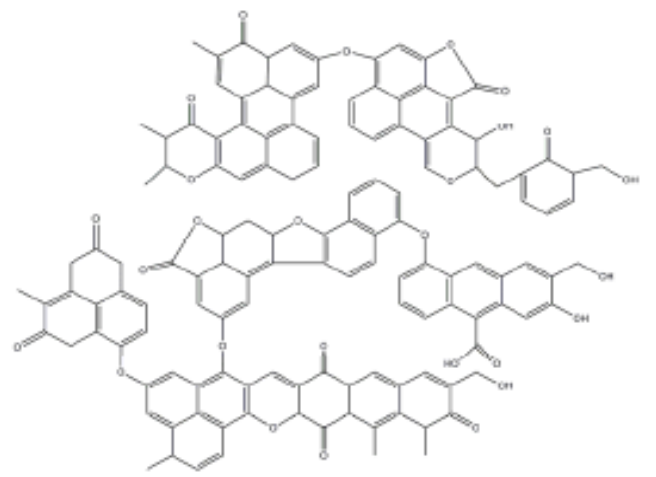

a)

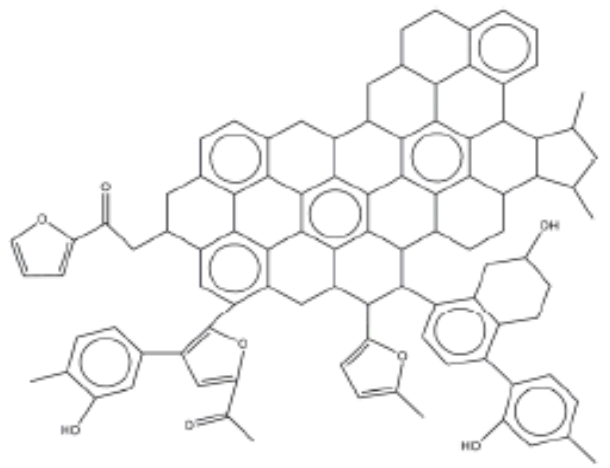

b)

Figure 6 - Early structural models proposed for HTC. a) Adapted from Ref. 151a; b) Adapted from Ref. 152.

\subsubsection{Hydrothermal carbons from saccharides}

Hydrothermal treatment of saccharides essentially involves three main steps: dehydration, polymerization and finally carbonization/aromatization. It is well accepted in the literature that upon the dehydration of glucose, firstly isomerisation to fructose thatches place (i.e. the Lobry de Bruyn Alberda van Ekenstein transformation). [154] Once fructose is formed as in intermediate, it looses three water molecules and forms hydroxymethylfurfural (HMF). Our research group and others demonstrated that indeed, HMF is the main "monomer" involved in the formation of HTC materials. During the dehydration of glucose, other low molecular weight compounds are formed such as for example levulinic and formic acid (Figure 7). They result via the reaction of HMF with water (Figure 8d). These small molecules also contribute to the HTC carbon network formation either via aldol reactions (i.e. between HMF and levulinic acid) or by simple physisorption. The small molecular weight acids have also a catalytic role as they lower the $\mathrm{pH}$ and thus promote further dehydration reactions. [155] When pentoses, (5-C carbohydrates) are used instead, the formation of HTC goes towards the formation of furfural, as intermediate instead of HMF resulting in a more condensed HTC structure. 


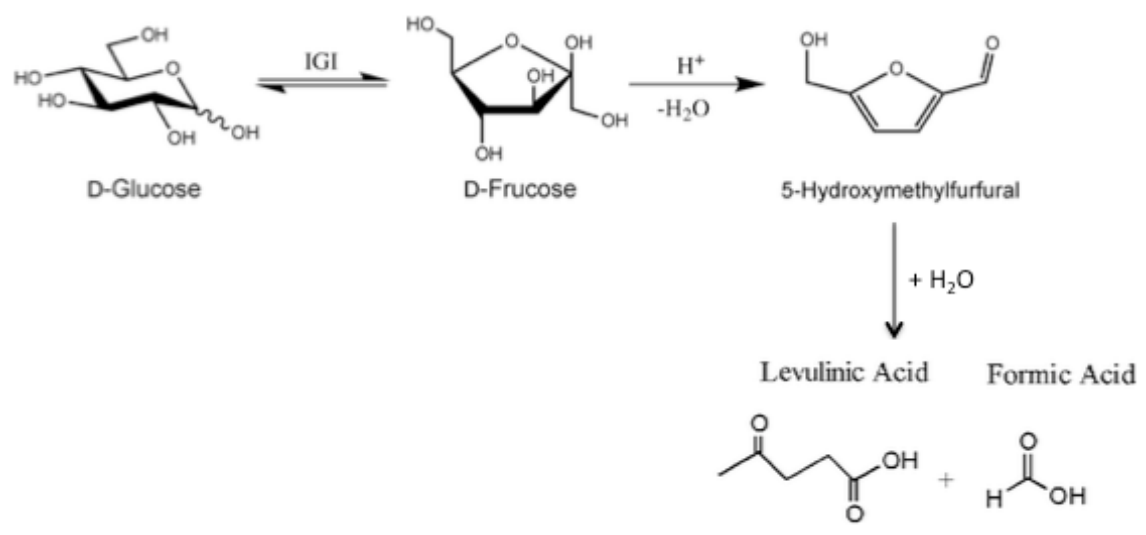

Figure 7 - Glucose dehydration to HMF via fructose isomerisation; further rehydration of HMF into levulinic and formic acid

The first, very important, question to which one must provide an answer is to establish a relationship between the type of carbohydrates, their complexity and the final HTC carbon structure. A preliminary ${ }^{13} \mathrm{C}$ ssNMR study on HTC carbons derived from different mono and polysaccharides (i.e. fructose, glucose, starch, xylose) highlighted that the main factor affecting the chemical nature of the HTC product is the structure of the parent sugar. [150, 156] Pentoses (e.g. xylose) derived HTC carbons possess a more marked aromatic character than hexoses (e.g. glucose). Such a difference is demonstrated by a more intense peak at $\delta=125-129 \mathrm{ppm}$ in the ${ }^{13} \mathrm{C}$ CP-MAS ssNMR spectrum in the former case, which is characteristic of aromatic carbons belonging to graphitic or long range conjugated double bonds structures. The different HTC reaction intermediates (HMF versus furfural) may be the explanation for such a finding. As reported in literature, the reactivity of these two intermediates is indeed different, as a consequence it also reflects in the chemical structure of the respective HTC carbons. [157] Further Gas-Chromatography coupled to Mass Spectrometry (GCMS) and solution ${ }^{13} \mathrm{C}$ NMR experiments on the glucose system confirmed that the major intermediate in the reaction mixture is 5-HMF. This finding, coupled to the evidence that the ${ }^{13} \mathrm{C}$ ssNMR spectrum of 5HMF derived HTC carbon is very similar to all HTC spectra obtained from different types of mono and hexose polysaccharides, led to the conclusion that polymerization/condensation reactions involving 5HMF monomers are the route of formation of HTC carbon. Furthermore by a simple comparison of ${ }^{13} \mathrm{C}$ CP-MAS NMR spectra of various HTC materials, it was also observed that the degree of initial polymerization of the hexose-based saccharides (mono, di- or poly-saccharides) does not influence the final structure, since all the ${ }^{13} \mathrm{C}$ spectra of HTC carbons derived from hexose-based saccharides are characterized by identical resonances. 
Obviously the next question arising is how do the HTC materials form from HMF and what chemical reactions are involved. In other words, what chemical reactions are taking place in the autoclave during the HTC process? A clear and straightforward answer cannot be provided at this stage due to the complexity and the multitude of reactions occurring at the same time under hydrothermal conditions. In situ monitoring with LC-MS could provide some answers; however to the best of our knowledge such experiments have not been yet performed. At this stage, we can only presume some potential reactions by simply having a look in organic chemistry textbooks on furan chemistry. (Figure 8) HMF is a highly reactive molecule, which can react further either via its substituents (hydroxy and carbonyl) or via the furan ring. The hydroxyl group can be involved in nucleophilic substitution reactions (Figure 8a). The aldehyde group of HMF can undergo aldol condensations with aldehydres or $\alpha$-ketones (Figure 8b). In the presence of alcohols, the same aldehyde group can form hemiacetals (Figure 8c).

The furan ring can react with water resulting in ring opening and formation of levulinic and formic acid as described previously (Figure 7, Figure 8d). Diels-Alder reactions between the conjugated furan ring (Figure 8e) or the conjugated aldehyde substituent on the furan ring (Figure 8f) and a double bond resulting during HTC by fractionation of biomass can lead to aromatization. 
a)

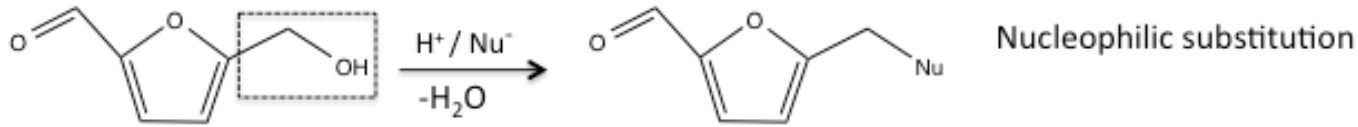

b)

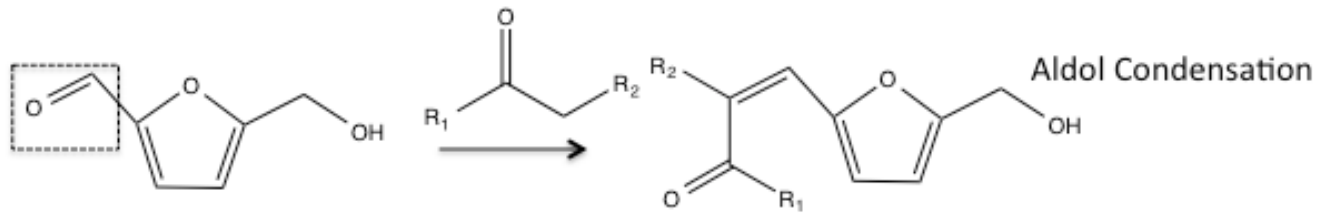

c)

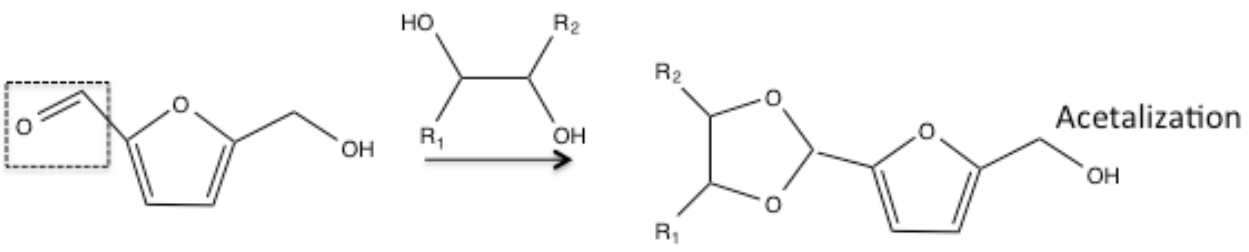

d)<smiles>O=Cc1cccc(CO)c1CCO</smiles>
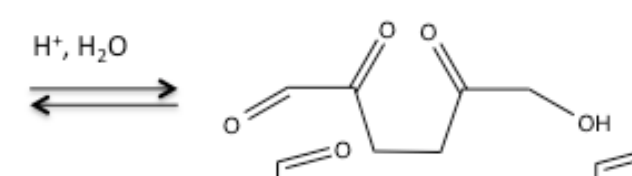

Ring Opening

e)

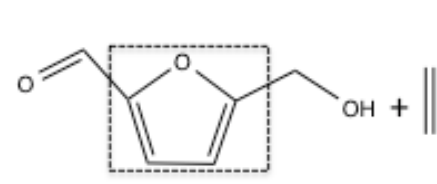

$\longrightarrow$

f)

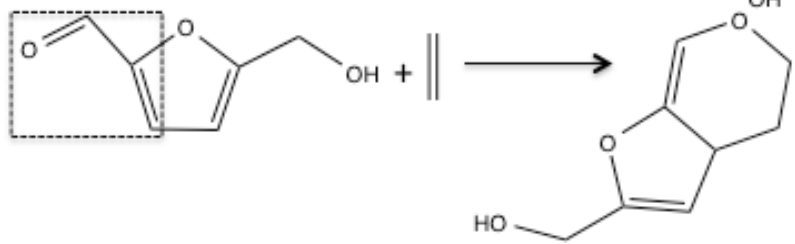

Diels Alder at the aldehyde substituent

Figure 8 - Possible chemical reactions of HMF during the hydrothermal carbonization process

According to Patil et al, the acid-catalyzed conversion of 5-hydroxymethylfurfural (HMF) produces levulinic and formic acids in equal amounts. Aldol addition and condensation are proposed as important reactions in the acid-catalyzed growth of HTC, adding HMF to 2,5-dioxo-6-hydroxyhexanal. [158] This finding is supported by the infrared (IR) spectra which indicate that the furan ring and hydroxymethyl group of HMF are present in the humins, but the carbonyl group is not.

There is no doubt that indeed the aldol reactions between levulinic acid derived alpha hydrogen diketones play a very important role in the formation of HTC however this is not the only reaction happening inside the autoclave. This was also recently observed by Weckhuysen et al who study the formation mechanism of " humins". They showed that "humin” (HTC) formation involves reactions other than aldol condensations. A study on their molecular structure using elemental analysis, IR, solid 
state ${ }^{13}$ C NMR spectra and pyrolysis- GC-MS revealed, in good agreement with our observations, a furanic structure with alcohol, acid, ketone and aldehyde functional groups, which is formed via a dehydration pathway. Based on this information a model for the molecular structure for glucosederived humins was proposed. It was also found that xylose-derived humins have a more conjugated molecular structure. [159] Obviously, one can not provide a simple answer to the questions: How do HTC materials for and what is their precise chemical structures? The HTC structure is strongly influenced by the process parameters such as precursor type and concentration, $\mathrm{pH}$, residence time, pressure, temperature, etc. In the next paragraph, we show how ssNMR has brought clear-cut answers to the structural resolution of HTC and in particular how it was able to prove the presence of a large extent of furan moieties in their core.

Figure 9 shows typical ${ }^{13} \mathrm{C}$ CP-MAS spectra of several HTC materials obtained from various sources: glucose, xylose, HMF and furfural. [150] It is quite striking the fact HTC from glucose and HMF are very close both in terms of morphology (refer to Ref. 150 for SEM images) and NMR signature. This is also the case for HTC obtained from furfural and xylose. These experiments bring an important information in term of the chemical paths engaged by HMF and furfural precursors in the formation of HTC. At the same time, ${ }^{13} \mathrm{C}$ ssNMR spectra show a large number of signals from 0 ppm to $210 \mathrm{ppm}$, thus suggesting the presence of a complex network of aliphatic $(\delta<100 \mathrm{ppm})$, aromatic (160 ppm $<\delta<100$ ppm) and carbonyl ( $\delta>160$ ppm) groups. In Ref. 150 it was shown that similar spectra could be obtained from a large number of precursor carbohydrates, undoubtedly showing a reaction mechanism common for several types of sugars. For this reason, a sound ssNMR work has been carried on a model, fully ${ }^{13} \mathrm{C}$-labeled, HTC from glucose. 


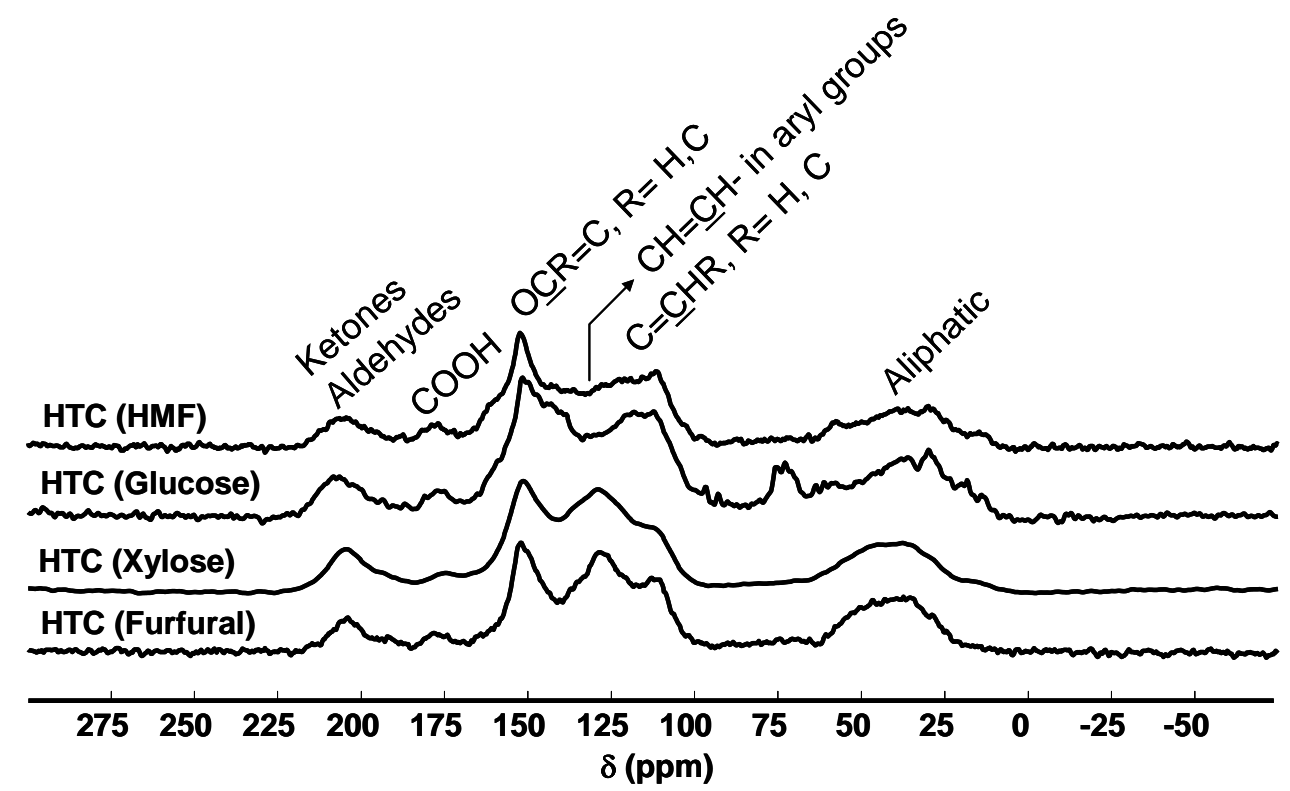

Figure 9 - Typical ${ }^{13} \mathrm{C}$ CP-MAS spectra obtained on HTC from glucose, xylose, HMF and furfural

Initially, one should precisely attribute the ${ }^{13} \mathrm{C}$ resonances in the typical CP-MAS spectrum and in particular it is important to identify, for instance, $\mathrm{C}, \mathrm{CH}, \mathrm{CH}_{2}$ and $\mathrm{CH}_{3}$ carbons but also the exact nature of the aromatic signal. To do so, several techniques can be combined together to record ${ }^{13} \mathrm{C}$ spectra at $14 \mathrm{kHz}$ MAS rate, as shown in Figure 10, where the variation in relative intensities in the spectra is a typical result of the spectroscopic filter used, directly related to the type of pulse sequence employed: SPE (Single Pulse Excitation) is recorded for quantification purposes; CP (Cross Polarization) is acquired at a contact time of $\mathrm{t}_{\mathrm{CP}}=3 \mathrm{~ms}$; INEPT (Insensitive Nuclei Enhanced by Polarization Transfer), a typical liquid-state technique, explores through-bond J-coupling interactions; DQ-SQ (Double Quantum Single Quantum) spectrum, extracted from the two-dimensional experiment presented later (and in Ref. 156), is useful to identify a larger number of peaks (A through M), corresponding to specific chemical groups, undetectable with other pulse sequences. The combination of these experiments recorded on the same sample allow to state the following: the CP and SPE spectra are very similar, telling that the material is macroscopically homogeneous from a chemical point of view; INEPT is a more straightforward alternative to filter-out non-protonated carbons as compared to the Dipolar Dephasing experiment, more systematically employed in the study of chars, as widely discussed above. 

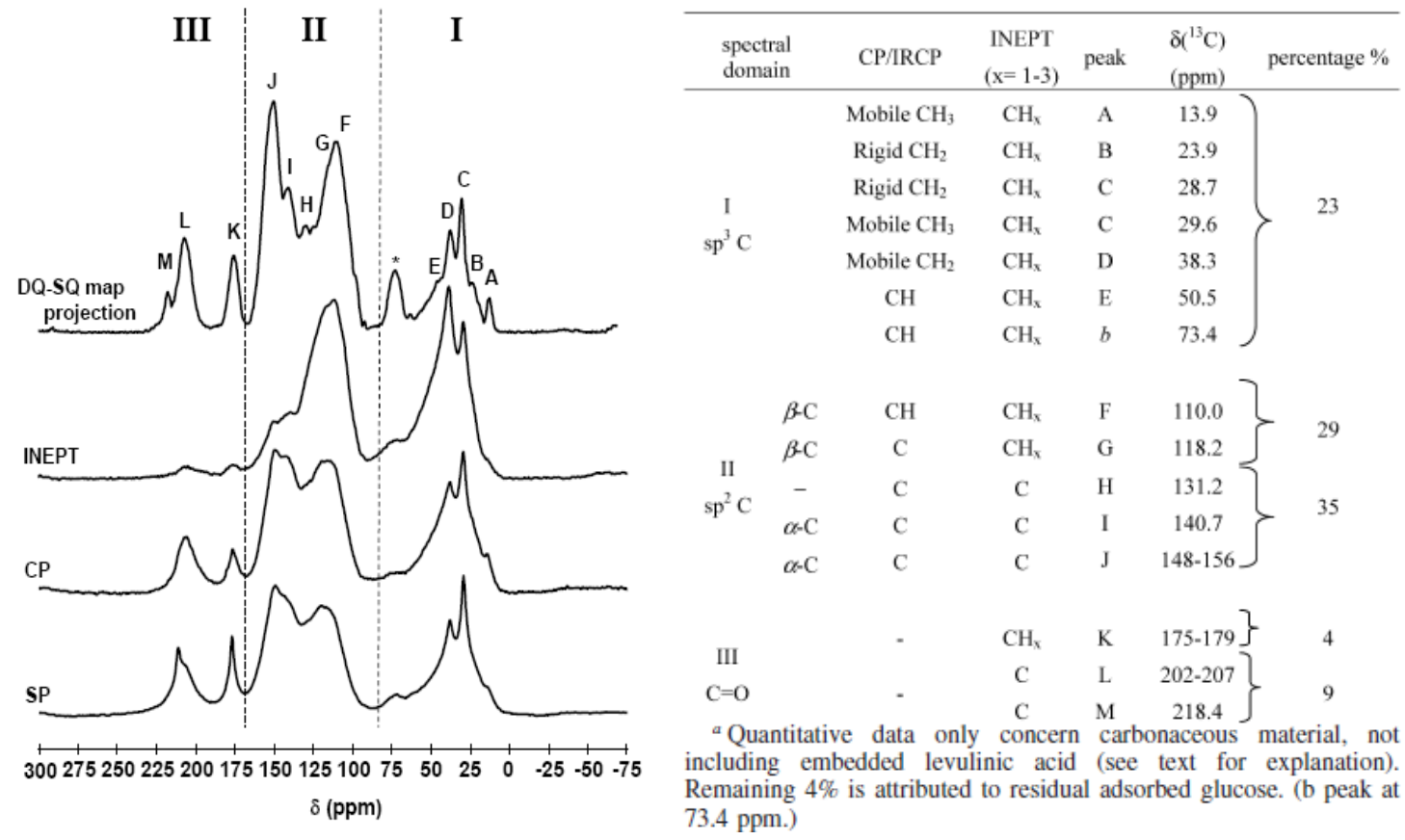

Figure $10-{ }^{13} \mathrm{C}$ MAS NMR spectra of HTC obtained from glucose and relative attribution. SP=SPE, Single Pulse Excitation ; $\mathbf{C P}=$ Cross Polarization experiment ; INEPT= Insensitive Nuclei Enhanced by Polarization Transfer experiment; DQ-SQ= Double Quantum Single Quantum, projection of the 2D experiment presented in Ref. 156

Even if the experiments presented in Figure 10 help assigning each signal to a specific functional group, some ambiguity can still occur, especially for the broader signals (e.g., peaks, F or E). In this case, a full CP analysis at variable contact times, combined with an accurate spectral deconvolution based on the DQ-SQ spectrum, can be very helpful to bring more answer. For instance, Figure 11 presents a detailed Inversion Recovery Cross Polarization (IRCP) study of a fully-labeled ${ }^{13} \mathrm{C}$ HTC sample obtained from glucose. IRCP is a CP-based technique conceived to probe the local proton environment around a carbon nucleus. Discrimination between the various ${ }^{13} \mathrm{CH}_{\mathrm{x}}$ sites depending on the $\mathrm{x}$ value and between rigid and mobile ${ }^{13} \mathrm{CH}_{\mathrm{x}}$ sites is then possible. The main advantage of this experiment relative to the standard CP sequence is that the magnetization starts from an optimum value, then decreases and eventually becomes negative when increasing the inversion recovery time, $t_{i}$. It is thus easy to visualize differences in inversion dynamics of various signals especially when they overlap. On the basis of theoretical arguments, the relative rates of polarization are expected to be as follows: [160]

$$
\mathrm{CH}_{3} \text { (static) }>\mathrm{CH}_{2}>\mathrm{CH}>\mathrm{CH}_{3} \text { (rotating), C(non-protonated) }
$$


For the IRCP experiments presented in Figure 11, a contact time $\mathrm{t}_{\mathrm{CP}}=3 \mathrm{~ms}$ was chosen in order to maximize the polarization of the ${ }^{13} \mathrm{C}$ nuclei, while 21 spectra were recorded for various inversion times, $t_{i}$, ranging from $1 \mu$ s to 5 ms. Briefly, Figure 11a presents the comparison between the resolved DQ-SQ and a typical IRCP spectra, where the (A) to (E) attributions are used to deconvolute the former (refer to part c) of the figure). Figure 11b shows selected IRCP spectra recorded at variable $t_{i}$, thus putting in evidence the distinct behaviour of each chemical group upon signal inversion. Figure 11c shows the deconvolution process of the IRCP spectra while part d) presents the evolution of the normalized integrated $(I)$ intensity with $t_{i}$. The minimum value of the $I\left(t_{i}\right)$ for each curve identifies a typical ${ }^{13} \mathrm{CH}_{\mathrm{x}}$ group: $I\left(t_{i}\right)=-1 / 3,0$ and $>0$ respectively represent $\mathrm{CH}_{2}, \mathrm{CH}$ and $\mathrm{CH}_{3}$ groups.
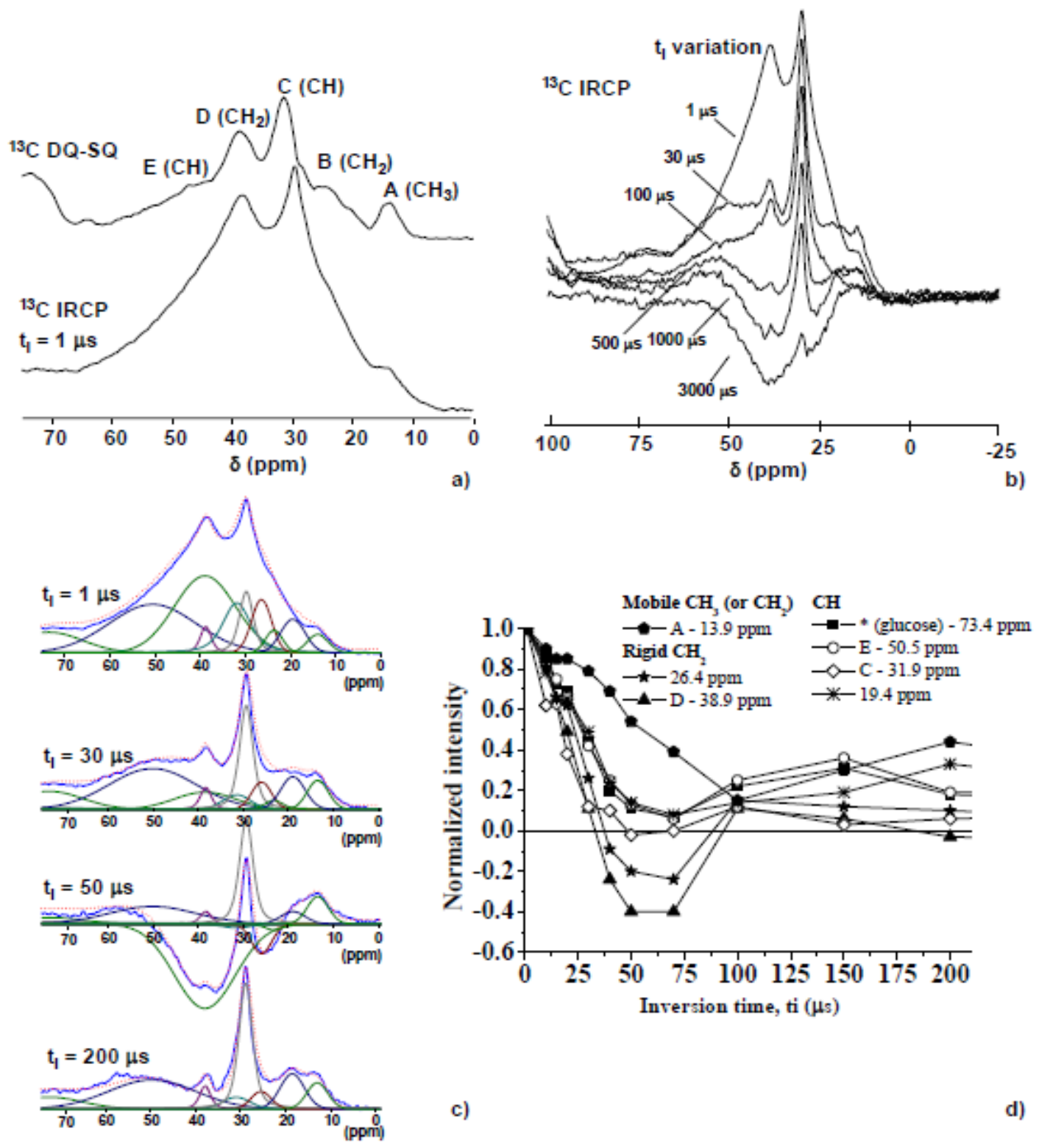

Figure 11 - Inversion Recovery Cross Polarization experiment performed on a ${ }^{13} \mathrm{C}$-labelled HTC sample. Adapted from Ref. [156]. For attribution, please refer to table in Figure 10. 
Finally, connectivity among carbon sites can be done using a 2D experiment, as discussed in previous examples on cellulose, for instance. In this case, ${ }^{13} \mathrm{C}$ homonuclear DQ-SQ experiments have been used to deduce the major bonding patterns within HTC. On-diagonal peaks indicate ${ }^{13} \mathrm{C}$ spin pairs, belonging to equal chemical environments, while off-diagonal cross-peaks show the linkage between carbons that are present in different functional groups. Figure 12, adapted from ref.156 and 161, shows the typical 2D ${ }^{13} \mathrm{C}-{ }^{13} \mathrm{C}$ DQ-SQ maps of HTC (part a) and thermally-treated HTC (part b). The structural schemes given in parts c) and d) are obtained from their analysis.

Two important results are extracted from this experiment, and which clearly show how models given in Figure 6 are inconsistent with the NMR results:

- 151-110 ppm cross-peaks connection. These cross peaks, of equivalent intensities, are strongly interconnected, indicating that HTC is dominated by a $\mathrm{O}-\mathrm{C}=\mathrm{C}-$ type of bond. $\mathrm{O}-\underline{\mathrm{C}}=$ and $\mathrm{C}=\underline{\mathrm{C}}-$ moieties respectively resonate at $151 \mathrm{ppm}$ and $110 \mathrm{ppm}$. According to the discussion on the chemical formation of HTC, one realizes that this connection is the main motif of a furan ring, which is the main intermediates in the HTC formation. Scheme in part c) summarizes the main structural motif of HTC.

- 127 ppm, on-diagonal, peak. Intra-carbon interactions typically found in conjugated aromatic rings are expected at such position, as expected after the models given in Figure 6. Such an on-diagonal cross peak is not detected, thus suggesting that aromatic arene-like rings are relatively rare species in glucose-derived HTC carbon (processing temperature: $180^{\circ} \mathrm{C}$ ). However, after a pyrolysis step of HTC at $350^{\circ} \mathrm{C}$, the on-diagonal cross peak at $127 \mathrm{ppm}$ starts to appear, as indicated by the arrow in Figure 12, part c). This is the clear sign of increasing amounts of condensed arene moieties, as schematized in part d).

The combination of these two points suggest that furan moieties are the major constituent of HTC carbon materials obtained from glucose and, considering the work detailed in Ref. 150, all hexoses excluding cellulose, as presented in the following section. 


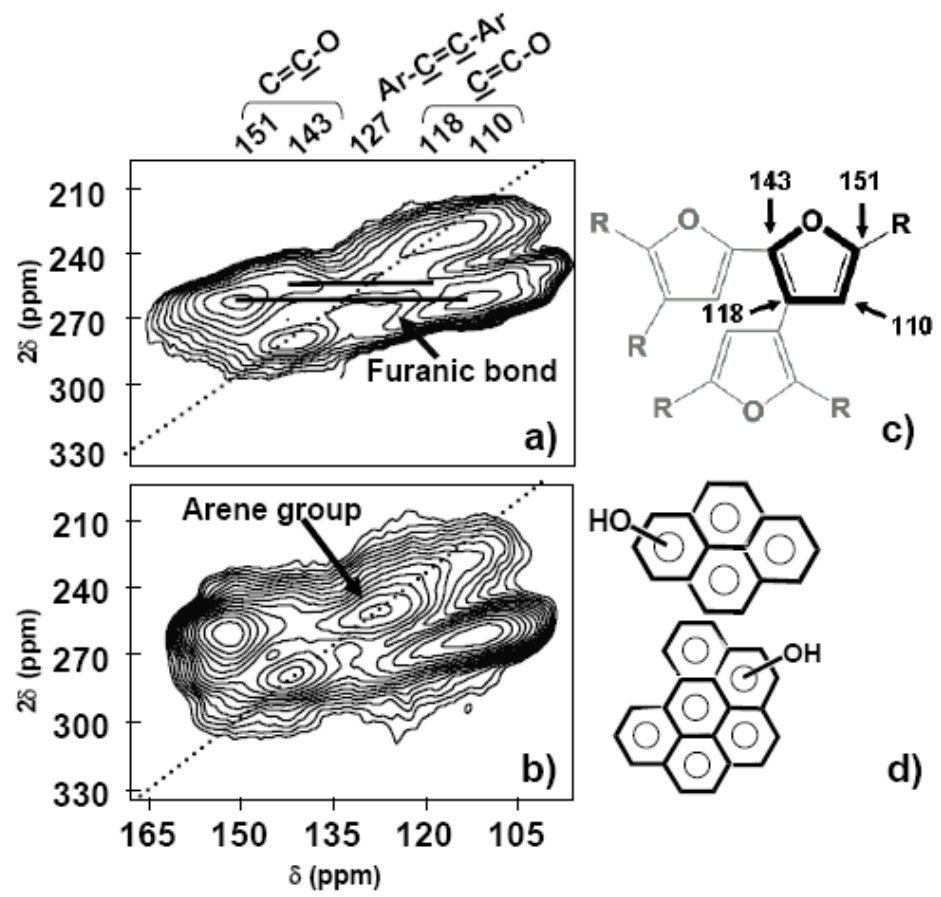

Figure 12 - 2D ${ }^{13} \mathrm{C}-{ }^{13} \mathrm{C}$ DQ-SQ MAS NMR correlation spectrum for: a) HTC obtained from glucose (T= 180 $\left.{ }^{\circ} \mathrm{C}\right)$; b) calcined $\mathrm{HTC}$ at $350^{\circ} \mathrm{C}$. c) Scheme of the simplest furan-based structural motif found in HTC. d) Condensed arene moieties developed after calcination.

The NMR experiments indicate the furans to be mostly 2,5-substituted, therefore aldol condensation can be considered to be indeed one of the most important occurring reaction in the formation of hydrothermal carbons. Therein, diketones will react with the very reactive aldehyde function of HMF and with other diketones.

The involved dehydrofurans and double bond give rise to some Diels-Alder reactions with the inherent diene substructure of furanes creating further cross-linking and additionally aromatic structures observed in a very small percentage from NMR. Formation of the abundant $\mathrm{CH}_{2}$ groups acting as linkers between furan rings may originate from nucleophilic addition after possible elimination of the hydroxyl group on HMF. The nucleophilic attack on the aldehyde group of HMF from a second furanic unit may lead to hydroxyl species that can, in turn, be eliminated with subsequent electron rearrangement and formation of a $\mathrm{sp}^{2} \mathrm{CH}$ carbon between two furan moieties. The formation of specific $\mathrm{CH}_{3}$ and $\mathrm{COOH}$ ending groups (from $\mathrm{C} \alpha$ of furan ring) was previously reported. [157] In summary, we can speak of a set of dehydration, polymerisation, condensation and addition and aromatisation reactions, which lead to the final chemical structure of HTC.

From NMR we found that about $60 \%$ of the carbon atoms belong to a cross-linked furan-based structure. Furan moieties are directly linked either via the R-carbon or via $\mathrm{sp}^{2}$ - or $\mathrm{sp}^{3}$-type carbon groups, where cross-linking can occur. Additional cross-linking sites are located at the $\beta$ carbons of the 
furan ring. We also found that levulinic acid, one of the decomposition products of hydroxymethylfurfural (HMF), is highly abundant in the final material as embedded molecule.

It is indeed very challenging to fully understand the chemistry behind the formation of HTC materials. In situ monitoring of the reaction using NMR or LC-MS are alternatives. However, these are difficult to achieve because of the very severe conditions inside the autoclave. In this respect the use of

${ }^{13} \mathrm{C}$ solid state $\mathrm{NMR}$ on ${ }^{13} \mathrm{C}$ labelled glucose derived materials together with revising furan chemistry helped us to propose a potential mechanism and a final chemical structure of HTC materials.

A very recent paper by Heeres et al. has also performed a thorough characterization of the HTC structure obtained from glucose and fructose involving ${ }^{13} \mathrm{C}$ solid state studies. The ${ }^{13} \mathrm{C}-\mathrm{NMR}$ spectra and the findings are very similar to our results. In addition, the authors also performed pyrolysis product distribution studies on these HTC materials. From these results it was concluded that furanics were the main liquid products at low temperatures while at higher temperatures phenolics and benzofuranes are observed. This is a very interesting study as it opens new perspectives for the HTC materials to be used also as platform materials for the production of interesting biochemical which may serve as building blocks for renewable polymers, biofuels and biofuel additives. [162]

\subsubsection{Hydrothermal carbon from cellulose}

HTC materials derived from hexoses have very close ${ }^{13} \mathrm{C}$ NMR spectra [150], thus indicating that the mechanism of formation must be very similar despite the initial chemical nature of the sugar. However, this is not the case for HTC carbons obtained from cellulose. At an hydrothermal temperature of $\mathrm{T}=180^{\circ} \mathrm{C}$, the typical value used in the case of carbohydrates, cellulose is still unaffected as its ${ }^{13} \mathrm{C}$ spectrum is unchanged from the native material. One must use at least $\mathrm{T}=200^{\circ} \mathrm{C}$ to start observing a chemical transformation. At this temperature, the ${ }^{13} \mathrm{C}$ spectrum is easily traceable to a typical carbonaceous material, similar to what has been described so far. However, a major difference occurs. HTC from cellulose, independently from the processing temperature $\left(200^{\circ} \mathrm{C}<\mathrm{T}<280^{\circ} \mathrm{C}\right)$, always displays a strong resonance in the 120-130 ppm region, and which is not observed in a pure glucose-based HTC below $200^{\circ} \mathrm{C}$. [163] These data show that the amount of aromatic arene-like groups is sensibly higher in cellulose-derived HTC than in other hexose-derived carbons. If one argues that this depends on the higher temperature used to degrade cellulose, it is still unclear the reason why the central resonance at $\delta=125-129 \mathrm{ppm}$ is always present even at very short reaction times, [163] contrarily to what was observed for the treatment of glucose as a function of time at the same temperature. It seems then that the hydrothermal carbonisation of cellulose does not proceed solely 
through a HMF-derived intermediate, as observed in the case of the model monosaccharide (i.e. glucose) and other hexoses. The major conversion mechanism seems instead thought to be the direct transformation of the cellulosic substrate into a final carbonaceous material composed of polyaromatic arene-like networks, presumably involving reactions that are normally characteristic of the pyrolysis process. During cellulose pyrolysis, the char formation is attributed to a manifold of reactions leading to cellulose intramolecular rearrangement and formation of a cellulose-derived polymeric compound, referred to as "intermediate cellulose”, discussed above and in Ref. 114. This reaction intermediate then converts to aromatic network structures at extended reaction times. $[4,5,164,165]$ Even if this mechanistic speculation is well supported by the similar ${ }^{13} \mathrm{C}$ NMR profiles of cellulose-derived HTC carbon and char obtained from lignocellulosic biomass pyrolysis, [120,121] very recent experiments seem to show that, as it was found for the pyrolitic treatment of cellulose, the processing conditions are of extreme importance and can lead to contradictory results.

In the specific case of cellulose-derived HTC, Berge et al. [166] have just found, using the ratio between the furan/arene signatures in ${ }^{13} \mathrm{C}$ solid state NMR, that it is actually possible to isolate furanrich intermediates at short reaction times (generally below 5h depending on the chosen temperature) and slow heating rates. These finding are very important as far as the understanding of the actual behaviour of cellulose degradation through hydrothermal conditions is concerned, especially if compared to the process undergoing during pyrolysis. In fact, this work goes in the sense of comparing biomass derived chars, obtained from direct pyrolysis, and HTC process, which becomes an obvious question that needs to be addressed in order to place HTC within the context of thermo-chemical processing techniques. This was already addressed in a previous work, [163] where we had shown how the analogies/difference between pyrolysis and HTC can be quantified using the furan-to-arene ratio calculated from the corresponding NMR resonances. Upon pyrolysis, the carbon content of HTC products increases from $60 \%$ to about $90 \%$, as expected. The corresponding ${ }^{13} \mathrm{C}$ SPE MAS NMR data [161] show that, if the amount of arene groups appreciably increases between HTC and its counterpart calcined at $350^{\circ} \mathrm{C}$, the two materials are still very similar, as confirmed by $2 \mathrm{D}$ DQ-SQ ${ }^{13} \mathrm{C} N \mathrm{NMR}$ experiments (Figure 12). However, increasing the pyrolysis temperature from $350^{\circ} \mathrm{C}$ to $550^{\circ} \mathrm{C}$ results in the disappearance of furanic associated resonances, as polyaromatic arene-like species become the most dominant structural motif. A $750^{\circ} \mathrm{C}$ treatment leads to the enhanced aromatization of the HTC, as indicated by the drifting of the central aromatic resonance to a lower chemical shift $(\delta=125 \mathrm{ppm})$ and by the broadening of its profile. Both features are indicative of an extended delocalized $\pi$-system and of a reduced mobility of the carbon species. [126] 2D DQ-SQ ${ }^{13} \mathrm{C}$ NMR experiments confirm these results [161] and provide stronger evidence for the early models models given in Figure 6. Similar trends have 
been observed, for instance, during the pyrolysis of polyfurfuryl alcohol (PFA) derived furan-rich resins. [118,167] At higher temperatures, the peak at $\delta=127 \mathrm{ppm}$ becomes more and more intense, thus indicating that the whole material is composed of condensed aromatic rings, as expected at these temperatures.

The ${ }^{13} \mathrm{C}$ NMR analysis of pyrolyzed HTC samples turns into a very useful analytical tool to follow the development of the carbon structure as a function of pyrolysis temperature. A comparison between pyrolyzed sugars and $\mathrm{HTC}\left(\mathrm{T}=350^{\circ} \mathrm{C}\right)$ shows that the aromatic region (i.e. $\left.\delta=100-150 \mathrm{ppm}\right)$ of the former has a slightly different profile. The difference arises mainly from the lack of the $\delta=118$ 110 ppm shoulder in the pyrolyzed sugar samples, indicating the possible absence of furan groups. If this was the case, then both spectra should not show the resonance at $\delta=148-151 \mathrm{ppm}$, which is instead still present. However, such a peak can also be attributed to oxygen-substituted arene-type moieties, which form during the pyrolysis process. [161] The direct comparison between pyrolyzed sugars and HTC shows how the former process is able to generate an additional intermediate stage, rich in furans, between the parent sugar and the polyaromatic char structure, obtained from high-temperature pyrolysis.

Very interestingly, these studies are in very good agreement with a similar work by Cao et al [168] in which two types of swine-manure chars, hydrothermally produced hydrochar and slowpyrolysis pyrochar, and their raw swine-manure solid were characterized using advanced solid-state ${ }^{13} \mathrm{C}$ NMR spectroscopy. The authors also looked at the differences occurring in the resulting HTC chemical structure upon washing the product only with water or acetone. Interestingly it was found that acetone removed the soluble intermediates deposited on the hydrochar, as shown by the decrease of O-alkyl (primarily carbohydrates), corresponding increase of aromatic/olefinic carbons and complete removal of $\mathrm{OCH}_{3}$ groups. This is in good agreement with our studies on Soxhlet extracted HTC samples from which an important amount of levulinic acid can be extracted from the glucose-derived HTC. [169]. Please also note the ${ }^{13} \mathrm{C}$-NMR of glucose HTC showed a high amount of embedded levulinic acid. [150] As in our case, the pyrochar produced from slow pyrolysis was structurally different from HTC hydrochars. The dominant component of pyrochar was aromatics, whereas that of hydrochars was alkyl moieties.

Despite a clear trend in the low amount of literature on this topic, a recent study [166] brings some additional, contradictory, insight to the discussion. In fact, it seems that different HTC processing conditions, heating rate in particular, on cellulose can help controlling its degradation process and put in evidence the presence of large amounts of furans with respect to polyaromatic clusters. This is 
clearly shown by the sequence of ${ }^{13} \mathrm{C}$ MAS NMR spectra shown in Figure 13, where cellulose was treated at $\mathrm{T}=225^{\circ} \mathrm{C}$ for $96 \mathrm{~h}$ (the corresponding heating rate profile is given in Figure $\mathrm{S} 1$ of Ref. 166). The spectrum recorded at the end is very similar to the one for cellulose-derived $\mathrm{HTC}$ at $\mathrm{T}=200^{\circ} \mathrm{C}$ or to pyrolyzed $\mathrm{HTC}$ at $\mathrm{T}=350^{\circ} \mathrm{C}$. On the contrary, the one recorded at short time ( $\mathrm{t}=4 \mathrm{~h}$ ) is rather characteristic of a furan-rich sample, where the arene resonance at $125 \mathrm{ppm}$ is of lower intensity than the two shoulders at 150/110 ppm, typical for furans. At higher heating rates, the furan-rich spectra are observed at reaction times shorter than $2 \mathrm{~h}$. Even if the presence of furans at low processing temperatures is not surprising, and actually quite expected, it shows once again the importance of processing time, temperature and heating rates and suggests that future works on this topic should carefully consider them as key parameters to explore and adjust in order to better understand the true behavior of biomass submitted to HTC.

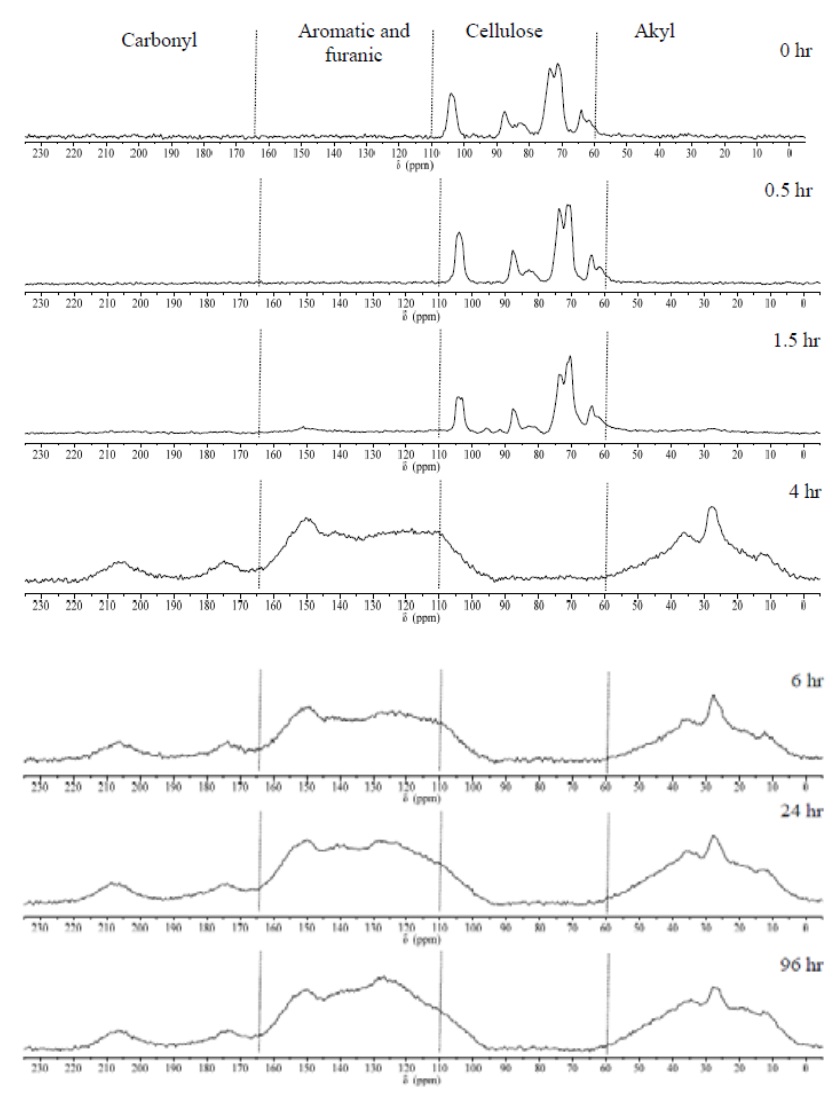

Figure 13 - Evolution of the ${ }^{13} \mathrm{C}$ MAS NMR spectrum of cellulose under $\mathrm{HTC}$ conditions at $\mathrm{T}=225^{\circ} \mathrm{C}$ during 96 hours. From Ref. [166].

In Figure 14 we show a summary of the effect of hydrothermal and pyrolysis processes pathways on hexose-based carbohydrates, including cellulose (pentoses are not included). In particular, the typical ${ }^{13} \mathrm{C}$ CP-MAS NMR spectra are provided, since they can be considered as the fingerprint of the 
carbonaceous materials. Three main stages were identified: furans are the major structural unit, furans and arene groups are present within the structure, the whole material is composed of an extended aromatic network. Meanwhile, four different pathways to reach each stage are also summarized as a function of the main processing conditions explored so far. The main message is that the furan-to-arene ratio in the final material can be tuned as a function of the initial biomass source (e.g., glucose vs. cellulose) and nature of the hydrothermal process. For instance, the furan-rich HTC carbon stage (topright of Figure 14) can only be obtained either via hydrothermal treatment of hexose-based carbohydrates, excluding cellulose, in a rather straightforward way or by being very precise on the heating rate control when using cellulose. Pentoses, which are not discussed in Figure 14, have been found to form mainly arene-rich compounds.

Hexoses and hydrolysable hexose polysaccharides
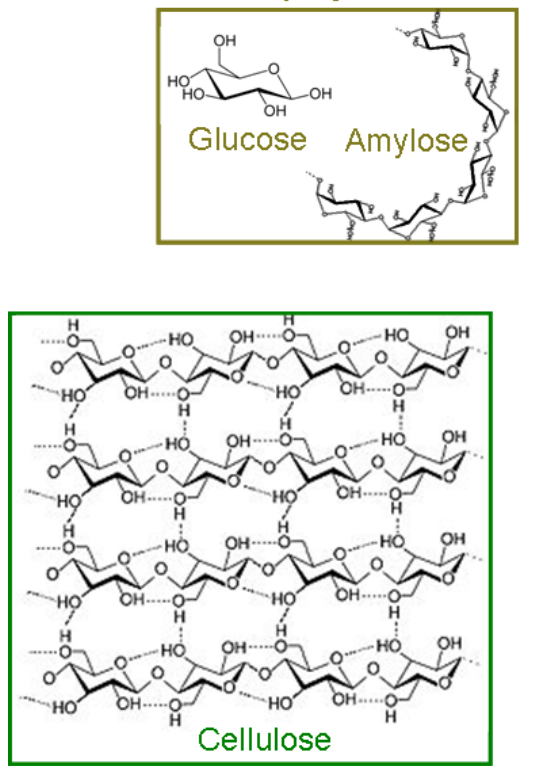

Non-hydrolysable hexose polysaccharides

Pyrolysis
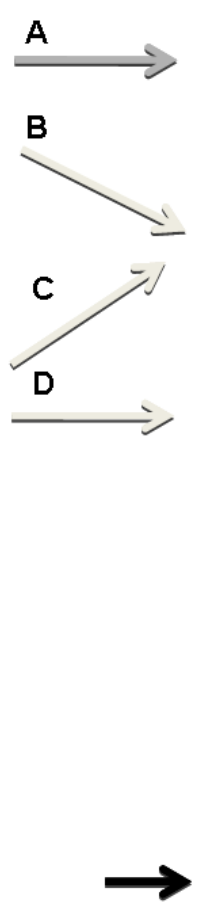

E

$\mathrm{C}-\mathrm{T}>200^{\circ} \mathrm{C}$ slow heating rates

$\mathrm{D}-\mathrm{T}>200^{\circ} \mathrm{C}$ fast heating rates

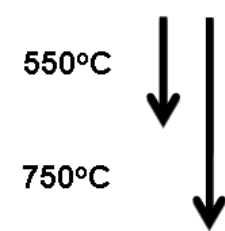

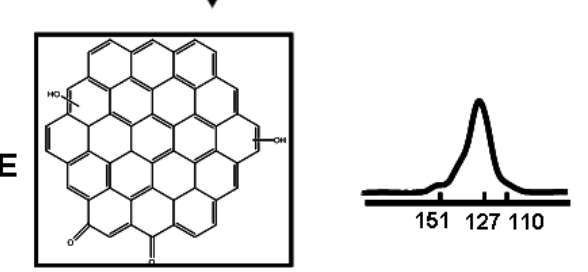

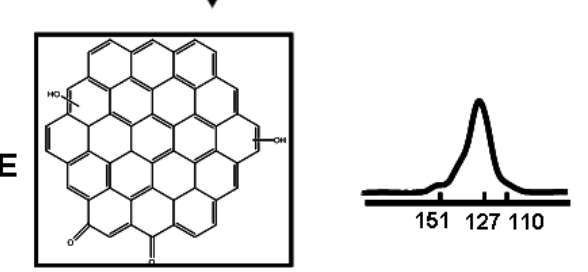

$B-T \geq 200^{\circ} \mathrm{C}$ for long reaction times

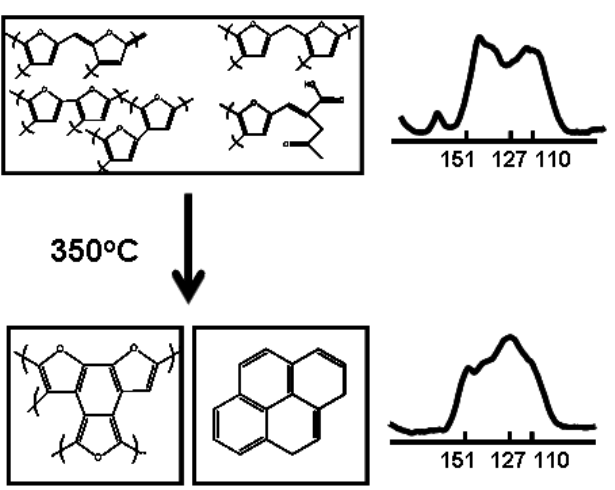

rothermal treatment and pyrolysis on hexoses and

A short note should be mentioned about hydrothermal treatment of lignin. At the moment, lignin is hardly transformed into char by hydrothermal treatment, at least at temperatures below $250^{\circ} \mathrm{C}$ and selfgenerated pressures. In more complex biomass (e.g., wood), only the cellulose part seems to be affected. [163] 


\subsection{Conclusions}

The conclusion section is divided into 2 parts. In 6.1, we want to provide a handy view of the most relevant ${ }^{13} \mathrm{C}$ spectra for both biomass and chars. This includes typical spectra that one may find in the literature and common assignments. It should be made clear that this is only a meant to guide the inexperienced reader towards more specific studies. In 6.2, we provide a more general conclusion on this review.

\subsection{Typical ${ }^{13} \mathrm{C}$ CP-MAS spectra of biomass and chars}

Figure 15 summarizes the typical solid state ${ }^{13} \mathrm{C}$ CP-MAS NMR response for the most important constituents of biomass (lignin, cellulose) and their derived chars, as discussed in this review. The corresponding attribution and schematic units are given in Table 2 and Scheme 1. This is meant to provide at a first glance the typical spectroscopic response of a large variety of materials and allow an immediate comparison between them and one's own NMR results. Please note that data relative intensities may vary with the contact time, the reader should then not take the intensity parameter for

granted but carefully check it in the original works. The lignin spectrum (Figure 15b) is meant as pure Alcell lignin, while most studies report the NMR spectrum of wood, which also includes the cellulose fraction. Coal is generally characterized by a strong aromatic and aliphatic response; however, the exact features of each spectrum depend on the type of material. This is shown in Figure 15c. For biochar, HTC and torrefaction, it is difficult to speak of a single NMR response. Here, we report three typical examples in which the fingerprint of the initial biomass is completely lost and we show the temperature effect for the HTC derivative of glucose (Figure 15e). 

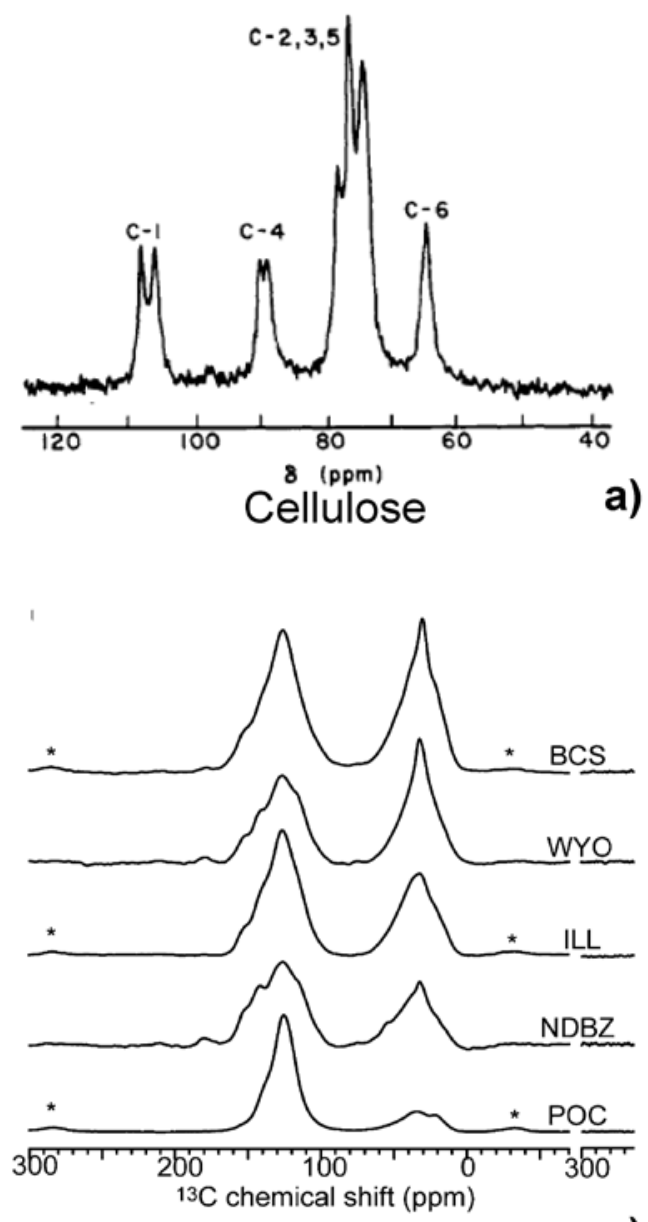

Coals

c)

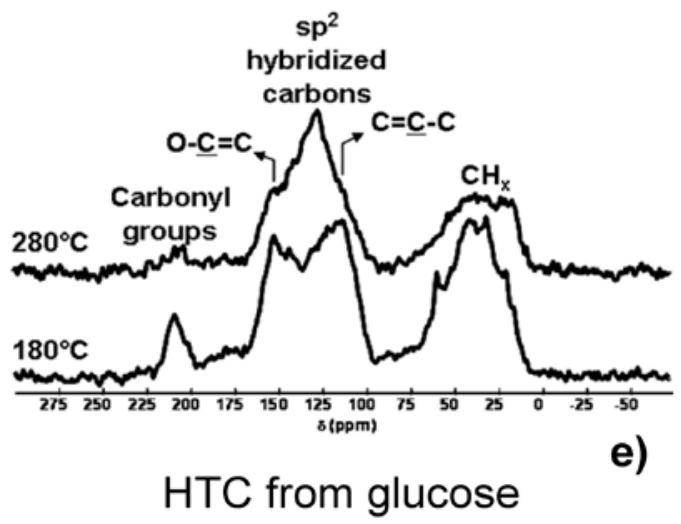

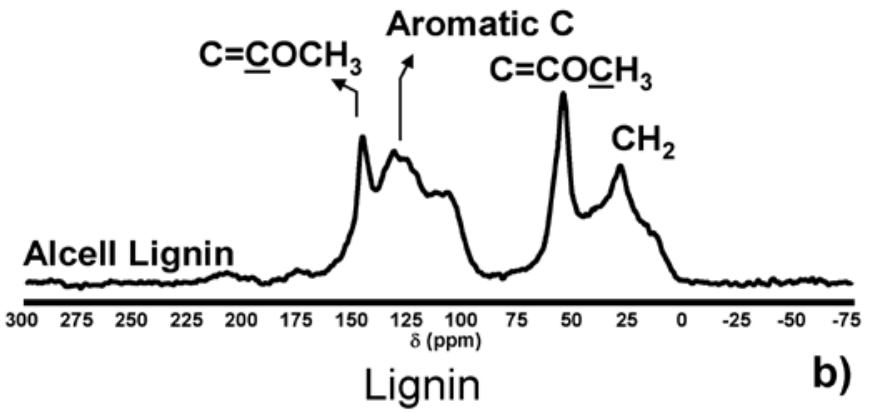

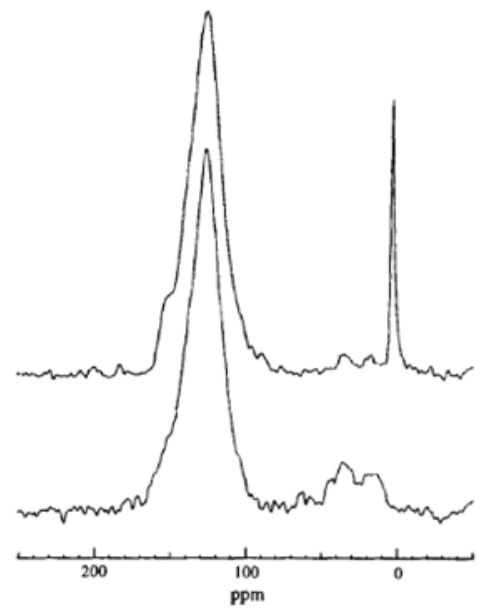

Char from biomass

d)

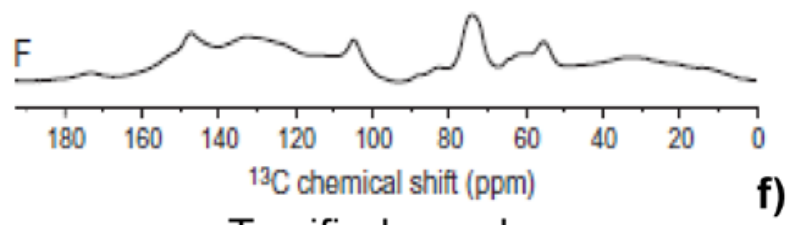

Torrified wood

Figure 15 - Typical ${ }^{13} \mathrm{C}$ CP-MAS spectra of a) cellulose (from Ref. 87); b) Alcell Lignin (adapted from Ref. 163; c) Commercial coals $(B C S=$ Blind Canyon, WYO= Wyodak-Anderson, ILL= Illinois \#6, NDBZ= North Dakota BeulahZap, POC= Pocahontas \#6. Adapted from Ref. 112); d) Char from biomass (bottom spectrum: CP; Top spectrum: SPE; biomass type: eucalyptus waste; $\mathrm{T}=450^{\circ} \mathrm{C}, \mathrm{P}=0.5 \mathrm{MPa}$ ), adapted from Ref. 107; e) HTC from glucose at two temperatures $\left(\mathrm{T}=180^{\circ} \mathrm{C}, 280^{\circ} \mathrm{C}\right)$, adapted from Ref. 163; f) Torrified wood, from Ref. 144 . Important note, the cross polarization times are not the same for all spectra. 


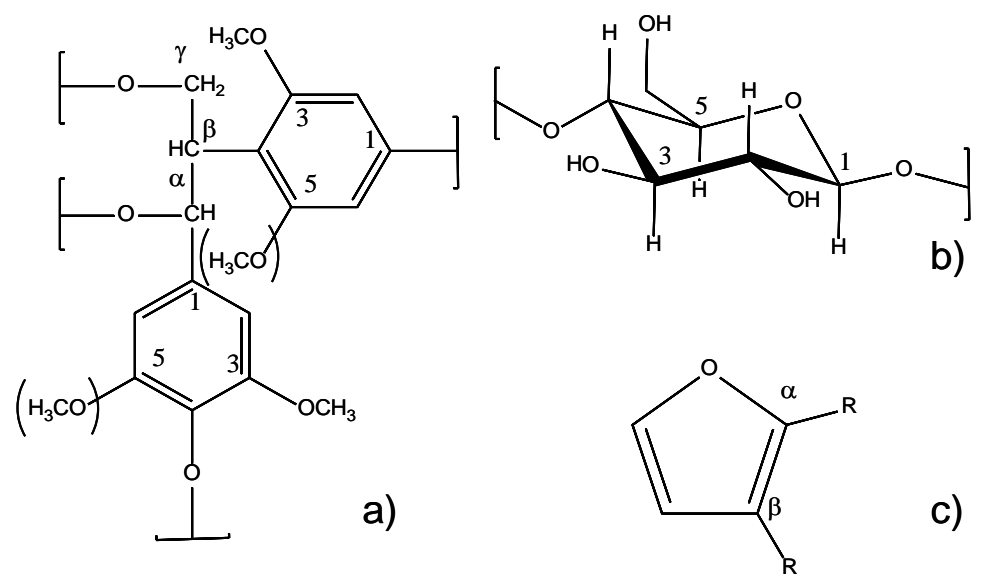

Scheme 1 -a) Lignin, b) glucose (in cellulose) and c) furan units

Assignments in Table 2 are meant to be accurate but still indicative. If they are quite solid for lignin and cellulose, one should carefully verify them for chars in the case of comparison with one's own carbonaceous material and refer to the given comments.

Table 2 - Typical chemical shift values and relative attribution in lignin, cellulose and derived chars. Details of the assignments are referred to Scheme 1. Adapted from Ref. 144, 156, 161, 163 and references therein.

\begin{tabular}{|c|c|c|c|}
\hline Material & Chemical shift & Assignment & Comment \\
\hline \multirow{10}{*}{ Lignin } & 153 & S-3 (e), S-5 (e) & \multirow{10}{*}{$\begin{array}{l}\text { Aromatic units: } \\
\text { S= syringyls (two } \\
\text { methoxyl groups) } \\
\text { G= guaiacyls (one } \\
\text { methoxyl group) }\end{array}$} \\
\hline & $147-150$ & $\begin{array}{l}\text { S-3 (ne), S-5 (ne) G-3 } \\
\text { (ne, e), G4 (ne, e) }\end{array}$ & \\
\hline & $137-140$ & $\begin{array}{l}\text { S-1 (e), S-4 (e), G-1 } \\
\text { (e) }\end{array}$ & \\
\hline & 132-135 & $\begin{array}{l}\text { S-1 (ne), S-4 (ne), G-1 } \\
\text { (ne), }\end{array}$ & \\
\hline & 121 & G6 & \\
\hline & 106-114 & G5, G6, S2, S6 & \\
\hline & 84 & $\mathrm{C} \beta$ & \\
\hline & 75 & $\mathrm{C} \alpha$ & \\
\hline & 62 & $\mathrm{C \gamma}$ & \\
\hline & 56 & $\mathrm{OCH}_{3}$ & \\
\hline \multirow{7}{*}{ Cellulose } & 172 & $-\underline{\mathrm{COO}}-(\mathrm{H})$ & \multirow{7}{*}{$\begin{array}{l}\mathrm{H}=\text { hemicellose } \\
\mathrm{C}=\text { cellulose }\end{array}$} \\
\hline & $101-105$ & C-1 & \\
\hline & 89 & C-4 (ordered in C) & \\
\hline & 84 & C-4 (disordered in C) & \\
\hline & $72-75$ & $\mathrm{C}-3, \mathrm{C}-3, \mathrm{C}-5$ & \\
\hline & $61-65$ & C-6 & \\
\hline & 21 & $\mathrm{CH}_{3}$ & \\
\hline \multirow{2}{*}{ Coals/Chars/HTC } & $13-15$ & $\mathrm{CH}_{3}$ & \\
\hline & $22-40$ & $\mathrm{CH}_{2}$ & Rigid or mobile \\
\hline
\end{tabular}




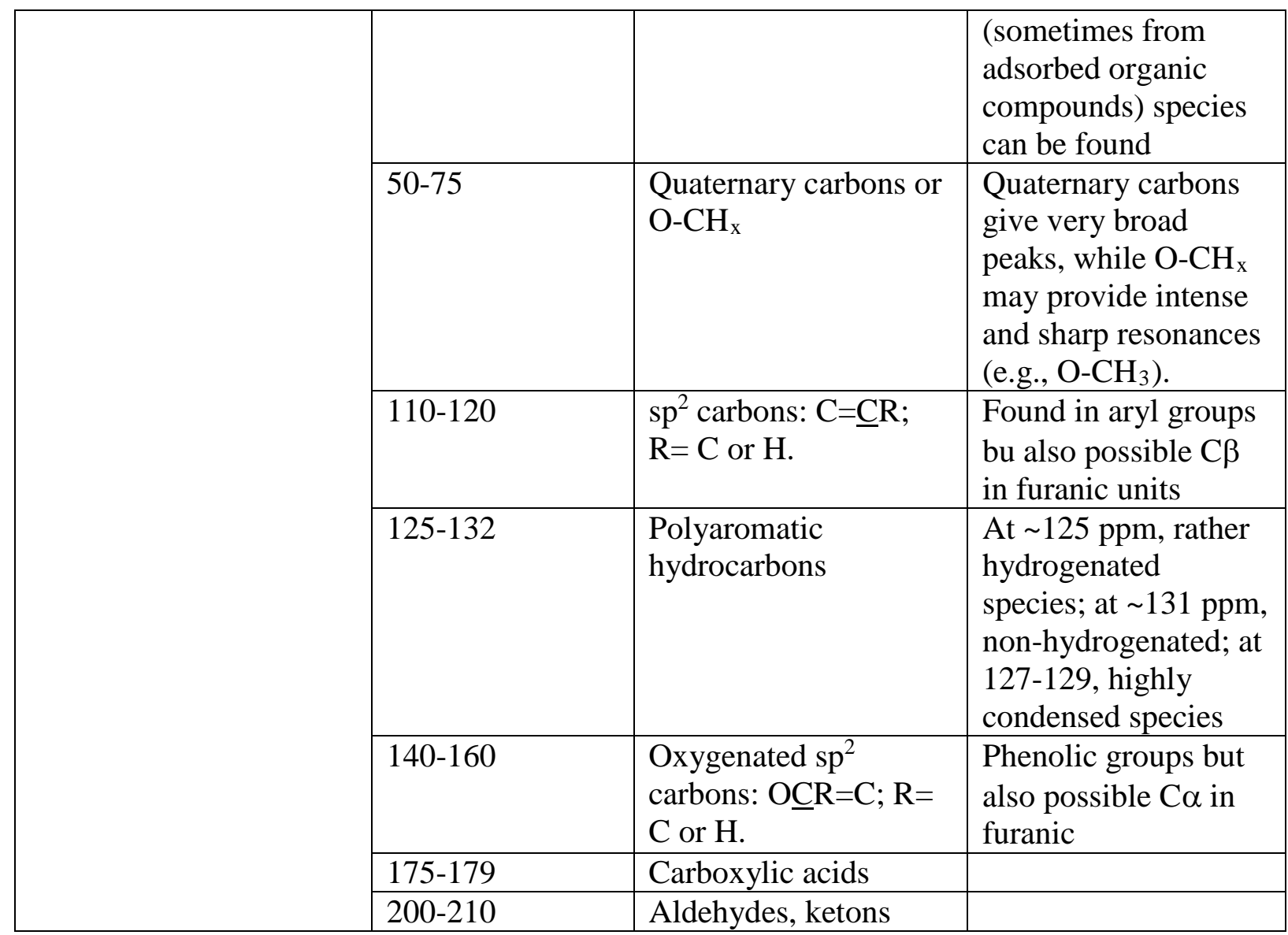

\subsection{Final remarks}

Characterization of the structural features of biomass (cellulose and lignin) and its derived carbon materials has been, and still is, an intense field of research. Several analytical tools (i.e. XRD, IR, Raman, XPS) have been exploited for such a task, however they all yield limited information due to the amorphous character, chemical complexity and heterogeneity of most of these materials. In this review paper, it has been shortly shown the main outcomes and advantages that solid-state ${ }^{13} \mathrm{C}$ NMR studies have brought in the latter years regarding carbonaceous material characterization from biomass and in particular in the analysis of those samples, which are either not soluble in any solvent or their structure is largely affected by the solubilization process (e.g. lignin), thus making the structural analysis via solution NMR very approximate or even rather useless. The main solid state NMR tools (single pulse excitation, cross polarization, dipolar dephasing, J-filtering, double quantum single quantum spectroscopy) are introduced in the beginning of this work and their importance on the structural resolution is eventually demonstrated on selected types of biomass (cellulose, lignin) and some of the derived carbonaceous materials. In fact, even if ${ }^{13} \mathrm{C}$ low abundancy, low sensitivity and long relaxations times can be a major problem, the theoretical and technical developments of the 
technique in the past 50 years have made the study of this nucleus easily accessible. In particular, the use of cross polarization combined to magic angle spinning using protons as source of magnetization has largely contributed to study complex carbonaceous materials without isotopic enrichment. As shown throughout the review, this technique has been largely exploited in the study of carbons obtained from hydrothermal treatment of biomass. Other techniques have revealed to be extremely powerful in terms of spectral editing: dipolar dephasing, for instance, enables the distinction between protonated from non-protonated carbons, just as the solid state version of the INEPT pulse sequence, typical in solution NMR. These are particularly useful in the study of fused aromatic rings that form clusters that extend from few to several units. Evaluation of the cluster size was also done using an indirect technique which is based on following the chemical shift of adsorbed benzene. More advanced experiments like the use of multiple quantum coherences to select spin pairs interacting through dipolar coupling are successfully tested to draw the carbon-carbon skeleton of any amorphous carbonaceous material, provided that isotopic enrichment is done. Whenever that would not be possible, very recent studies have shown that one can use dynamic nuclear polarization to enhance by one or two orders of magnitude the ${ }^{13} \mathrm{C}$ signal under natural isotopic abundance conditions and record a $2 \mathrm{D}$ experiment in few hours, rather than several days.

To this regard, the recent development of hydrothermal carbons from carbohydrates demonstrated to be a nice playground to apply the most recent advances in solid state NMR to real case studies, to which NMR strongly contributed to highlight the complicated problem of structural resolution. In this particular case, furans were highlighted as being the main structural component of the final carbonaceous solids, contrarily to what it was known before on the basis of other spectroscopic techniques. According to very recent works, the chemical composition of hydrothermal carbons can be quantified in terms of furan-to-arene groups ratio. Such parameter was found to depend on the processing temperatures and times and, most interestingly, on the initial parent carbohydrate structure. For instance, while glucose-derived HTC can contain large amounts of furanic groups, this is never the case for cellulose-derived HTC. Interestingly, very recent results based on ssNMR could eventually show that even in cellulose-derived carbons one can isolate furanyl groups, thus opening more opportunities to solve the complex problem hidden behind the thermal degradation of cellulose, under both hydrolytic and pyrolytic conditions.

\section{References}


1 L. dela Rosa, M. Pruski, D. Lang, B. Gerstein, Characterization of the Argonne Premium Coals by Using ${ }^{1} \mathrm{H}$ and ${ }^{13} \mathrm{C}$ NMR and FT-IR spectroscopies, Energy \& Fuels, 6, 460-468 (1992)

2 P. F. Barron, M. A. Wilson, Humic soil and coal structure study with magic-angle spinning ${ }^{13} \mathrm{C} \mathrm{CP}-\mathrm{NMR}$, Nature, 289, 22 (1981)

3 P. Tekely, D. Nicole, J. Brondeau, J.J. Delpeuch, Application of Carbon-13 Solid State High resolution NMR to the study of proton mobility. Separation of rigid and mobile components in coal structure, J. Phys. Chem. C, 90, 5608 (1986)

4 I. Pastorova, R. E. Botto, P. W. Arisz, J. J. Boon, Cellulose char structure: a combined analytical Py-GC-MS, FTIR and NMR study, Carbohydrate Research, 262, 27-47 (1994)

5 J. B. Wooten, J. I. Seeman, M. R. Hajaligol, Observation and Characterization of Cellulose Pyrolysis

Intermediates by ${ }^{13} \mathrm{C}$ CPMAS NMR. A New Mechanistic Model, Energy Fuels, 18, 1-15 (2004)

6 J. C. C. Freitas, A. G. Cunha, F. G. Emmerich, Solid-state NMR methods applied to the study of carbon materials. In: Radovic LR, (ed.), Chem. Phys. Carbon, Vol. 31, p. 85-169. Boca Raton: Taylor \& Francis, 2012. 7 R. E. Botto, Y. Sanada (ed). Magnetic resonance of carbonaceous solids. Advances in Chemistry Series, Vol. 229. Washington: American Chemical Society, 1993.

8 C. E. Snape, Analysis of fossil fuels. In: Analytical NMR, ed. Field LD, Sternhell S, p. 65-113. Chichester: John Wiley \& Sons, 1989.

9 M. A. Wilson NMR techniques and applications in geochemistry and soil chemistry. Oxford: Pergamon Press, 1987

10 K. D. Bartle, D. W. Jones Nuclear magnetic resonance spectroscopy. In: Karr Jr. C (ed), Analytical methods for coal and coal products, Vol. II, Chapter 23, p. 104-160. New York: Academic Press, 1978.

11 X. Cao, J. Yang, J. Mao, Characterization of kerogen using solid-state nuclear magnetic resonance spectroscopy: A review, Intern. J. Coal Geol., 108, 83-90 (2013)

12 P. Conte, R. Spadaccini, A. Piccolo, State of the art of CPMAS ${ }^{13} \mathrm{C}$ NMR spectroscopy applied to natural organic matter, Prog. Nucl. Magn. Reson. Spectrosc., 2004, 44, 215-223

13 N. Baccile, J. Weber, C. Falco, M.-M. Titirici, Characterization of Hydrothermal Carbonization Materials, Ch. 6, in Sustainable Carbon Materials from Hydrothermal Processes, Ed. M.-M. Titirici, 2013, John Wiley and Sons

14 M. H. Levitt, Spin Dynamics: Basics of Nuclear Magnetic Resonance, Wiley \& Sons Ltd., West sussex, 2001

15 M. J. Duer, Introduction to solid state NMR spectroscopy, Wiley-Blackwell, 2004

16 K. Schmidt-Rohr, H. W. Spiess, Multidimensional Solid state NMR and Polymers, Academic Press, London, 1994

17 M. Mehring, Principles of High Resolution NMR in Solids, Springer, 1983

18 E. R. Andrew, E. Szczesniak, A historical account of NMR in the solid state, Prog. Nucl. Magn. Res., 28, 11 (1995)

19 F. Blanc, C. Copéret, A. Lesage, L. Emsley, High resolution solid state NMR spectroscopy in surface organometallic chemistry: access to molecular understanding of active sites of well-defined heterogeneous catalysts, Chem. Soc. Rev., 37, 518 (2008)

20 D. D. Laws, H.-M. L. Bitter, A.. Jerschow, Solid-state NMR spectroscopic methods in chemistry, Angew. Chem. Int. Ed., 41, 3096 (2002)

21 E. R. Andrew, A. Bradbury, R. G. Eades, Nuclear Magnetic Resonance Spectra from a Crystal rotated at High Speed, Nature, 182, 1659 (1958)

22 A. E. Bennett1, C. M. Rienstra1, M. Auger1, K. V. Lakshmi, R. G. Griffin1, Heteronuclear decoupling in rotating solids. J. Chem. Phys. 1995, 103, 6951

23 A. Lesage Recent advances in solid-state NMR spectroscopy of spinI= 1/2 nuclei. Phys. Chem. Chem. Phys. 2009, 11, 6876

24 J.-D. Mao, K. Schmidt-Rohr, Recoupled long-range C-H dipolar dephasing in solid state NMR, and its use for spectral selection of fused aromatic rings, J. Magn. Res., 162, 217 (2003)

25 H. Takahashi, D. Lee, L. Dubois, M. Bardet, S. Hediger, G. De Paepe, Rapid Natural-Abundance 2D 13C13C Correlation Spectroscopy Using Dynamic Nuclear Polarization Enhanced Solid-State NMR and MatrixFree Sample Preparation, Angew. Chem. Int. Ed., 2012, 51, 11766-11769

26 I. J. Lowe Free Induction Decays of Rotating Solids, Phys. Rev. Lett, 1959, 2, 285-287. 
27 Pines, A., Gibby, M. G., Waugh, J. S., (1973) Proton-enhanced NMR of dilute spins in solids, J. Chem. Phys., 59, 569

28 Gareth A. Morris, Ray Freeman (1979). "Enhancement of Nuclear Magnetic Resonance Signals by Polarization Transfer". Journal of the American Chemical Society 101 (3): 760-762.

29 D. G. Cory, W. M. Ritchey, Inversion Recovery Cross-Polarization NMR in Solid Semicrystalline Polymers, Macromolecules 1989,22, 1611-1615

30 Bodenhausen, G.; Ruben, D.J. (1980). "Natural abundance nitrogen-15 NMR by enhanced heteronuclear spectroscopy". Chemical Physics Letters 69 (1): 185-189

31 Lesage, A., Emsley, L. (2001) Through-bond heteronuclear single-quantum correlation spectroscopy in solidstate NMR, and comparison to other through-bond and through-space experiments, J. Magn. Res., 148, 449 32 Lesage, A., Sakellariou, D., Steuernagel, S., Emsley, L. (1998) Carbon-proton chemical shift correlation in solid state NMR by through-bond multiple quantum spectroscopy, J. Am. Chem. Soc., 120, 13194 33 Lesage, A., Auger, C., Caldarelli, S., Emsley, L. (1997) Determination of through-bond carbon-carbon connectivities in solid-state NMR using the INADEQUATE experiment, J. Am. Chem. Soc., 119, 7867 34 Caravatti, P., Bodenhausen, G., Ernst, R. R. (1982) Heteronuclear solid-state correlation spectroscopy, Chem. Phys. Lett., 89, 363; Caravatti, P., Braunschweiler, L., Ernst, R. R. (1983) Heteronuclear correlation spectroscopy in rotating solids, Chem. Phys. Lett., 100, 305

35 Brown, S. P. (2007) Probing proton-proton proximities in the solid state, Progr.Nucl. Magn. Res. Spec., 50, 199

36 Lee, Y.K., Kurur, N.D., Helmle, M., Johannessen, O.G., Nielsen, N.C., Levitt, M.H. (1995) Efficient dipolar recoupling in the NMR of rotating solids. A sevenfold symmetric radiofrequency pulse sequence, Chem. Phys. Lett., 242, 304

37 Brinkmann, A., Edén, M., Levitt, M. H. (2000) Synchronous helical pulse sequences in magic-angle spinning nuclear magnetic resonance: Double quantum recoupling of multiple-spin systems, J. Chem. Phys., 112, 8539

38 W. Kolodziejski, J. Klinowski, J., Kinetics of cross-polarization in solid-state NMR: a guide for chemists. Chem. Rev. 102, 613-628 (2002)

39 P. Kumar, D. M. Barret, M. J. Delwiche, P. Stroeve Methods for Pretreatment of Lignocellulosic Biomass for Efficient Hydrolysis and Biofuel Production Ind. Eng. Chem. Res. 2009, 48, 3713

40 D. Klemm, B. Heublein, H.-P. Fink, A. Bohn Angew Chem. 2005, 117, 3422

41M. P. Pandey, C. S. Kim Lignin depolymerization and conversion: a review of thermochemical methods.

Chem Eng Technol. 2011, 34, 29-41

42 Y. S. Sun XBL, S. T. Zhang, R. Zhang, X. Y. Wang. Kinetic study for Fe(NO3)3 catalyzed hemicellulose hydrolysis of different corn stover silages. Bioresour .Technol. 2011, 102, 2936

43 H. D. Willauera, J. G. Huddlestonb, M. Lia, R. D. Rogers, Investigation of aqueous biphasic systems for the separation of lignins from cellulose in the paper pulping process, . J Chromatogr, Biomed Appl. 2000, 743, 12735

44 M. Kim, G. Aita, D. F. Day. Appl Biochem Biotechnol. 2010, 161, 34-40

45 N.-E. El Mansouri, J. Salvado Structural characterization of technical lignins for the production of adhesives: Application to lignosulfonate, kraft, soda-anthraquinone, organosolv and ethanol process lignins. Indus. Crops Products. 2006, 24, 8-16

46 G. Ward, Y. Hadar, C. G. Dosoretz Lignin peroxidase-catalyzed polymerization and detoxification of toxic halogenated phenols. J. Chem. Technol. Biotechnol. 2003, 78, 1239

47 J. Zakzeski, A. L. Jongerius, P. C. A. Bruijnincx, B. M. Weckhuysen, Catalytic Lignin Valorization Process for the Production of Aromatic Chemicals and Hydrogen, ChemSusChem, 5, 1602-1609, (2012)

48 J. Zakzeski, P. C. Bruijnincx, A. L. Jongerius, B. M. Weckhuysen, The catalytic valorization of lignin for the production of renewable chemicals, Chem Rev., 110, 3552-3599, (2010)

49 C. E. Snape, D. E. Axelson, R. E. Botto, J.J. Delpuech, P. Tekely, B. C. Gerstein, M. Pruski, G. E. Maciel, M. A. Wilson, Quantitative reliability of aromaticity and related measurements on coals by 13C n.m.r. A debate. Fuel 1989, 68, 547-560

50 R. J. Smernik, J. A. Baldock, J. M. Oades, A. K. Whittakerz, Determination of T1rH Relaxation Rates in Charred and Uncharred Wood and Consequences for NMR Quantitation, Sol. St. Nucl. Magn. Reson., 22, 50-70 (2002) 
51 R. Vanholme, B. Demedts, K. Morreel, J. Ralph, W. Boerjan, Lignin Biosynthesis and Structure, Plant Physiology, 153, 895-905 (2010)

52 J. M. Harkin, Lignin - a natural polymeric product of phenol oxidation. In Oxidative Coupling of Phenols, ed. Taylor, W.I. \& Battersby, A.R. Marcel Dekker, New York, 243-321, 1967

53 J. M. Harkin, Lignin. In Chemistry and Biochemistry of Herbage, ed. Butler, G.W. Academic Press, London, 323-373, 1973

54 K. Freudenberg, A. C. Neish, Constitution and Biosynthesis of Lignin, Springer-Verlag, Berlin-HeidelbergNew York, 1968

55 G. Brunow, Oxidative coupling of phenols and the biosynthesis of lignin. In Lignin and Lignan Biosynthesis, ed. N. G. Lewis, S. Sarkanen, American Chemical Society, Washington, DC, 131-147, 1998

56 A. W. Glazer, H. Nikaido, Microbial Biotechnology: fundamentals of applied microbiology, W. H. Freeman, 1999

57 J. Ralph, C. Lapierre, J. M. Marita, H. Kim, F. C. Lu, R. D. Hatfield, et al. Elucidation of new structures in lignins of CAD- and COMT- deficient plants by NMR, Phytochemistry, 57, 993-1003 (2001)

58 Z. Xia, L. G. Akim, D. S. Argyropoulos, Quantitative 13C NMR analysis of lignins with internal standards, $J$. Agr. Food Chem., 2001, 49, 3573-3578

59 M. Bardet, D. Robert, K. Lundquist, S. Von Unge, Distribution of erythro and threo forms of different types of $\beta-O-4$ structures in aspen lignin by using the 13C NMR 2D INADEQUATE experiment, Magn. Reson.

Chem., 1998, 36, 597-600

60 M. Bardet, K. Lundquist, J. Parkas, D. Robert, S. Von Unge, 13C assignments of the carbon atoms in the aromatic rings of lignin model compounds of the arylglycerol beta-aryl ether type, Magn. Reson. Chem., 2006, 44, 976-979

61 D. J. Yelle, J. Ralph, C. R. Frihart, Characterization of nonderivatized plant cell walls using high-resolution solution-state NMR spectroscopy, Magn. Reson. Chem., 46, 508-517 (2008)

62 H. Kim, J. Ralph, Solution-state 2D NMR of ball-milled plant cell wall gels in DMSO-d6/pyridine-d5, Org.

Biomol. Chem., 8, 576-591 (2010)

63 J. Mao, K. M. Holtman, J. T. Scott, J. F. Kadla, K. Schmidt-Rohr, Differences between lignin in unprocessed wood, milled wood, mutant wood, and extracted lignin detected by 13C solid-state NMR, J. Agric. Food Chem., 2006, 54, 9677-9686

64 K. M. Holtman, H.-M. Chang, H. Jameel, J. F. Kadla, Quantitative C-13 NMR characterization of milled wood lignins isolated by different milling techniques, J. Wood Chem. Technol., 2006, 26, 21-34

65 J. Ralph, J. M. Marita, S. A. Ralph, R. D. Hatfield, F. Lu, R. M. Ede, et al. Solution-state NMR of lignins. In DS Argyropoulos, ed, Advances in Lignocellulosic Characterization, TAPPI Press, Atlanta, 55-108, 1999 66 J. Ralph, L. L. Landucci, NMR of lignins, In C. Heitner, D. R. Dimmel, eds, Lignins. Marcel Dekker, New York, 137-234, 2010

67 W. Kolodziejski, J. S. Frye, G. E. Maciel, C-13 Nuclear Magnetic-Resonance Spectrometry with Cross Polarization and Magic-Angle Spinning for Analysis of Lodgepole Pine Wood, Anal. Chem., 54, 1419-1424 (1982)

68 G. R. Hatfield, G. E. Maciel, O. Erbatur, G. Erbatur, Qualitative and quantitative analysis of solid lignin samples by carbon-13 nuclear magnetic resonance spextrometry, Anal. Chem., 1987, 59, 172-179

69 M. Bardet, M. F. Foray, Q.-K. Tran, High-resolution solid state CPMAS NMR study of archaeological woods, Anal. Chem., 2002, 74, 4386-4390

70 B. Kohn, M. Davis, G. E. Maciel, In situ study of dilute H2SO4 pretreatment of 13C-enriched poplar wood, using 13C NMR, Energy Fuels, 2011, 25, 2301-2313

71 M. Bardet, L. Emsley, M. Vincendon, Two-dimensional spin-exchange solid-state NMR studies of 13Cenriched wood, Sol. St. Nucl. Magn. Reson., 1997, 8, 25-32

$72 \mathrm{H}$. Wikberg, S. L. Maunu, Characterization of thermally modified hard- and softwoods by 13C CPMAS NMR, Carbohyd. Polym., 2004, 58, 461-466

73 N. G. Lewis, E. Yamamoto, J. B. Wooten, G. Just, H. Ohashi, G. H. N. Towers, Monitoring Biosynthesis of Wheat Cell-Wall Phenylpropanoids in Situ, Science, 237, 1344 (1978) 
74 N. G. Lewis, R. A. Razal, K. P. Dhara, E. Yamamoto, G. H. Bokelman, J. B. Wooten, Incorporation of [2-C13] Ferulic Acid, A Ligning Precursor, Into Leucaena-Leucocephala and Its Analysis by Solid-State C-13 NMRSpectroscopy, J. Chem. Soc., Chem. Commun., 1626 (1988)

75 T. L. Eberhardt, M. A. Bernards, L. He, L. B. Davin, J. B. Wooten, N. G. Lewis, Lignification in CellSuspension Cultures of Pinus-Taeda-In-Situ Characterization of a Gymnosperm Lignin, J. Biol. Chem., 268, 21088 (1993)

76 N. Terashima, R. H. Atalla, D. L. Vanderhart, Solid State NMR Spectroscopy Of Specifically ${ }^{13}$ C-Enriched Lignin In Wheat Straw From Coniferin, Phytochemistry, 46, 863-870 (1997)

77 E. Adler E. Lignin—Past, Present, and Future. Wood Sci. Techn., 11, 169-218 (1977); W. G. Glasser, S. Sarkanen Lignin. Properties and Materials, ACS Symposium Series No. 397, Washington DC, 1989; N. Fukagawa, G. Moshitsuka, A. Ishizu Isolation of a Syringyl b-O-4 rich End-wise type Lignin Fraction from Birch Periodate Lignin, J. Wood Chem. Technol., 12, 91-109 (1992)

78 P. G. Hatcher, Chemical Structural Models for Coalified Wood (Vitrinite) in Low Rank Coal. Org. Geochem., 16, 956-968 (1989)

79 G. D. Cody, G. Sághi-Szabó, Calculation of the 13C NMR chemical shift of ether linkages in lignin derived geopolymers: Constraints on the preservation of lignin primary structure with diagenesis, Geochim. Cosmochim. Acta, 63, 2, 193-205 (1999)

80 S. Supaluknari, I. Burgar, F. P. Larkins, High-Resolution Solid-State C-13 NMR-Studies Of Australian Coals, Org. Geochem., 15, 509-519 (1990)

81 P. S. Belton, S. F. Tanner, N. Cartier, H. Chanzy, High-Resolution Solid-State C-13 Nuclear MagneticResonance Spectroscopy of Tunicin, An Animal Cellulose, Macromolecules, 22, 1615 (1989)

82 P. T. Larsson, U. Westermark, T. Iversen, Determination of the cellulose I alpha allomorph content in a tunicate cellulose by CP/MAS C-13-NMR spectroscopy, Carbohydr. Res., 278, 339 (1995)

83 R. H. Atalla, D. L. VanderHart, Native Cellulose- A Composite Of 2 Distinct Crystalline Forms, Science, 223, 283 (1984)

84 D. L. VanderHart, R. Atalla, Studies of Microstructure in Native Celluloses Using Solid-State C-13 NMR, Macromolecules, 17, 1465 (1984)

85 R.H. Atalla, D.L. VanderHart, The role of solid state 13C NMR spectroscopy in studies of the nature of native celluloses, Solid State Nucl. Magn. Res., 1999, 15, 1-19

86 A. Lesage, M. Bardet, L. Emsley, Through-bond carbon-carbon connectivities in disordered solids by NMR, J. Am. Chem. Soc., 1999, 121, 10987-10993

87 R. H. Atalla, J. C. Gast, D. W. Sindorf, V. J. Bartuska, G. E. Maciel, 13C NMR spectra of cellulose polymorphs, J. Am. Chem. Soc., 1980, 102, 3249-3251

88 W. L. Earl, D. L. Vanderhart, High resolution, Magic Angle spinning 13C NMR of solid cellulose I, J. Am. Chem. Soc., 1980, 102, 3251-3252

89 G. E. Maciel, W. L. Kolodziejski, M. S. Bertran, B. E. Dale, 13C NMR and order in cellulose, Macromolecules, 1982, 15, 686-687

90 R. L. Dudley, C. A. Fyfe, P. J. Stephenson, Y. Deslandes, G. K. Hamer, R. H. Marchessault, High resolution 13C CP/MAS NMR spectra of solid cellulose oligomers and the structure of cellulose II, J. Am. Chem. Soc., 1983, 105, 2469-2472

91 A. Pines, M. G. Gibby, J. S. Waugh, Proton-enhanced NMR of dilute spins in solids, J. Chem. Phys., 1973, 59, 569-590

92 J. Schaefer, E. O. Stejskal, "Carbon-13 Nuclear Magnetic Resonance of Polymers Spinning at the Magic Angle, J. Am. Chem. Soc., 1976, 98, 1031

93 H. Lenholm, T. Larsson, T. Iversen, Determination of cellulose I $\alpha$ and I $\beta$ in lignocellulosic materials, Carbohydr. Res., 1994, 261, 119

94 P. T. Larsson, U. Westermark, T. Iversen, Determination of the cellulose I $\alpha$ allomorph content in a tunicate cellulose by CP/MAS 13C-NMR spectroscopy, Carbohydr. Res., 1995, 278, 339-343

95 P. T. Larsson, K. Wickholm, T. Iversen, A CP/MAS13C NMR investigation of molecular ordering in celluloses, Carbohydr. Res., 1997, 302, 19-25

96 K. Wickholm, P. T. Larsson, T. Iversen, Assignment of non-crystalline forms in cellulose I by CP/MAS 13C NMR spectroscopy, Carbohydr. Res., 1998, 312, 123-129 
97 K. Masuda, M. Adachi, A. Hirai, H. Yamamoto, H. Kaji, F. Horii, Solid state 13C and 1H spin diffusion NMR analyses of the microfibril structure for bacterial cellulose, Solid State Nucl. Magn. Reson., 2003, 23, 198212

98 H. Kono, T. Erata, M. Takai, Determination of the Through-Bond Carbon-Carbon and Carbon-Proton Connectivities of the Native Celluloses in the Solid State, Macromolecules, 2003, 36, 5131-5138

99 H. Kono, Y. Numata, T. Erata, M. Takai, 13C and 1H resonance assignement of mercerized cellulose II by two-dimensional MAS NMR spectroscopies, Macromolecules, 2004, 37, 5310-5316

100 T. Mori, E. Chikayama, Y. Tsuboi, N. Ishida, N. Shisa, Y. Noritake et al. Exploring the conformational space of amorphous cellulose using NMR chimica shift, Carbohyd. Polym., 2012, 90, 1197-1203

101 D. L. VanderHart, H.L. Retcofsky, Estimation of coal aromaticities by proton-decoupled carbon-13 magnetic resonance spectra of whole coals, Fuel, 1976, 55, 202-204

102 D. E. Axelson, Solid state nuclear magnetic resonance of fossil fuels, Multiscience, 1985, Montreal, Canada

103 R. M. Davidson, Nuclear magnetic resonance study of coal, 1986, IEA Coal Research, London,

104 L.B. Alemany, D. M. Grant, R. J. Pugmire, L. M. Stock, Solid state magnetic resonance spectra of Illinois No. 6 coal and some reductive alkylation products, Fuel, 1984, 63, 513-521

105 M. S. Solum, R. J. Pugmire, D. M. Grant, 13C solid state NMR of Argonne premium coals, Energy and Fuels, 1989, 3, 187-193

106 S. Supaluknari, I. Burgar, F. P. Larkins, High-resolution solid-state 13C NMR studies of Australian coals, Org. Geochem., 1990, 15, 509-519

107 M. M. Maroto-Valer, J. M. Andrésen, J. D. Rocha, C. E. Snape, Quantitative solid state 13C n.m.r. measurements on cokes, chars and coal tar pitch fractions, Fuel, 1996, 75, 1721-1726

108 J. Xiong, G. E. Maciel, In-situ varable temperature high resolution 1H NMR studies of molecular dynamics and structure in coal, Energy \& Fuels, 1997, 11, 856-865

109 M. M. Maroto-Valer, C. J. Atkinson, R. R. Willmers, C. E. Snape, Characterization of partially carbonized coals by solid state 13C NMR and optical microscopy, Energy \& Fuels, 1998, 12, 833-842

110 Y. Li, X. Cao, D. Zhu, M. A. Chappel, L. F. Miller, J. Mao, Characterization of coals and their laboratoryprepared black carbon using advanced solid-state 13C nuclear magnetic resonance spesctroscopy, Fuel Process. Technol., 2012, 96, 56-64

111 J. Z. Hu, M. S. Solum, C. M. V. Taylor, R. J. Pugmire, D. M. Grant, Structural determinatin in carbonaceous solids using advanced solid state NMR techniques, Energy \& Fuels, 2001, 15, 14-22

112 S. M. Althus, K. Mao, G. J. Kennedy, M. Pruski, Solid-state NMR studies of fossil fuels using one- and two-dimensional methods at high magnetic fields, Energy\& Fuels, 2012, 26, 4405-4412

113 M. M. Tang, R. Bacon, Carbonization of Celllose Fibers. 1. Low Temperature Pyrolysis, Carbon, 2, 211220 (1964)

114 J. Lédé, Cellulose pyrolysis kinetics: an historical review on the existence and role of intermediate active cellulose, J. Anal. Appl. Pyrol., 94, 17-32 (2012)

115 R. K. Sharma, J. B. Wooten, V. L. Balinga, M. R. Hajaligol, Characterization of Char from the Pyrolysis of Tobacco, Fuel, 80, 1825-1836 (2001)

116 S. Soares, N. M. P. S. Ricardo, S. Jones, F. Heatley, High Temperature Thermal Degradation of Cellulose in Air Studied Using FTIR and H-1 and C-13 solid-state NMR, Euro. Polym. J., 37, 737-745 (2001)

117 J. Zawadzki, M. Wisniewski, C-13 NMR Study of Cellulose Thermal Treatment J. Anal. Appl. Pyrolysis, 62, 111-121 (2002)

118 X. Zhang, J. Golding, I. Burgar, Thermal Decompostion Chemistry of Starch Studied by C-13 High-

Resolution Solid-State NMR Spectroscopy, Polymer, 43, 5791-5796 (2002)

119 S. Link, S. Arvelakis, H. Spliethoff, P. De Waard, A. Samoson, Investigation of Biomasses and Chars Obtained from Pyrolysis of Different Biomasses with Solid-State C-13and Na-23 Nuclear Magnetic Resonance, Energy Fuels, 22, 3523-3530 (2008)

120 M. Bardet, S. Hediger, G. Gerbaud, S. Gambarelli, J. F. Jacqot, M. F. Foray et al. Investigation with C-13 NMR, EPR, and Magnetic Susceptibility Measurements of Char Residues Obtained by Pyrolysis of Biomass, Fuel, 86, 1966-1976 (2007) 
121 K. David, Y. Pu, M. Foston, J. Muzzy, A. Ragauskas, Cross-polarization/magic angle spinning (CP/MAS) 13C nuclear magnetic resonance (NMR) analysis of chars from alkaline-treated pyrolyzed softwoods, Energy \& Fuels, 23, 498-501 (2009)

122 R. J. Smernik, R. S. Kookana, J. O. Skjemstad, NMR characterization of 13C-benzene sorbed to natural and prepared charcoals, Environ. Sci. Technol., 40, 1764-1796 (2006)

123 A. V. McBeath, R. J. Smernik, Variation in the degree of aromatic condensation of chars, Org. Geochem., 40, 1161-1168 (2009)

124 A. V. McBeath, R. J. Smernik, M. P. W. Schneider, M. W. I. Schmidt, E. L. Plant, Determination of the aromaticity and the degree of aromatic condensation of a thermosequence of wood charcoal using NMR, Org. Geochem., 42, 1194-1202 (2011)

125 P.v.R. Schleyer, C. Maerker, A. Dransfeld, H. Jiao, N.J.R. van Eikema Hommes, Nucleus-independent chemical shifts: a simple and efficient aromaticity probe. J. Am. Chem. Soc. 118, 6317-6318, (1996)

126 J. C. C. Freitas,_F. G. Emmerich, G. R. C. Cernicchiaro, L. C. Sampaio, T. J. Bonagamba Magnetic Susceptibility Effects on 13C MAS NMR Spectra of Carbon Materials and Graphite, Sol. State Nucl. Magn. Res. 20, 61-73 (2001)

127 X. Cao, J. J. Pignatello, Y. Li, C. Lattao, M. A. Chappell, N. chen, L. F. Miller, J. Mao, Characterization of wood chars produced at different temperatures using advanced solid-state 13C NMR spectroscopic techniques, Energy \& Fuels, 26, 5983-5991 (2012)

128 A. V. Bridgwater, 2012. Review of fast pyrolysis of biomass and product upgrading. Biomass Bioenergy 38 , 68-94

129 H. Ben, A. J. Ragauskas, Biores. Technol. 2013, 147, 577-584

130 S. Habets, P. J. de Wild, W. J. J. Huijgen , E. R. H. van Eck, Biores. Technol. 2013, 146, 585-590

131 S. Link, S. Arvelakis, H. Spliethoff, P. De Waard, A. Samoson Energy \& Fuels, 2008, 22, 3523-3530

132 X.-F. Li, Q. Xu, Y. Fu, Q.-X. Guo. Preparation and Characterization of Activated Carbon from Kraft Lignin via KOH Activation. Environ. Prog. Sus. En. 2014, 33, 519

133 R. Ruiz-Rosas, M. J. Valero-Romero, D. Salinas-Torres, J. Rodriguez-Mirasol, T. Cordero, E. Morallon, et al. Electrochemical performance of hierarchical porous carbon materials obtained from the infiltration of lignin into zeolite templates. ChemSusChem. 2014, 7, 1458

134 E. Frank, L. M. Steudle, D. Ingildeev, J. M. Sporl, M. R. Buchmeiser. Carbon fibers: precursor systems, processing, structure, and properties. Angew. Chem. Int. Ed., 2014, 53, 5262

135 M. Zhang, A. A. Ogale Carbon fibers from dry-spinning of acetylated softwood kraft lignin. Carbon 2014, 69, 626

136 J. Lin, K. Koda, S. Kubo, T. Yamada, M. Enoki, Y. Uraki. Improvement of Mechanical Properties of Softwood Lignin-Based Carbon Fibers. J. Wood Chem. Technol., 2014, 34, 111

137 A. J. Ragauskas, G. T. Beckham, M. J. Biddy, R. Chandra, F. Chen, M. F. Davis, et al. Lignin valorization: improving lignin processing in the biorefinery. Science, 2014, 344, 1246843

138 H. Marsh, F. Rodriguez-Reinoso, Elsevier, Oxford, 2006

139 A. M. M. Vargas, A. L. Cazetta, C. A. Garcia, J. C. G. Moraes, E. M. Nogami, E. Lenzi et al. Preparation and characterization of activated carbon from a new raw lignocellulosic material : Flamboyant (Delonix regia) pods, Journal of Environmental Management, 92, 178-184 (2011)

140 M. S. Solum, R. J. Pugmire, M. Jagtoyen, F. Derbyshire, Evolution of carbon structure in chemically activated wood, Carbon, 33, 9, 12471254 (1995)

141 A. M. Puziy, O. I. Poddubnaya, R. P. Socha, J. Gurgul., M. Wisniewski, XPS and NMR studies of phosphoric acid activated carbons, Carbon, 46, 2113 - 2123 (2008)

142 H. N. Cheng, L. H. Wartelle, K. T. Klasson, J. C. Edwards, Solid-state NMR and ESR studies of activated carbons produced from pecan shells, Carbon, 48, 2455-2469 (2010)

143 a) D. Ciolkosz, R. A. Wallace A review of torrefaction for bioenergy feedstock production. Biofuels Bioprod. Bioref. 2011, 5, 317; b) J. S. Tumuluru, C. T. Wright, J. R. Hess, K. L. Kenney. A review of biomass densification systems to develop uniform feedstock commodities for bioenergy application. Biofuels Bioprod. Bioref. 2011, 5, 683; c) M. J. C. van der Stelt, H. Gerhauser, J. H. A. Kiel, K. J. Ptasinski. Biomass upgrading by torrefaction for the production of biofuels: A review. Biomass Bioener. 2011, 35, 3748; d) M. P. Robbins, G. Evans, J. Valentine, I. S. Donnison, G. G. Allison New opportunities for the exploitation of energy crops by 
thermochemical conversion in Northern Europe and the UK. Prog. Ener. Comb. Sci. 2012, 38, 138; e) J. J. Chew, V. Doshi Recent advances in biomass pretreatment - Torrefaction fundamentals and technology. Renew. Sus. Ener. Rev. 2011, 15, 4212

144 T. Melkior, S. Jacob, G. Gerbaud, S. Hediger, L. Le Pape, L. Bonnefois, M. Bardet, NMR analysis of the transformation of wood constituents by torrefaction, Fuel, 92 271-280 (2012)

145 H. Ben, A. J. Ragauskas, Torrefaction of Loblolly pine, Green Chem., 14, 72 (2012)

146 J. Parka, J. Menga, K. H. Limb, O. J. Rojasa,c, S. Parka,Transformation of lignocellulosic biomass during torrefaction, J. Anal. Appl. Pyrol. 100 199-206 (2013)

147 A. Zheng, Z. Zhao, S. Chang, Z. Huang, X. Wang, F. He, H. Li, Effect of torrefaction on structure and fast pyrolysis behavior of corncobs, Biores. Technol., 128 370-377 (2013)

148 S. J. Hill, W. J. Grigsby, P. W. Hall Chemical and cellulose crystallite changes in Pinus radiata during torrefaction, Biomass Bioen., 56, 92-98 (2013)

149 Titirici M-M, White RJ, Falco C, Sevilla M. Black perspectives for a green future: hydrothermal carbons for environment protection and energy storage. Energy Environ Sci. 5, 6796-6822 (2012)

150 M.-M. Titirici, M. Antonietti, N. Baccile, Hydrothermal Carbon from Biomass: A comparison of the Local

Structure from Poly- to monosaccharides and pentoses/hexoses, Green Chem., 10, 1204-1212 (2008)

151 M. Sevilla, A. B. Fuertes., Chemical and Structural Properties of Carbonaceous Products Obtained by

Hydrothermal Carbonization of Saccharides, Chem. Eur. J., 15, 4195 - 4203 (2009); b) M. Sevilla, A. B.

Fuertes, The Production of Carbon Materials by Hydrothermal Carbonization of Cellulose, Carbon, 47, 2281-

2289 (2009)

152 A. Chuntanapum, Y. Matsumura, Formation of Tarry Material from 5-HMF in Subcritical and Supercritical

Water, Ind. Eng. Chem. Res. 48, 9837-9846 (2009). In this paper, authors study the residual solid product

observed from the hydrothermal treatment of hydroxymethylfurfural and refer to it as "tarry material" and not as hydrothermal carbon.

153 C. Yao, Y. Shin, L.-Q. Wang, C. F. Jr. Windisch, W. D. Samuels, B. W. Arey et al. Hydrothermal Dehydration of Aqueous Fructose Solutions in a Closed System, J. Phys. Chem. C, 111, 15141 (2007)

154 a) B. M. Kabyemela, T. Adschiri, R. M. Malaluan, K. Arai Glucose and fructose decomposition in subcritical and supercritical water: Detailed reaction pathway, mechanisms, and kinetics. Ind. Eng. Chem. Res. 1999, 38, 2888; b) M. Möller, P. Nilges, F. Harnisch, U. Schröder Subcritical Water as Reaction Environment: Fundamentals of Hydrothermal Biomass Transformation. Chem. Sus. Chem. 2011, 4, 566

155 a) B. Hu, K. Wang, L. H. Wu, S. H. Yu, M. Antonietti, M.-M. Titirici. Engineering Carbon Materials from the Hydrothermal Carbonization Process of Biomass. Adv. Mater. 2010, 22, 813; b) T. M. Aida, K. Tajima, M. Watanabe, Y. Saito, K. Kuroda, T. Nonaka, et al. Reactions of D-fructose in water at temperatures up to 400 degrees C and pressures up to 100 MPa. J. Supercrit. Fluids. 2007, 42, 110.

156 N. Baccile, G. Laurent, F. Babonneau, F. Fayon, M.-M. T., M. Antonietti, Structural Characterization of Hydrothermal Carbon Spheres by Advanced Solid-State MAS C-13 NMR Investigations, J. Phys. Chem. C, 113, 9644-9654 (2009)

157 A. Gandini, M. N. Belgacem, Furans in Polymer Chemistry, Progress in Polymer Science, 22, 1203, (1997) 158 S. K. R. Patil, C. R. F. Lund Formation and Growth of Humins via Aldol Addition and Condensation during Acid-Catalyzed Conversion of 5-Hydroxymethylfurfural. Ener. Fuels. 2011, 25, 4745

159 I. van Zandvoort, Y. Wang, C. B. Rasrendra, E. R. H. van Eck, P.C. A. Bruijnincx, Hero J. Heeres et al. ChemSusChem, 6, 1745-1758 (2013)

160 Alemany, L. B.; Grant, D. M.; Pugmire, R. J.; Alger, T. D.; Zilm, K. W. J. Am. Chem. Soc. 1983, 105, 2142

161 C. Falco, F. Perez Caballero, F. Babonneau, C. Gervais, G. Laurent, M.-M. Titirici et al. Hydrothermal Carbon from Biomass : Structural Differences between Hydrothermal and Pyrolyzed Carbons via C-13 Solid State NMR, Langmuir, 27, 14460-14471 (2011)

162 C. B. Rasrendra, M. Windt, Y. Wang, S. Adisasmito, I. G. B. N. Makertihartha, E. R. H. van Eck, et al. Experimental studies on the pyrolysis of humins from the acid-catalysed dehydration of C6-sugars. J. Anal. Appl. Pyrol. 2013, 104, 299

163 C. Falco, N. Baccile, M.-M. Titirici, Morphological and structural differences between glucose, cellulose and lignocellulosic biomass derived hydrothermal carbons, Green Chem., 13, 3273-3281 (2011) 
164 D. Knezevic, W. van Swaaij, S. Kersten, Hydrothermal Conversion Of Biomass. II. Conversion Of Wood, Pyrolysis Oil, And Glucose In Hot Compressed Water, Ind. Eng. Chem. Res., 49, 104 (2010)

165 E. B. Sanders, A. I. Goldsmith, J. I. Seeman, A model that distinguishes the pyrolysis of D-glucose, Dfructose, and sucrose from that of cellulose. Application to the understanding of cigarette smoke formation, $J$. Anal. Appl. Pyrol., 66, 29 (2003)

166 X. Lu, P. J. Pellechia, J. R.V. Flora, N. D. Berge, Influence of reaction time and temperature on product formation and characteristics associated with the hydrothermal carbonization of cellulose, Biores. Technol., 138, 180-190 (2013)

167 C. L. Burket, R. Rajagopalan, A. P. Marencic, K. Dronvajjala, H.C.Foley, Genesis of porosity in polyfurfuryl alcohol derived nanoporous carbon, Carbon, 32, 1233, (1994)

168 X. Cao, K. S. Ro, M. Chappell, Y. Li, J. Mao, Chemical Structures of Swine-Manure Chars Produced under Different Carbonization Conditions Investigated by Advanced Solid-State 13C Nuclear Magnetic Resonance (NMR) Spectroscopy, Energy Fuels, 25, 388-397 (2011)

169 L. Yu, C. Falco, J. Weber, R. J. White, J. Y. Howe M. M. Titirici, Langmuir, 28, 12373-12383 (2012) 